NATIONAL LABORATORY

\title{
Tensile Hoop Behavior of Irradiated Zircaloy-4 Nuclear Fuel Cladding
}

\section{December 2006}

\author{
Prepared by \\ R. A. Jaramillo \\ W. R. Hendrich \\ N. H. Packan
}

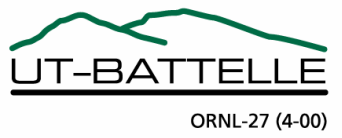




\section{DOCUMENT AVAILABILITY}

Reports produced after January 1, 1996, are generally available free via the U.S. Department of Energy (DOE) Information Bridge.

Web site http://www.osti.gov/bridge

Reports produced before January 1, 1996, may be purchased by members of the public from the following source.

National Technical Information Service

5285 Port Royal Road

Springfield, VA 22161

Telephone 703-605-6000 (1-800-553-6847)

TDD 703-487-4639

Fax 703-605-6900

E-mail info@ntis.fedworld.gov

Web site http://www.ntis.gov/support/ordernowabout.htm

Reports are available to DOE employees, DOE contractors, Energy Technology Data Exchange (ETDE) representatives, and International Nuclear Information System (INIS) representatives from the following source.

Office of Scientific and Technical Information

P.O. Box 62

Oak Ridge, TN 37831

Telephone 865-576-8401

Fax 865-576-5728

E-mail reports@osti.gov

Web site http://www.osti.gov/contact.html

This report was prepared as an account of work sponsored by an agency of the United States Government. Neither the United States government nor any agency thereof, nor any of their employees, makes any warranty, express or implied, or assumes any legal liability or responsibility for the accuracy, completeness, or usefulness of any information, apparatus, product, or process disclosed, or represents that its use would not infringe privately owned rights. Reference herein to any specific commercial product, process, or service by trade name, trademark, manufacturer, or otherwise, does not necessarily constitute or imply its endorsement, recommendation, or favoring by the United States Government or any agency thereof. The views and opinions of authors expressed herein do not necessarily state or reflect those of the United States Government or any agency thereof. 
Physical Sciences Directorate

\title{
TENSILE HOOP BEHAVIOR OF IRRADIATED ZIRCALOY-4 NUCLEAR FUEL CLADDING
}

\author{
R. A. Jaramillo \\ W. R. Hendrich \\ N. H. Packan
}

Date Published: December 2006

\author{
Prepared by \\ OAK RIDGE NATIONAL LABORATORY \\ Oak Ridge, Tennessee 37831-6283 \\ managed by \\ UT-BATTELLE, LLC \\ for the \\ U.S. DEPARTMENT OF ENERGY \\ under contract DE-AC05-00OR22725
}





\section{CONTENTS}

Page

LIST OF FIGURES

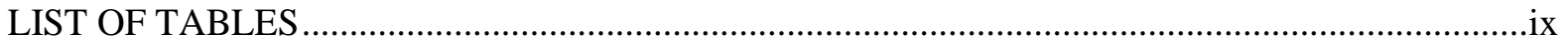

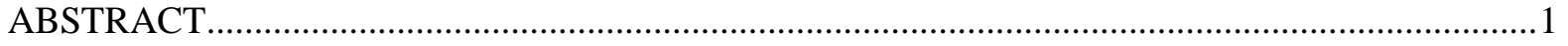

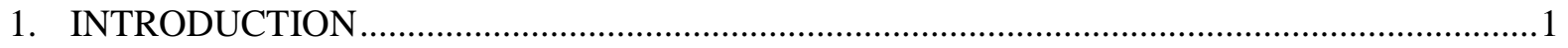

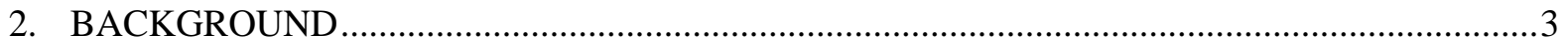

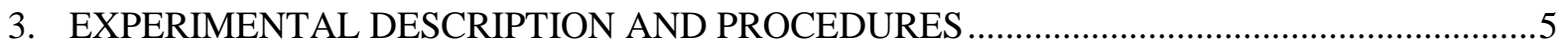

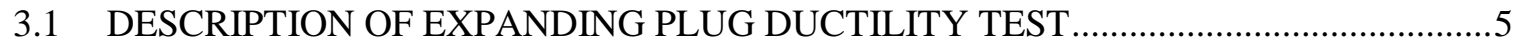

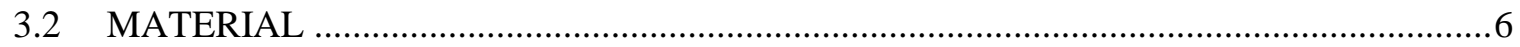

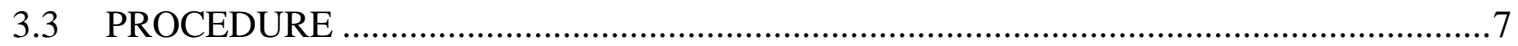

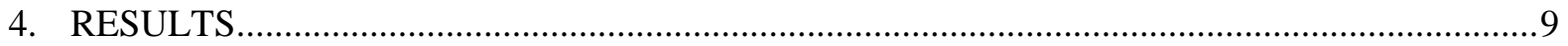

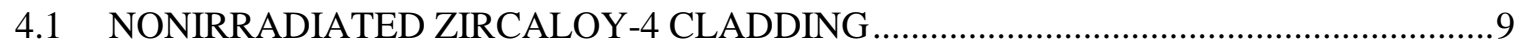

4.2 IRRADIATED ZIRCALOY-4 CLADDING FOR 9-GWd/MT FUEL BURNUP...............10

4.3 IRRADIATED ZIRCALOY-4 CLADDING FOR 21-GWd/MT FUEL BURNUP.............14

4.4 IRRADIATED ZIRCALOY-4 CLADDING FOR 30-GWd/MT FUEL BURNUP.............17

4.5 IRRADIATED ZIRCALOY-4 CLADDING FOR 40-GWd/MT FUEL BURNUP.............20

4.6 IRRADIATED ZIRCALOY-4 CLADDING FOR 50-GWd/MT FUEL BURNUP............23

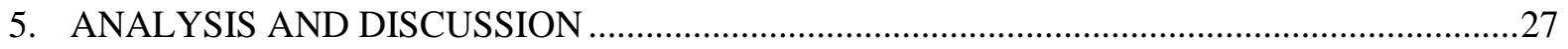

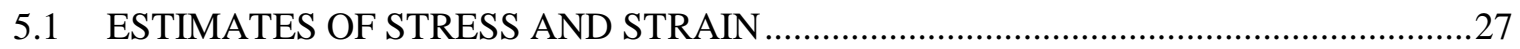

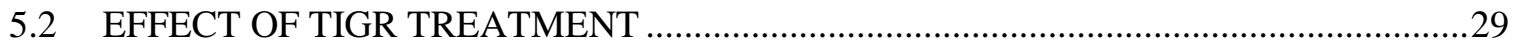

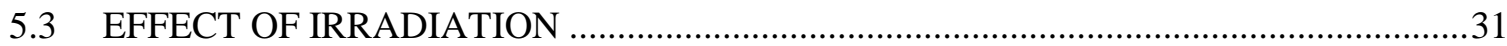

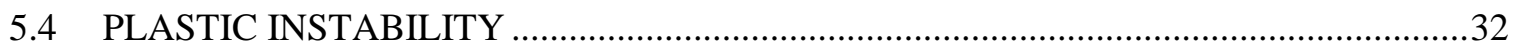

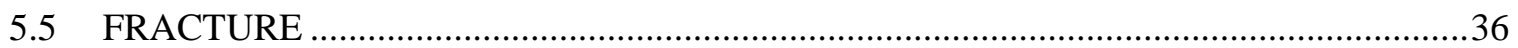

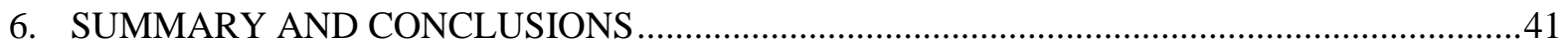

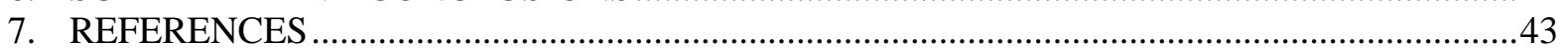





\section{LIST OF FIGURES}

Figure

Page

1 Schematic of expanded plug test setup for clad ductility testing

2 Prototype of test setup for clad ductility test showing relative positions of plug, specimen, and proximity transducers

Load and displacement plots for unirradiated Zircaloy-4 clad specimen BLGS-4 ............9

Load and displacement plots for unirradiated Zircaloy-4 clad specimen BLGS-5 ...........10

Load and displacement plots for unirradiated Zircaloy-4 clad specimen BLGS-6 ........... 10

Load and displacement plots for non-TIGR, 9-GWd/MT fuel burnup cladding

specimen 1 ...

7 Load and displacement plots for non-TIGR, 9-GWd/MT fuel burnup cladding specimen 2 .

8 Load and displacement plots for non-TIGR, 9-GWd/MT fuel burnup cladding specimen 3

9 Load and displacement plots for TIGR, 9-GWd/MT fuel burnup cladding specimen 1

10 Load and displacement plots for TIGR, 9-GWd/MT fuel burnup cladding specimen 2 ...

11 Load and displacement plots for TIGR, 9-GWd/MT fuel burnup cladding specimen 3

12 Load and displacement plots for non-TIGR, 21-GWd/MT fuel burnup cladding specimen 1

13 Load and displacement plots for non-TIGR, 21-GWd/MT fuel burnup cladding specimen 2 .

14 Load and displacement plots for non-TIGR, 21-GWd/MT fuel burnup cladding specimen 3

15 Load and displacement plots for TIGR, 21-GWd/MT fuel burnup cladding specimen 1 .....

16 Load and displacement plots for TIGR, 21-GWd/MT fuel burnup cladding specimen 2 ...

17 Load and displacement plots for TIGR, 21-GWd/MT fuel burnup cladding specimen 3

18 Load and displacement plots for non-TIGR, $30 \mathrm{GWd} / \mathrm{MT}$ fuel burnup cladding specimen 1.

19 Load and displacement plots for non-TIGR, 30-GWd/MT fuel burnup cladding specimen 2 ...

20 Load and displacement plots for non-TIGR, 30-GWd/MT fuel burnup cladding specimen 3

21 Load and displacement plots for TIGR, 30-GWd/MT fuel burnup cladding specimen 1 .....

22 Load and displacement plots for TIGR, 30-GWd/MT fuel burnup cladding specimen 2 .

23 Load and displacement plots for TIGR, 30-GWd/MT fuel burnup cladding specimen 3 .

24 Load and displacement plots for non-TIGR, 40-GWd/MT fuel burnup cladding specimen 1 
Load and displacement plots for non-TIGR, 40-GWd/MT fuel burnup cladding specimen 2 .....

26 Load and displacement plots for non-TIGR, 40-GWd/MT fuel burnup cladding specimen 3 .....

Load and displacement plots for TIGR, 40-GWd/MT fuel burnup cladding specimen 1 .

Load and displacement plots for TIGR, 40-GWd/MT fuel burnup cladding specimen 2 .

Load and displacement plots for TIGR, 40-GWd/MT fuel burnup cladding specimen 3 .

Load and displacement plots for non-TIGR, 50-GWd/MT fuel burnup cladding

specimen FP8-2

Load and displacement plots for non-TIGR, 50-GWd/ MT fuel burnup cladding specimen FP8-3

Load and displacement plots for non-TIGR, 50-GWd/MT fuel burnup cladding specimen FP9-1

Load and displacement plots for non-TIGR, 50-GWd/MT fuel burnup cladding specimen FP9-2

Load and displacement plots for non-TIGR, 50-GWd/MT fuel burnup cladding specimen FP9-3

Hoop stress-strain curves calculated using thin-walled pressurized cylinder, thick-walled pressurized cylinder, and uniaxial tensile test scaling method .................... 28 Load vs OD hoop strain for TIGR-treated (red) and nontreated (black)

9-GWd/MT irradiated Zircaloy cladding.

21-GWd/MT irradiated Zircaloy cladding.

Load vs OD hoop strain for TIGR-treated (red) and nontreated (black)

30-GWd/MT irradiated Zircaloy cladding. 30

Load vs OD hoop strain for TIGR-treated (red) and nontreated (black)

40-GWd/MT irradiated Zircaloy cladding.

Load and displacement plots for non-TIGR, 50-GWd/MT fuel burnup cladding

specimen FP9-3

SEM photograph showing fractured Zircaloy-4 cladding irradiated to

50-GWd/MT burnup....

SEM photograph showing fractured Zircaloy-4 cladding irradiated to 30-GWd/MT burnup.

Optical photograph showing a shear band in deformed Zircaloy-4 cladding irradiated to 21-GWd/MT burnup

SEM micrographs showing the fracture surface of Zircaloy-4 cladding irradiated

to 21-GWd/MT fuel burnup

SEM micrographs showing the fracture surface of Zircaloy-4 cladding irradiated

to 50-GWd/MT fuel burnup 
50 SEM micrographs showing the fracture surface of Zircaloy-4 cladding irradiated to $50 \mathrm{GWd} / \mathrm{MT}$ fuel burnup 



\section{LIST OF TABLES}

Table

Page

1 Chemical composition of Zircaloy-4 alloy

.6

2 Fuel burnup levels and the associated dpa and fast fluence for irradiated

cladding.

3 Parameters and goodness-of-fit values for power law description [Eq. (5.6)] of yield strength as a function of neutron fluence 



\begin{abstract}
A method for evaluating the room temperature ductility behavior of irradiated Zircaloy-4 nuclear fuel cladding has been developed and applied to evaluate tensile hoop strength of material irradiated to different levels. The test utilizes a polyurethane plug fitted within a tubular cladding specimen. A cylindrical punch is used to compress the plug axially, which generates a radial displacement that acts upon the inner diameter of the specimen. Position sensors track the radial displacement of the specimen outer diameter as the compression proceeds. These measurements coupled with ram force data provide a load-displacement characterization of the cladding response to internal pressurization. The development of this simple, cost-effective, highly reproducible test for evaluating tensile hoop strain as a function of internal pressure for irradiated specimens represents a significant advance in the mechanical characterization of irradiated cladding.

In this project, nuclear fuel rod assemblies using Zircaloy-4 cladding and two types of mixed uranium-plutonium oxide (MOX) fuel pellets were irradiated to varying levels of burnup. Fuel pellets were manufactured with and without thermally induced gallium removal (TIGR) processing. Fuel pellets manufactured by both methods were contained in fuel rod assemblies and irradiated to burnup levels of 9, 21, 30, 40, and $50 \mathrm{GWd} / \mathrm{MT}$. These levels of fuel burnup correspond to fast (E > $1 \mathrm{MeV})$ fluences of $0.27,0.68,0.98,1.4$ and $1.7 \times 10^{21}$ neutrons $/ \mathrm{cm}^{2}$, respectively. Following irradiation, fuel rod assemblies were disassembled; fuel pellets were removed from the cladding; and the inner diameter of cladding was cleaned to remove residue materials. Tensile hoop strength of this cladding material was tested using the newly developed method. Unirradiated Zircaloy-4 cladding was also tested. With the goal of determining the effect of the two fuel types and different neutron fluences on clad ductility, tensile hoop strength tests were performed on cladding for these varying conditions. Experimental data revealed negligible performance differences for cladding containing TIGR vs nonTIGR processed fuel pellets. Irradiation hardening was observed in tensile hoop data as the strength of the cladding increased with increasing neutron dose and appeared to saturate for a fast fluence of $1.7 \times 10^{21}$ neutrons $/ \mathrm{cm}^{2}$.
\end{abstract}

\title{
1. INTRODUCTION
}

The U.S. Department of Energy (DOE) Fissile Materials Disposition Program (FMDP) is pursuing reactor burnup of mixed uranium-plutonium oxide (MOX) fuel for disposal of surplus weapons-grade plutonium. The utilization of MOX fuel is supported by extensive MOX fuel irradiation experience that has been generated principally in Europe through research, development, and deployment programs since the mid-1950s. MOX fuel has been utilized domestically in test reactors and on an experimental basis in a number of commercial light-water reactors (LWRs). More than 300,000 MOX fuel rods have been successfully irradiated in the United States and Europe. Most of this experience has been with reactor-grade plutonium. To pursue disposition of surplus weaponsusable plutonium via reactor irradiation, it must be demonstrated that surplus weapons-derived or weapons-grade (WG) plutonium performs in a manner consistent with the reactor-grade MOX experience base.

There are several differences between weapons-derived MOX fuel and commercial MOX fuel, such as the proportion of ${ }^{239} \mathrm{Pu}$. However, a primary concern is the gallium content found in weaponsgrade plutonium that is not present in reactor-grade plutonium. Gallium alloying is used to improve dimensional stability, formability, and machinability of plutonium by stabilizing the FCC (facecentered-cubic) phase. ${ }^{1}$ This improves dimensional control in components and reduces problems associated with casting and forming processes. The current knowledge base for MOX fuel does not include an accounting for the presence of gallium in fuel pellets.

An important question to be addressed for weapons-derived MOX fuel is that of imbrittlement of the cladding during irradiation. While irradiation-induced loss of ductility has been established and 
quantified for many cladding materials, the potential synergistic effects of irradiation and the unique constituents (i.e., gallium) of weapons-derived MOX fuel are not known. The Postirradiation Cladding Ductility Test Program was formulated for the DOE and is conducted by Oak Ridge National Laboratory (ORNL) to evaluate radiation-induced ductility loss. The program focus is on development, validation, and application of technology for the determination of the tensile failure ductility limits for MOX fuel cladding irradiated in the Advanced Test Reactor (ATR) at Idaho National Laboratory (INL). The scope of the project includes (1) the development of techniques for machining and handling of small ring-type test specimens from irradiated MOX test cladding,

(2) development and validation of a specimen and test fixture for use in a hot cell environment, and

(3) testing of cladding specimens subjected to fluence levels as high as $1.7 \times 10^{21}$ neutrons $/ \mathrm{cm}^{2}(\mathrm{E}>$ $1 \mathrm{MeV}$ ). Testing is performed at ORNL in the Core Conduction Cooldown Test Facility (CCCTF) hot cell in Building 3525.

The Postirradiation Cladding Ductility Test Program was conducted in several phases. The first phase was to develop, validate, and demonstrate technology for remote handling, cutting, and testing of small ring specimens of cladding material. This phase culminated in the successful preparation of specimens and ductility demonstration tests of irradiated $\left[6.8 \times 10^{20}\right.$ neutrons $\left./ \mathrm{cm}^{2}(\mathrm{E}>1 \mathrm{MeV})\right] \mathrm{MOX}$ test fuel cladding. These demonstration results have been previously reported. ${ }^{2}$ The second phase covered ductility testing of irradiated MOX test fuel cladding for fast neutron fluences over the range $0.27-1.40 \times 10^{21}$ neutrons $/ \mathrm{cm}^{2}(\mathrm{E}>1 \mathrm{MeV}) .{ }^{3}$ The third phase extended the range of neutron fluences to $0.27-1.7 \times 10^{21}$ neutrons $/ \mathrm{cm}^{2}(\mathrm{E}>1 \mathrm{MeV})$. This report is a comprehensive presentation of all irradiated cladding ductility tests. It includes a presentation of results, analysis, discussion, and summary. 


\section{BACKGROUND}

The use of Zircaloy-4 as fuel cladding is motivated by its unique combination of properties such as strength, corrosion resistance and low thermal neutron cross section. ${ }^{4}$ The use of this material in nuclear fuel assemblies exposes it to the extreme environments associated with nuclear reactor operation. Therefore, it is critical to understand changes in microstructure and properties of cladding over the life of a fuel pellet assembly.

Irradiation hardening of zirconium alloys and the associated decrease in ductility is an area of significant concern for the designers and operators of LWRs for determining life cycles and optimizing reactor performance. As the material hardens, a loss of ductility occurs ${ }^{4}$ and could lead to brittle failure of cladding during accident scenarios. Therefore, knowing the strength and ductility of Zircaloy cladding throughout the component life cycle is critical for defining and conforming to the safety envelope.

Previous research has addressed irradiation hardening of zirconium alloys. ${ }^{5-7}$ Higgy and Hamad $^{5}$ reported results for tensile testing of irradiated Zircaloy-2 and Zircaloy-4. Specimens were irradiated at low temperature $\left(<100^{\circ} \mathrm{C}\right)$ up to a fluence of $1.43 \times 10^{20}$ neutrons $/ \mathrm{cm}^{2}(>1 \mathrm{MeV})$ and at elevated temperature $\left(320-360^{\circ} \mathrm{C}\right)$ up to $1.53 \times 10^{21}$ neutrons $/ \mathrm{cm}^{2}(>1 \mathrm{MeV})$. Among the conclusions drawn were that irradiation hardening saturated during low-temperature irradiation but not for elevated temperature irradiation. The rate of irradiation hardening was greater at low-temperatures compared to elevated temperatures, and in Zircaloy-4, increase in strength due to cold work and/or fine grain size decreased the amount of irradiation hardening.

Yasuda et al. ${ }^{6}$ irradiated Zircaloy- 2 at $\sim 290^{\circ} \mathrm{C}$ and performed tensile testing at varying strain rates and temperatures. Test temperatures from $25^{\circ} \mathrm{C}$ to $400^{\circ} \mathrm{C}$ and strain rates from 0.05 to $5 \%$ per minute were applied. Two distinct failure morphologies, described as spiral and necking, were observed in fractured specimens. The spiral fracture surface was observed at temperatures equal to and less than $300^{\circ} \mathrm{C}$ for irradiation fluences greater than $\sim 3 \times 10^{20}$ neutrons $/ \mathrm{cm}^{2}$. Necking and increase failure elongation was seen in specimens tested at $400^{\circ} \mathrm{C}$ for all irradiation fluences. These results highlight the effect of test temperature on the ductility of irradiated cladding. It was also reported that irradiation increased the strain rate sensitivity of the yield strength.

Most recently, Byun and Farrell ${ }^{7}$ tensile tested annealed Zircaloy-4 irradiated up to $0.8 \mathrm{dpa}$ (displacements per atom) at $\sim 100^{\circ} \mathrm{C}$. Their data showed increases in yield strength from $\sim 400 \mathrm{MPa}$ to more than $600 \mathrm{MPa}$ due to irradiation, and the onset of saturation was not observed for the range of neutron fluences. A significant characteristic of the Zircaloy tensile flow curves was, for irradiation above $0.01 \mathrm{dpa}$, a stress drop associated with plastic instability, which occurred immediately upon plastic yielding. This result suggests that negligible post-yielding uniform elongation occurs in Zircaloy irradiated above $0.01 \mathrm{dpa}$ at low temperatures.

Because of their hexagonal-close-packed (HCP) crystallographic structure, cold working of zirconium alloys produces a preferred orientation of the crystals (texture). Such texture is the source of mechanical anisotropy that results in significantly higher yield strength values in the transverse direction of strip. ${ }^{8}$ Therefore, when determining mechanical properties of cladding, it is necessary to explicitly measure properties in the direction of interest. For clad tubing the circumferential or hoop direction is of concern because of the predominant tensile hoop stress associated with internal pressurization caused by fuel pellet expansion and/or release of fission gas products. Existing methods for tensile hoop testing of nuclear fuel cladding employ a ring tensile test. ${ }^{9,10}$ This method requires reduced gauge sections to be machined along the specimen circumference at locations $180^{\circ}$ apart. Tooling machined to match the curvature of the specimen inner diameter exerts a force such that the maximum stress is produced in the gauge sections. Such methods are costly and develop stress concentrations that generate localized strain as the deformation proceeds. Stress/strain concentrations and the associated gradients are undesirable for determining material properties.

As part of this project, the expanding plug internal pressurization test method for assessing the tensile hoop strength of irradiated cladding was developed. The development and demonstration of 
this method have been reported previously ${ }^{2}$ and will not be presented here. The expanding plug method was used to evaluate the tensile hoop strength of Zircaloy-4 nuclear fuel cladding irradiated to various neutron fluences. The results of these tests are presented and serve as a validation of the method for evaluating tensile hoop strength. 


\section{EXPERIMENTAL DESCRIPTION AND PROCEDURES}

\subsection{DESCRIPTION OF EXPANDING PLUG DUCTILITY TEST}

A simple test was developed to evaluate the tensile hoop strength of small tubular specimens representative of nuclear fuel cladding. The test uses a cylindrical polyurethane plug with a diameter nearly equal to the inner diameter (ID) of the tubular test specimen. The plug is compressed axially by a ram that produces a radial displacement. This radial displacement causes the plug to act upon the ID of the specimen and generate a pseudo internal pressurization. A schematic of the test configuration is shown in Fig. 1.

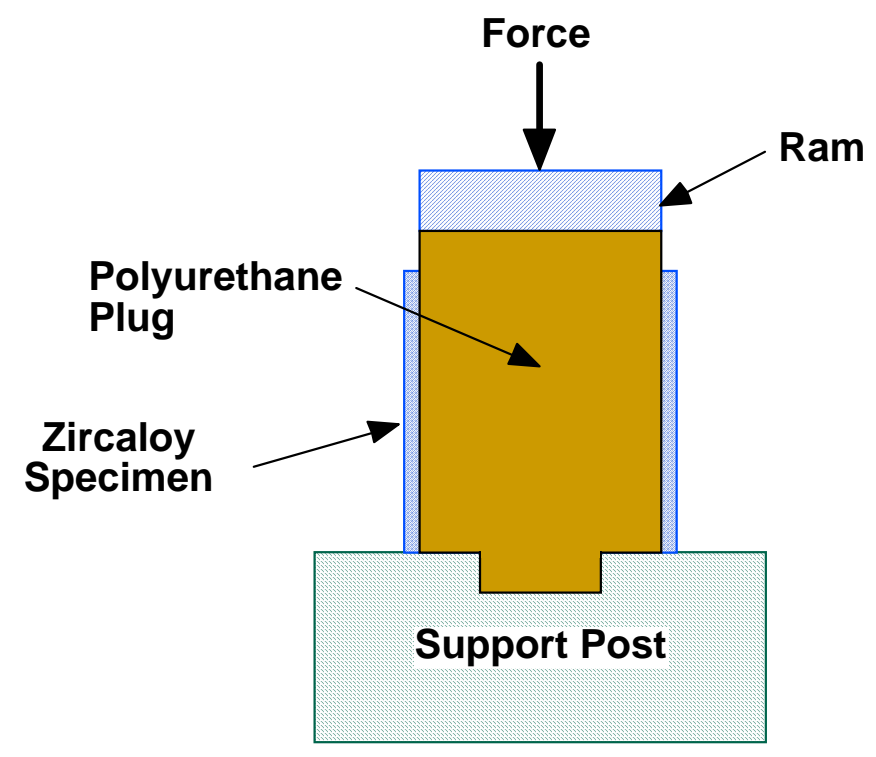

Fig. 1. Schematic of expanded plug test setup for clad ductility testing.

The three primary components of the test configuration are a polyurethane plug, cylindrical ram, and a support post or platen. The polyurethane plug with a hardness of Shore A 95 is machined such that a dowel extends at one end of the cylinder. The dowel is sized to fit within a shallow cylindrical recess in the support post. The purpose of the dowel is to align the specimen and plug directly beneath the cylindrical ram such that the plug is compressed without the specimen being contacted by the ram. The dowel also improved the uniformity of deformation compared to flat-bottomed plugs, which tended to expand the lower portion of the specimen greater than the upper half. ${ }^{11}$

As the ram compresses the plug, the radial displacement of the tube outer diameter is measured using two proximity probes located directly opposite each other. Data from the probes are used to continuously monitor and record the change in specimen diameter. The ram is attached to a load cell that measures the force required to compress the plug and, consequently, expand the specimen diameter. A photograph of test setup is shown in Fig. 2.

In summary, test outputs are ram force, ram displacement, and displacement of the specimen outer diameter. The ram force or total load includes the load required to compress the plug as well as deform the specimen. To evaluate the load required to deform the specimen only, the load required to deform the plug was measured in separate tests. In these tests, a plug was simply deformed without a specimen, and the resulting load-displacement data were used to adjust test data and obtain the load required to deform the specimen only. Although it is understood that the plug stress state without a specimen is inconsistent with that found in the actual test, it is reasonable to assume that the force to deform the specimen is the difference in the total force and the force required to deform the plug only. 


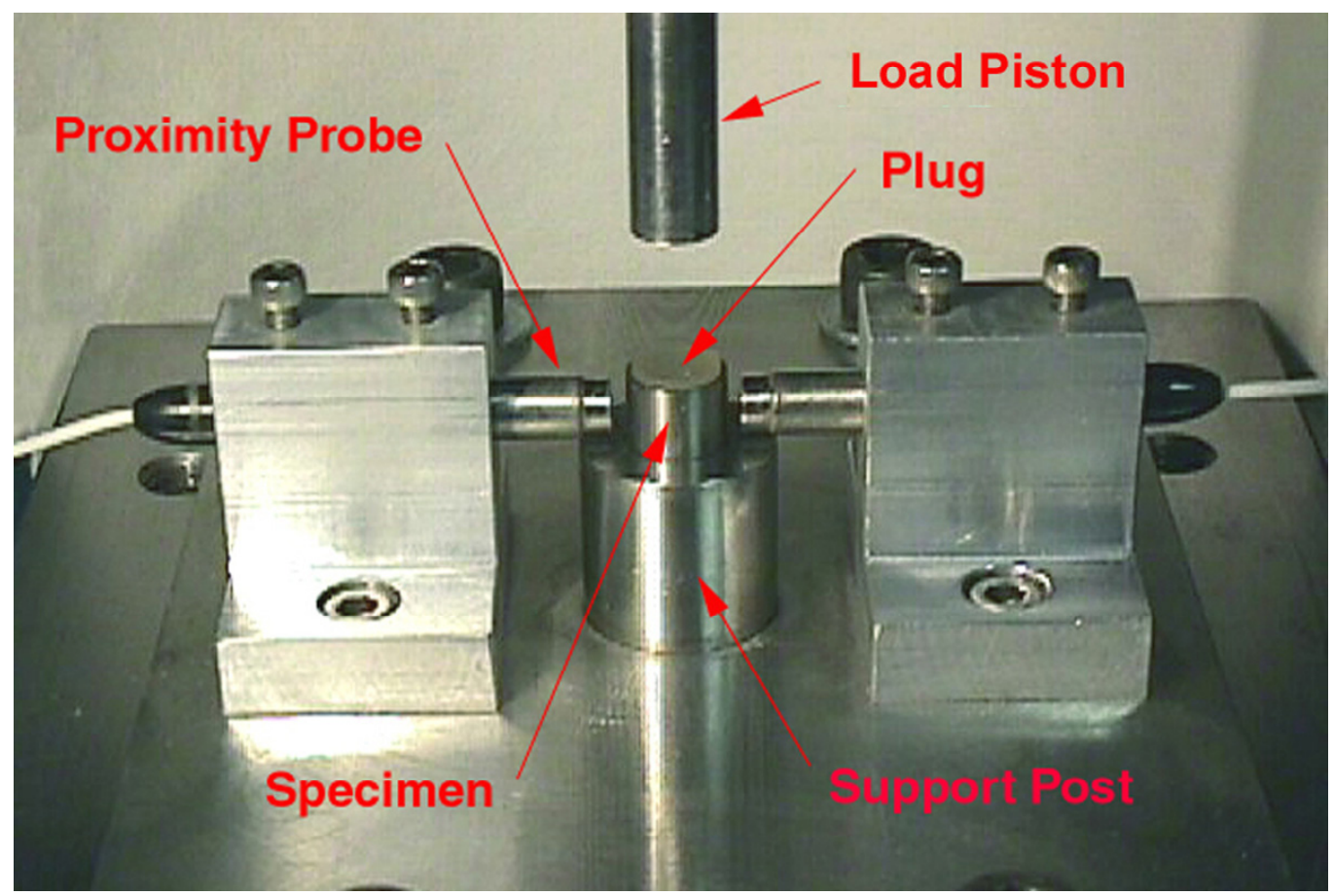

Fig. 2. Prototype of test setup for clad ductility test showing relative positions of plug, specimen, and proximity transducers.

This correction assumes that forces due to friction between the plug and sample are small enough to be considered negligible. Typically, the force to compress the plug monotonically increases to approximately $380 \mathrm{~N}$ at $1-\mathrm{mm}$ ram displacement.

\subsection{MATERIAL}

Zircaloy-4 is commonly used in nuclear reactors as fuel pellet cladding as well as for structural components. The material used in this study was tubing provided by Sandvik Special Metals Corporation in the annealed condition with reported tensile yield and ultimate strengths of 570 and $770 \mathrm{MPa}$, respectively. The chemical composition of the Zircaloy-4 heat used in this project is shown in Table 1.

Table 1. Chemical composition of Zircaloy-4 alloy

\begin{tabular}{ccccccc}
\hline Tin & Iron & Chromium & Silicon & Oxygen & Carbon & Zirconium \\
\hline $1.30 \mathrm{wt} \%$ & $0.22 \mathrm{wt} \%$ & $0.12 \mathrm{wt} \%$ & $85 \mathrm{ppm}$ & $1270 \mathrm{ppm}$ & $140 \mathrm{ppm}$ & Balance \\
\hline
\end{tabular}

The Zircaloy-4 tubing was used as cladding in fuel rod assemblies for the MOX irradiation program. Ductility test specimens were obtained from Zircaloy-4 cladding irradiated to various burnup levels containing MOX fuel pellets manufactured with two processing routes. The processes are different in that $\mathrm{PuO}_{2}$ feed powder was given a thermally induced gallium removal (TIGR) treatment in one process and not in the other. The TIGR process lowered the gallium content of the $\mathrm{PuO}_{2}$ powder from $8800 \mathrm{ppm}$ to $170 \mathrm{ppm}$. During sintering of pellets, gallium content was further reduced to 1.4 and $3.0 \mathrm{ppm}$ in TIGR treated and nontreated pellets, respectively. ${ }^{12}$

Plug expansion tests were performed on fuel pellet cladding irradiated at five different levels as well as unirradiated Zircaloy-4 tubing. The irradiation levels were characterized as fuel burnup with 
units of gigawatt-day per metric ton (GWd/MT). Table 2 shows the burnup levels used in this work and the associated dpa and neutron fast fluence.

Table 2. Fuel burnup levels and the associated dpa and fast fluence for irradiated cladding

\begin{tabular}{|c|c|c|}
\hline $\begin{array}{c}\text { Burnup } \\
\text { (GWd/MT) }\end{array}$ & $\begin{array}{l}\text { Displacements } \\
\text { per atom }^{a} \\
\text { (dpa) }\end{array}$ & $\begin{array}{c}\text { Fast fluence } \\
\text { (neutrons/cm } \\
\text { E }>1 \mathrm{MeV})\end{array}$ \\
\hline 9 & 0.5 & $2.7 \times 10^{20}$ \\
\hline 21 & 1.4 & $6.8 \times 10^{20}$ \\
\hline 30 & 2.0 & $9.8 \times 10^{20}$ \\
\hline 40 & 2.8 & $14.0 \times 10^{20}$ \\
\hline 50 & 3.4 & $16.8 \times 10^{20}$ \\
\hline
\end{tabular}

Estimates of cladding temperature during irradiation were obtained using computational simulation. ${ }^{13}$ An experiment-specific capsule assembly response thermal/swelling (CARTS) simulation code developed at ORNL to predict the thermal-mechanical response of capsule assemblies for the MOX experiment is capable of estimating cladding temperatures for a given linear heat generation rate. For the MOX irradiations, linear heat generation rates varied from $17-30 \mathrm{~kW} / \mathrm{m}$ with an average of approximately $24 \mathrm{~kW} / \mathrm{m}$. For these heat generation rates, cladding temperatures are estimated to range from $250-300^{\circ} \mathrm{C}$. Additional details of the irradiation experiment are not presented here but can be found in ORNL documentation. ${ }^{12}$

\subsection{PROCEDURE}

Experiments measured the radial expansion and associated loading of Zircaloy-4 cladding as a function of irradiation and fuel pellet gallium concentration associated with TIGR and non-TIGR treatments. An experimental procedure was developed as part of expanding plug test development and employed for testing of irradiated cladding.

Irradiated cladding was received in lengths varying from $40 \mathrm{~mm}$ to $120 \mathrm{~mm}$ with a tube outer diameter of $9.7 \mathrm{~mm}(0.38 \mathrm{in}$.) and a wall thickness of $0.6 \mathrm{~mm}(0.03 \mathrm{in}$.). Fuel pellets were removed from the cladding, and the clad ID was cleaned using a rotating wire brush. Test specimens were cut to a length of $7.1 \mathrm{~mm}$ and, if necessary, de-burred. Additional information regarding cleaning and cutting of cladding are provided elsewhere.,

Polyurethane plugs with a Shore A hardness of 95 were machined with a diameter of $8.3 \mathrm{~mm}$ (0.33 in.) and a length of $7.5 \mathrm{~mm}(0.295 \mathrm{in}$.) excluding the positioning dowel. For experiments where the specimen was deformed to fracture, a plug length of $7.7 \mathrm{~mm}$ was used. The polyurethane plug is placed on the support post with the positioning dowel fit within the receiving recess as shown in Fig. 1. The specimen is placed over the polyurethane plug, and the plug is preloaded to $178 \mathrm{~N}$ (40 lbs) to seat and center the plug. The test is initiated by axially compressing the plug with the ram. A ram velocity of $0.5 \mathrm{~mm} /$ minute was typically used, and a maximum displacement, usually $0.89 \mathrm{~mm}$ (0.035 in.), was specified. Upon reaching the maximum displacement, the plug unloaded, and the test terminated. Recorded outputs are time, ram displacement, ram load, and specimen OD radial displacements from each probe. Additional tests were performed for select irradiation levels in which the specimen was deformed to failure. It is important to note that the results presented in the following section were generated over a period of several years, and subtle inconsistencies may exist in the experimental procedure. Such inconsistencies will be reported with the associated results. 



\section{RESULTS}

\subsection{NONIRRADIATED ZIRCALOY-4 CLADDING}

Three tests were performed on nonirradiated cladding to provide a baseline of material performance as well as a comparison to irradiated material. Results of the tests are shown in Figs. 3-5. The figures plot radial displacement measured by each probe, the average of these measurements and load as a function of ram displacement. Because a constant ram velocity is applied, the ram displacement is linear with time.

The plots display two discrete deformation regimes: one associated with the initial elastic loading and the other related to the generation of plastic deformation. The load behavior for the three tests is remarkably consistent and shows a final load of $6.8 \mathrm{kN}$ prior to unloading. The displacement of the clad OD also shows good repeatability. For each test, an average maximum radial displacement of $\sim 190-205 \mu \mathrm{m}$ was recorded. However, for the plots shown in Fig. 3 and Fig. 4, a discrepancy in radial displacement was measured for each probe. This discrepancy is almost 40 and $35 \mu \mathrm{m}$ in Figs. 3 and 4, respectively, and appears during plastic deformation. In contrast, the plot in Fig. 5 reveals excellent correlation between probe measurements. Additional work is required to determine if these deviations are associated with material behavior, experimental setup, or a combination. It is speculated that this phenomenon is associated with subtle imperfections in plug and/or specimen geometry.

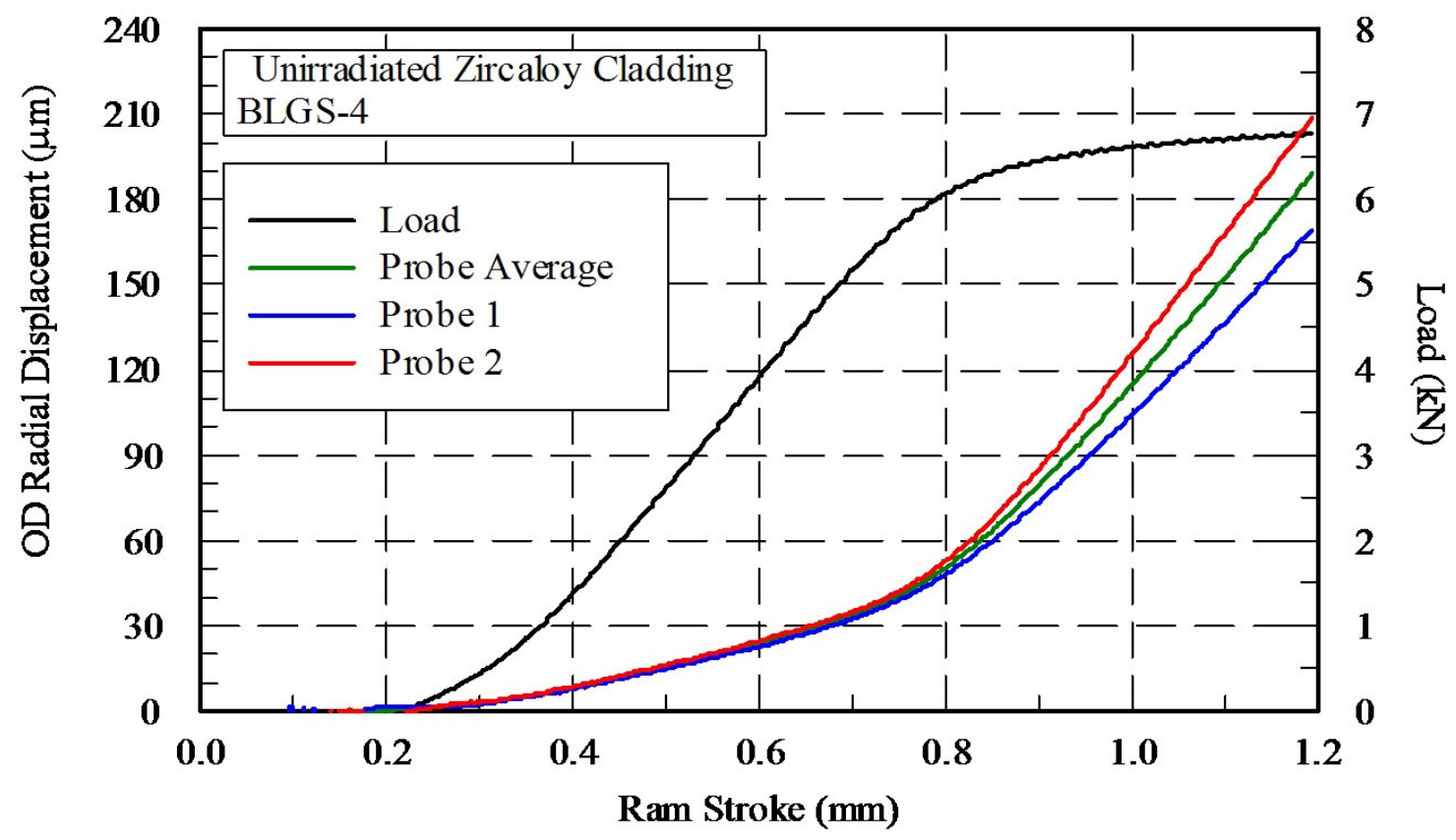

Fig. 3. Load and displacement plots for unirradiated Zircaloy-4 clad specimen BLGS-4. 


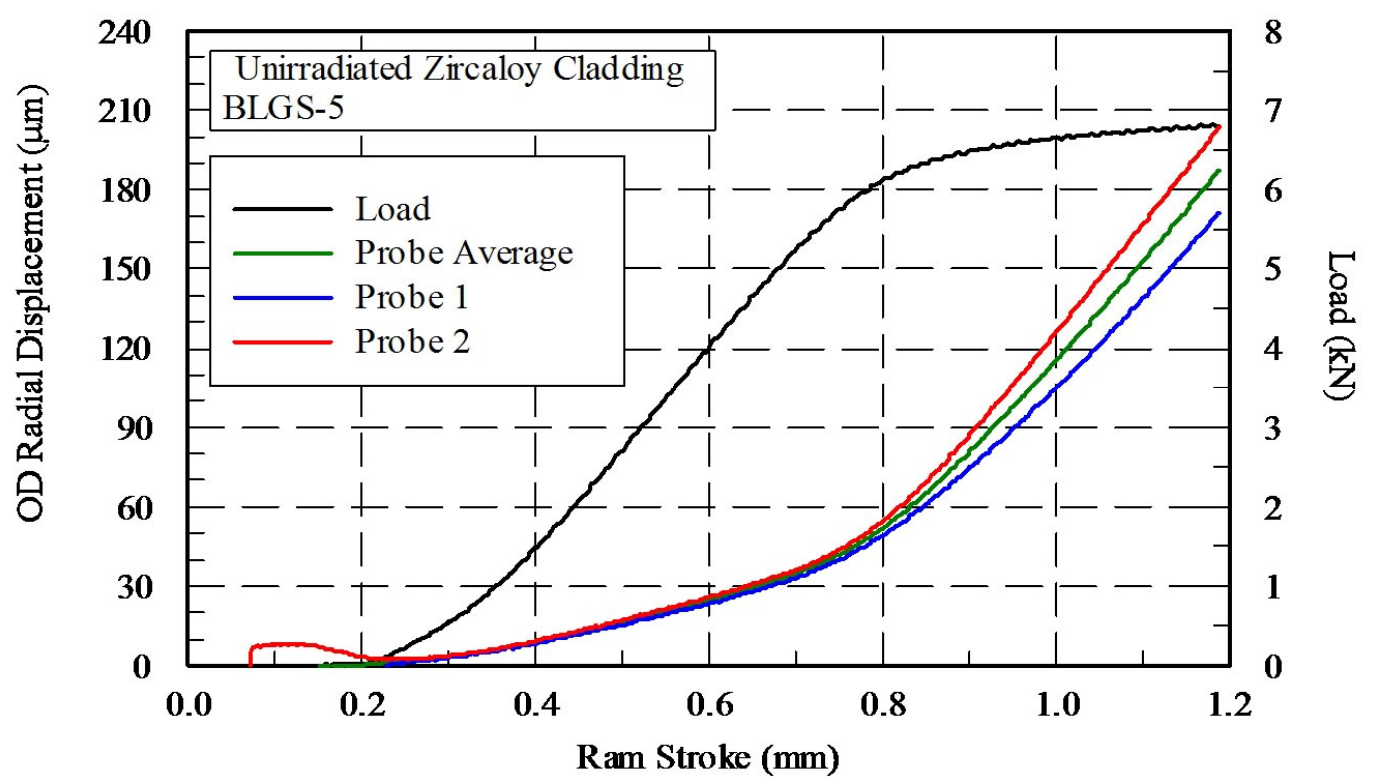

Fig. 4. Load and displacement plots for unirradiated Zircaloy-4 clad specimen BLGS-5.

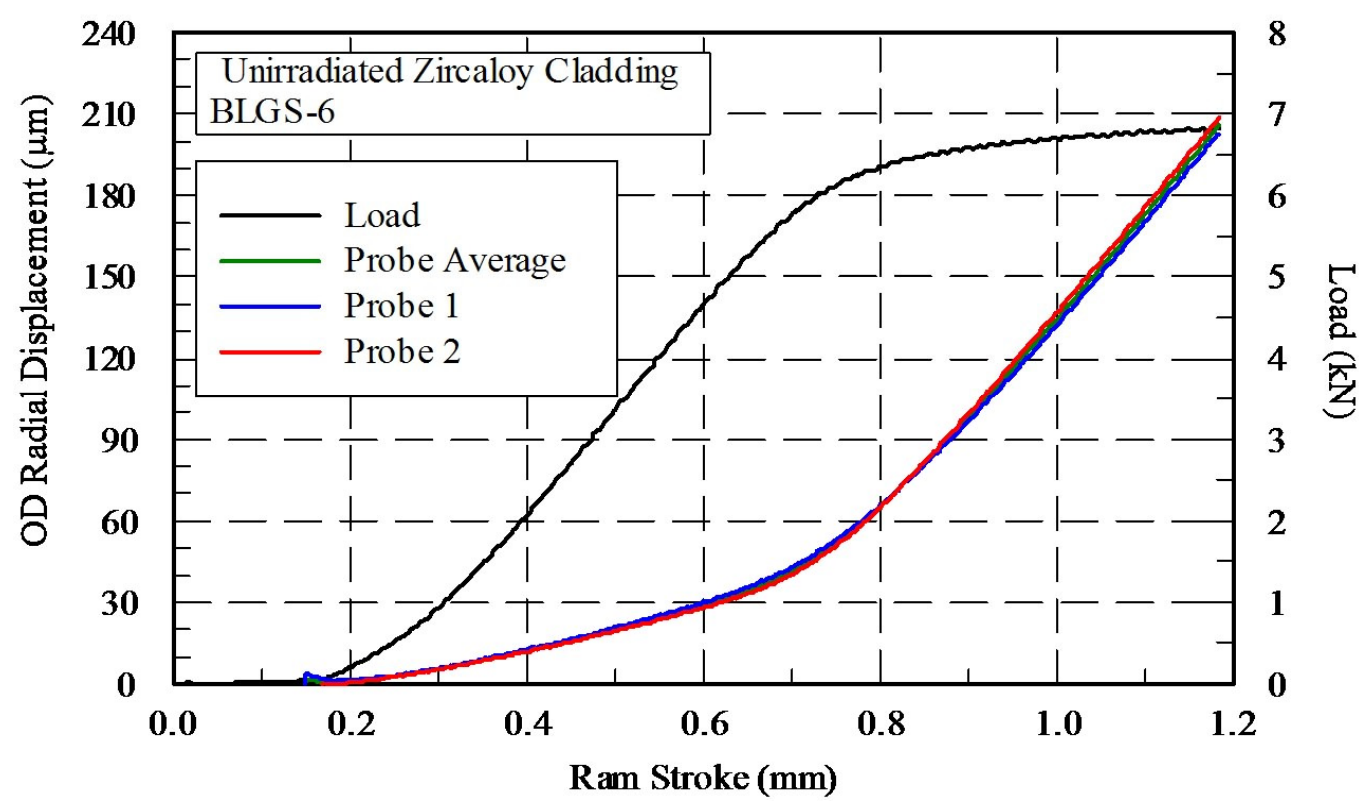

Fig. 5. Load and displacement plots for unirradiated Zircaloy-4 clad specimen BLGS-6.

\subsection{IRRADIATED ZIRCALOY-4 CLADDING FOR 9-GWd/MT FUEL BURNUP}

Results for ductility tests of cladding for fuel burnup of $9 \mathrm{GWd} / \mathrm{MT}$ are provided in this section. The results are composed of three tests for cladding containing fuel pellets fabricated without a TIGR treatment and three for cladding of TIGR-treated pellets. Results of the tests are shown in the following figures. The figures plot radial displacements, the average displacement, and load as a 
function of ram displacement (Figs. 6-8 for non-TIGR specimens and Figs. 9-11 for TIGR specimens).

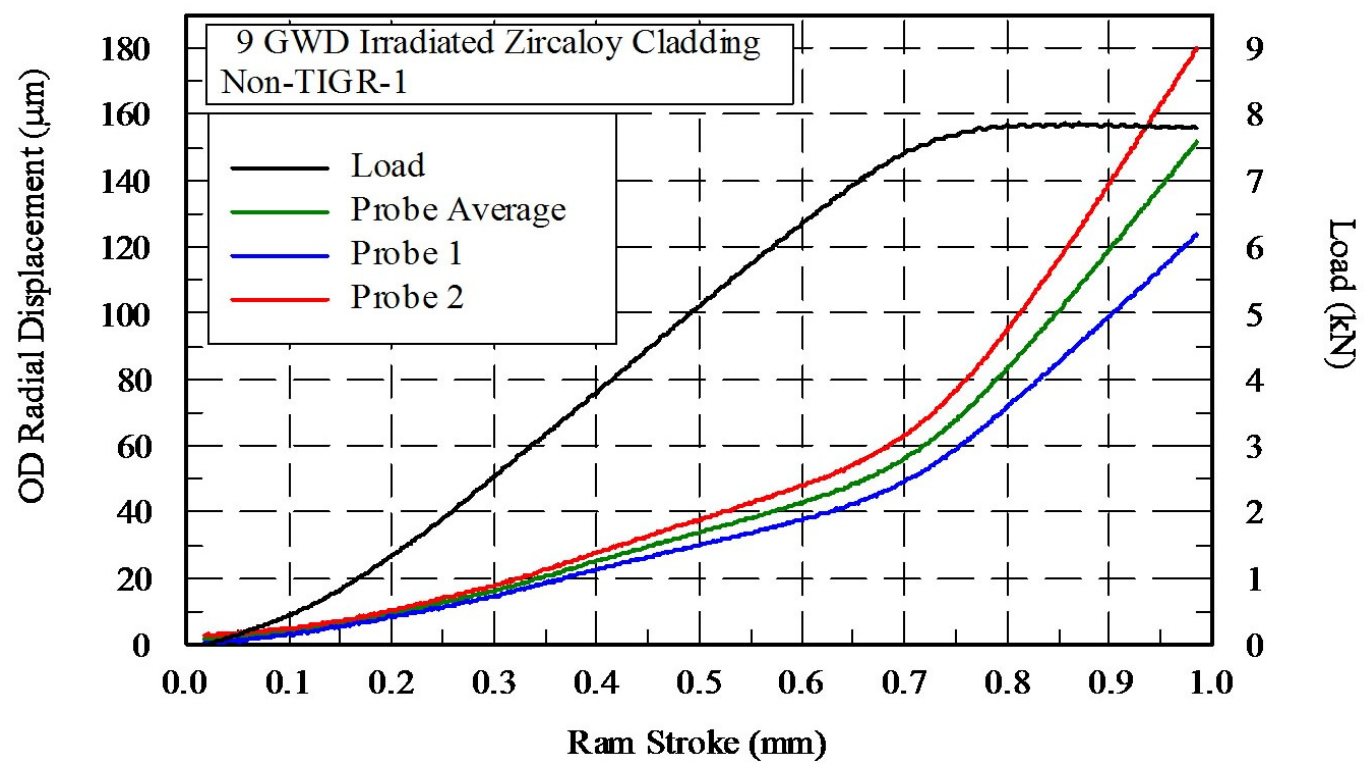

Fig. 6. Load and displacement plots for non-TIGR, 9-GWd/MT fuel burnup cladding specimen 1 .

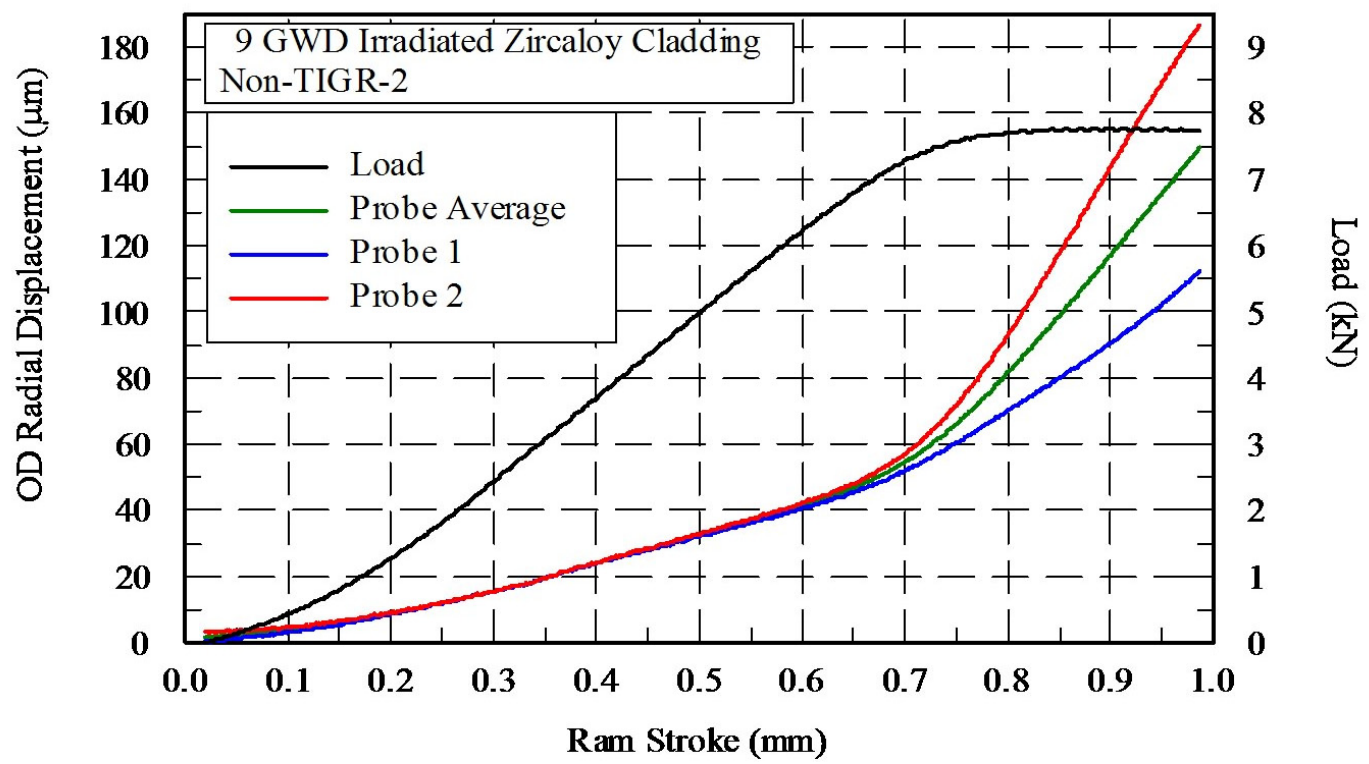

Fig. 7. Load and displacement plots for non-TIGR, 9-GWd/MT fuel burnup cladding specimen 2. 


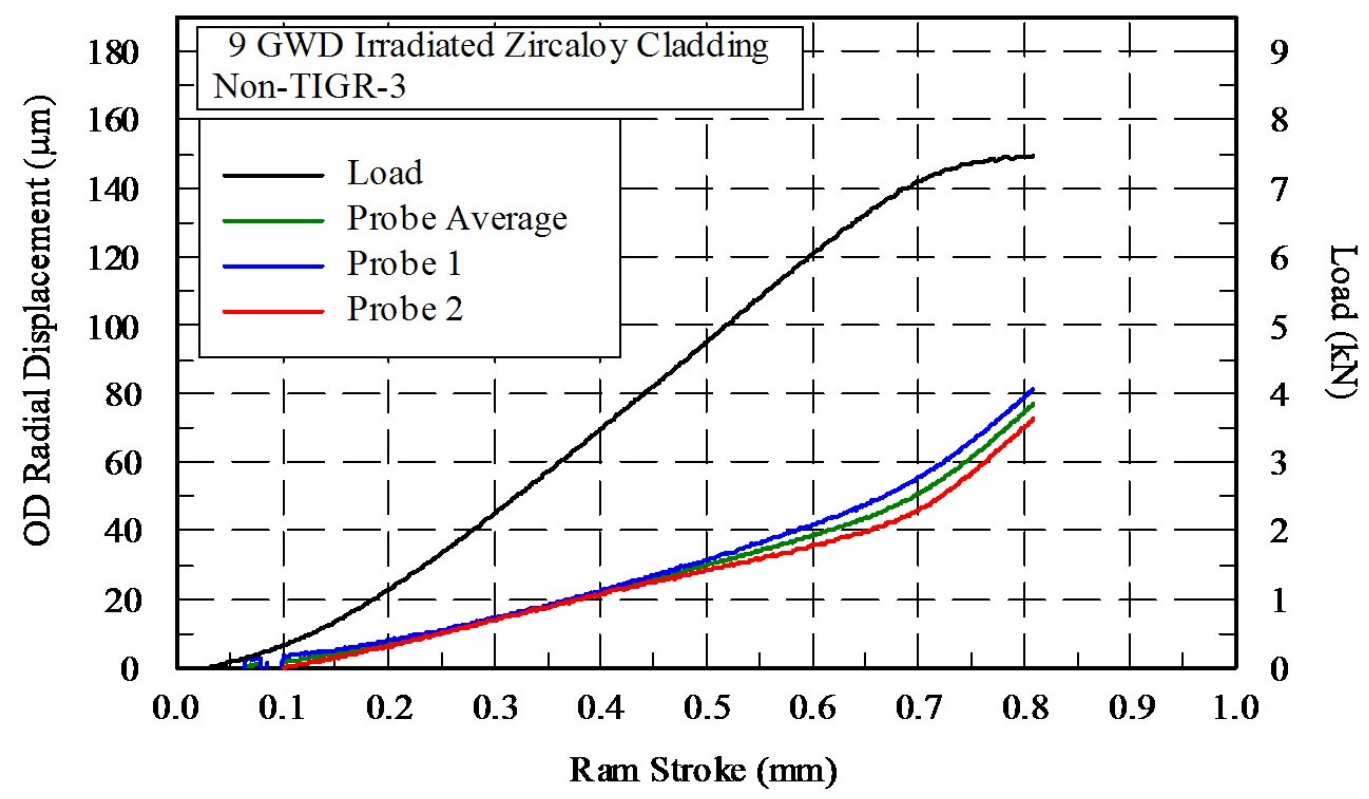

Fig. 8. Load and displacement plots for non-TIGR, 9-GWd/MT fuel burnup cladding specimen 3.

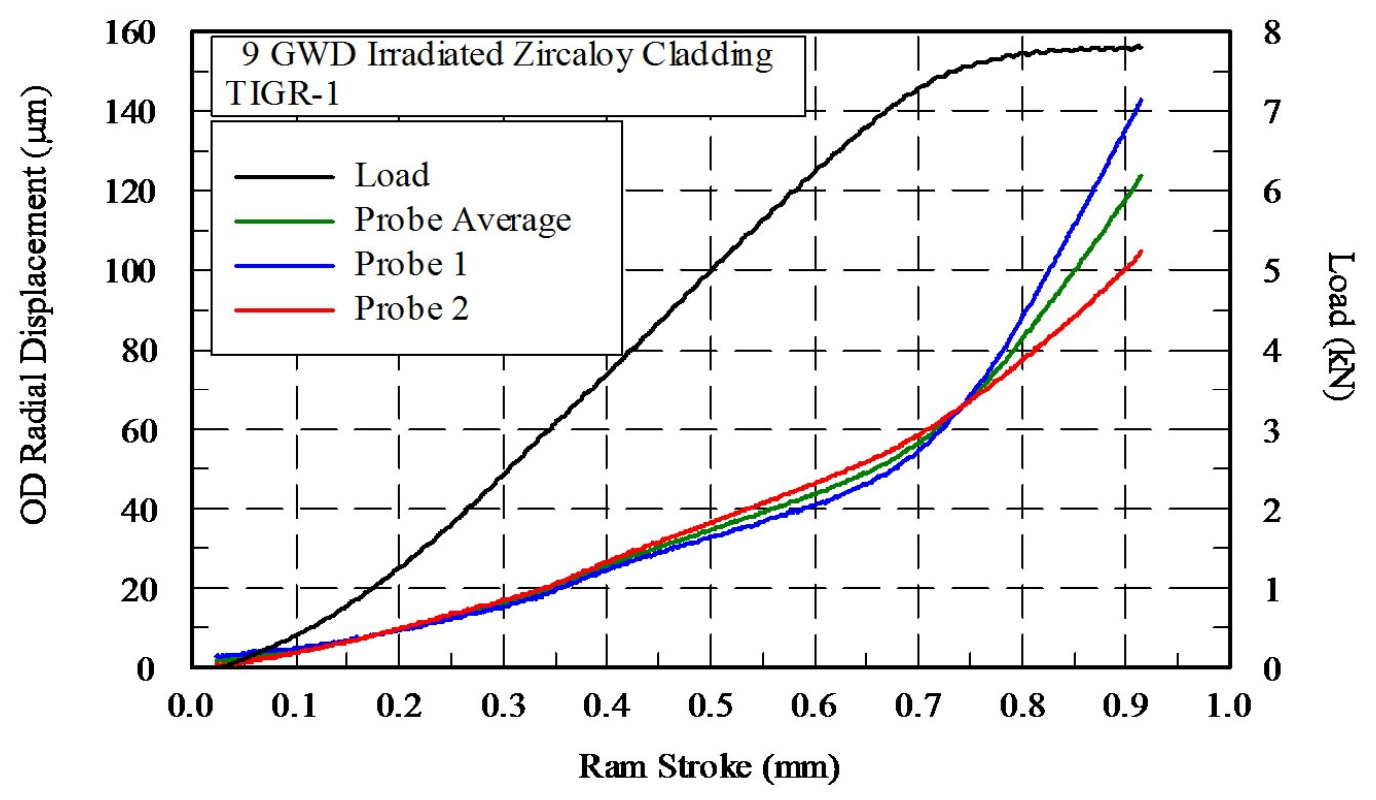

Fig. 9. Load and displacement plots for TIGR, 9-GWd/MT fuel burnup cladding specimen 1. 


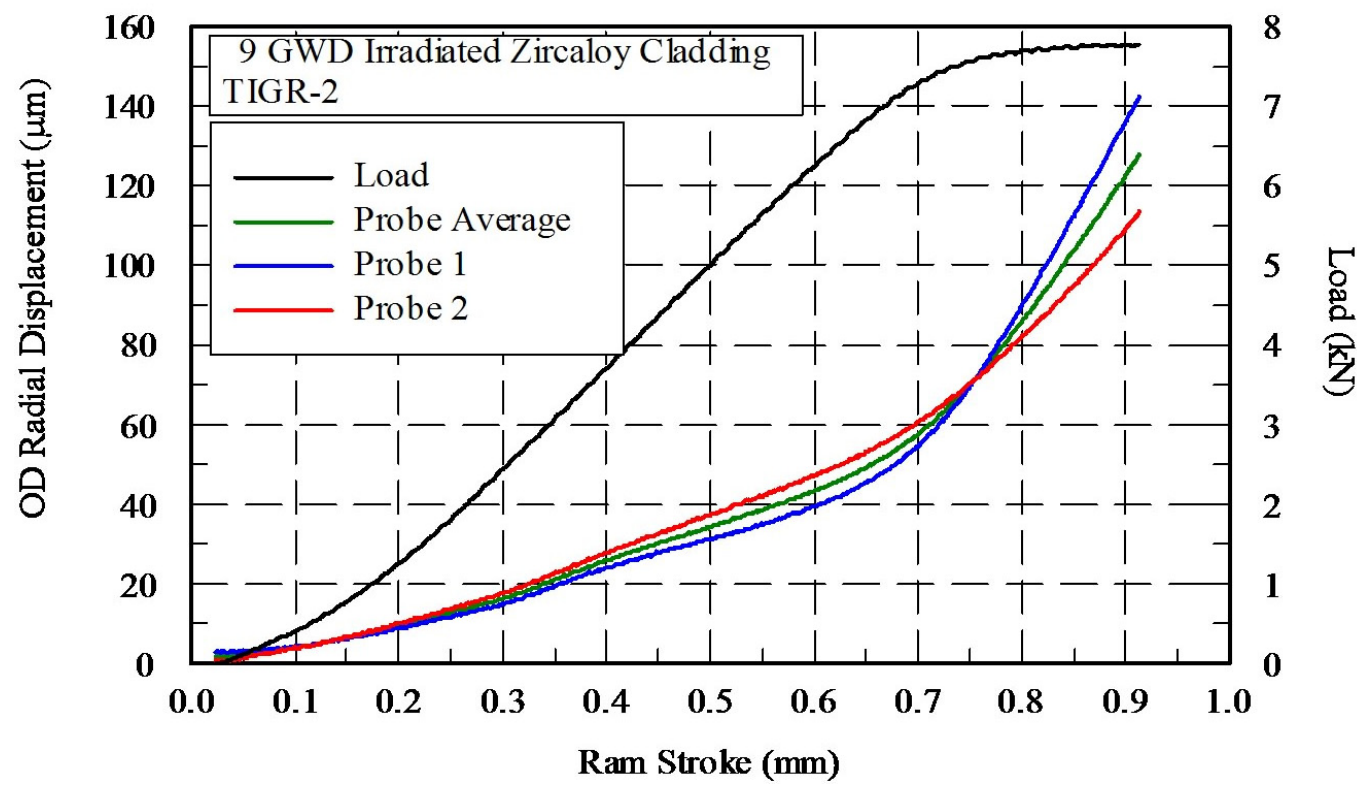

Fig. 10. Load and displacement plots for TIGR, 9-GWd/MT fuel burnup cladding specimen 2.

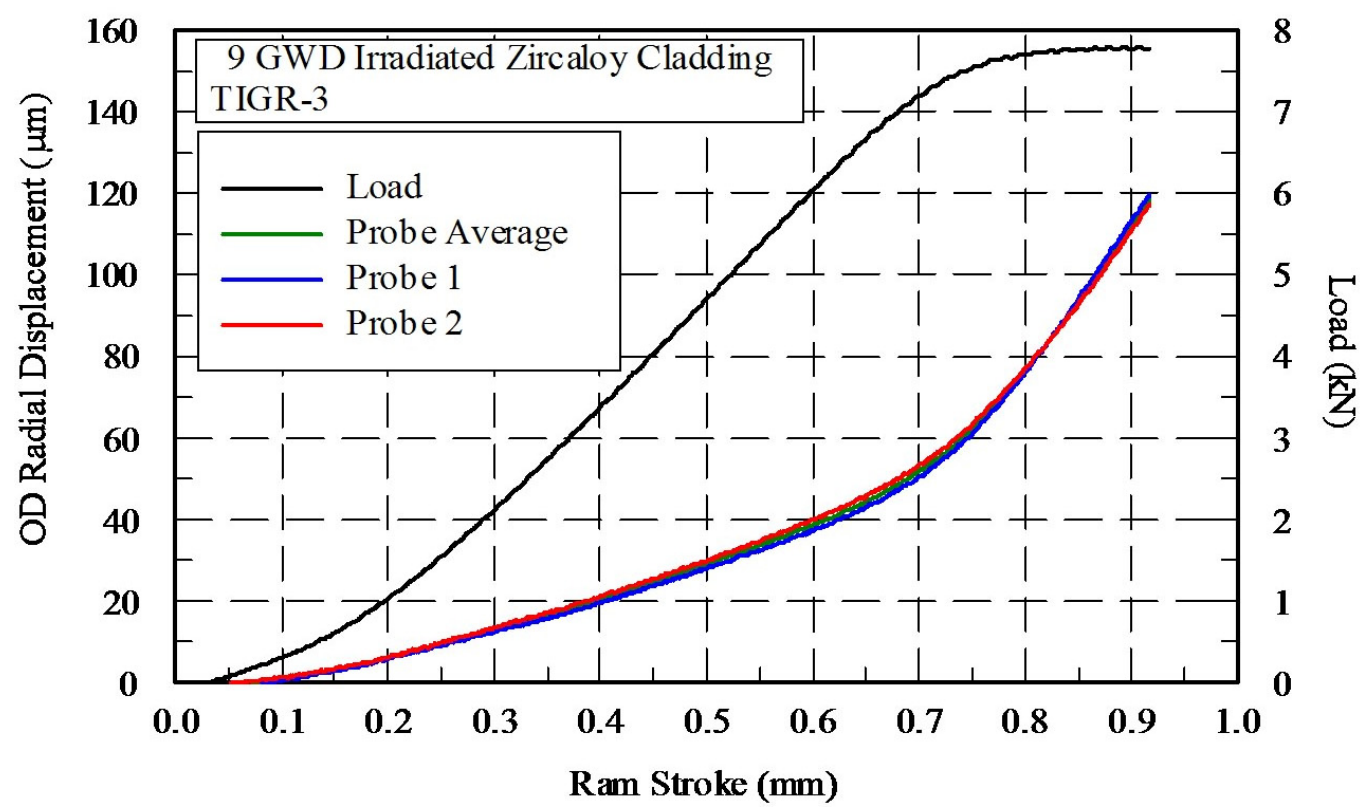

Fig. 11. Load and displacement plots for TIGR, 9-GWd/MT fuel burnup cladding specimen 3.

The non-TIGR specimens displayed a consistent maximum loading of about $7.5-8 \mathrm{kN}$. Of some concern is the large deviation in OD radial displacement measured by the two probes. The probe measurements had difference of nearly 60 and $80 \mu \mathrm{m}$ for specimens 1 and 2, respectively. This phenomenon appears to be associated with the plastic deformation regime, but some deviations are observed during the elastic portion of the plot. 
The plots for the TIGR treated specimens show behavior similar to that measured in the nonTIGR cladding. The load saturates at approximately $7.9 \mathrm{kN}$, and the average displacement of the OD is $120 \mu \mathrm{m}$ at $0.9-\mathrm{mm}$ ram stroke. With an exception to specimen 3, the TIGR samples showed some deviation in individual probe measurements of OD displacement. This is also similar to behavior seen in the non-TIGR specimens.

\subsection{IRRADIATED ZIRCALOY-4 CLADDING FOR 21-GWd/MT FUEL BURNUP}

Ductility test results for 21-GWd/MT fuel burnup cladding are shown in this section. The figures are the same format as the previous two sections and display data for non-TIGR specimens, Figs. 12-14, and TIGR specimens, Figs. 15-17.

The results for the non-TIGR, 21-GWd/MT tests showed a significant degree of consistency. The load saturated at approximately $8.2 \mathrm{kN}$ and an OD displacement of $105 \mu \mathrm{m}$ for $0.9 \mathrm{~mm}$ of ram stroke. The saturation load is slightly greater than the 9-GWd/MT values, and the OD displacement is less.

Like the 9-GWd/MT tests, the TIGR specimens show behavior consistent with the non-TIGR cladding. Also, the deviation in probe measurements is pronounced. In each case at the onset of plastic deformation, most of the OD displacement associated with plastic deformation is measured by one probe, while the other probe shows a subtle change in displacement rate.

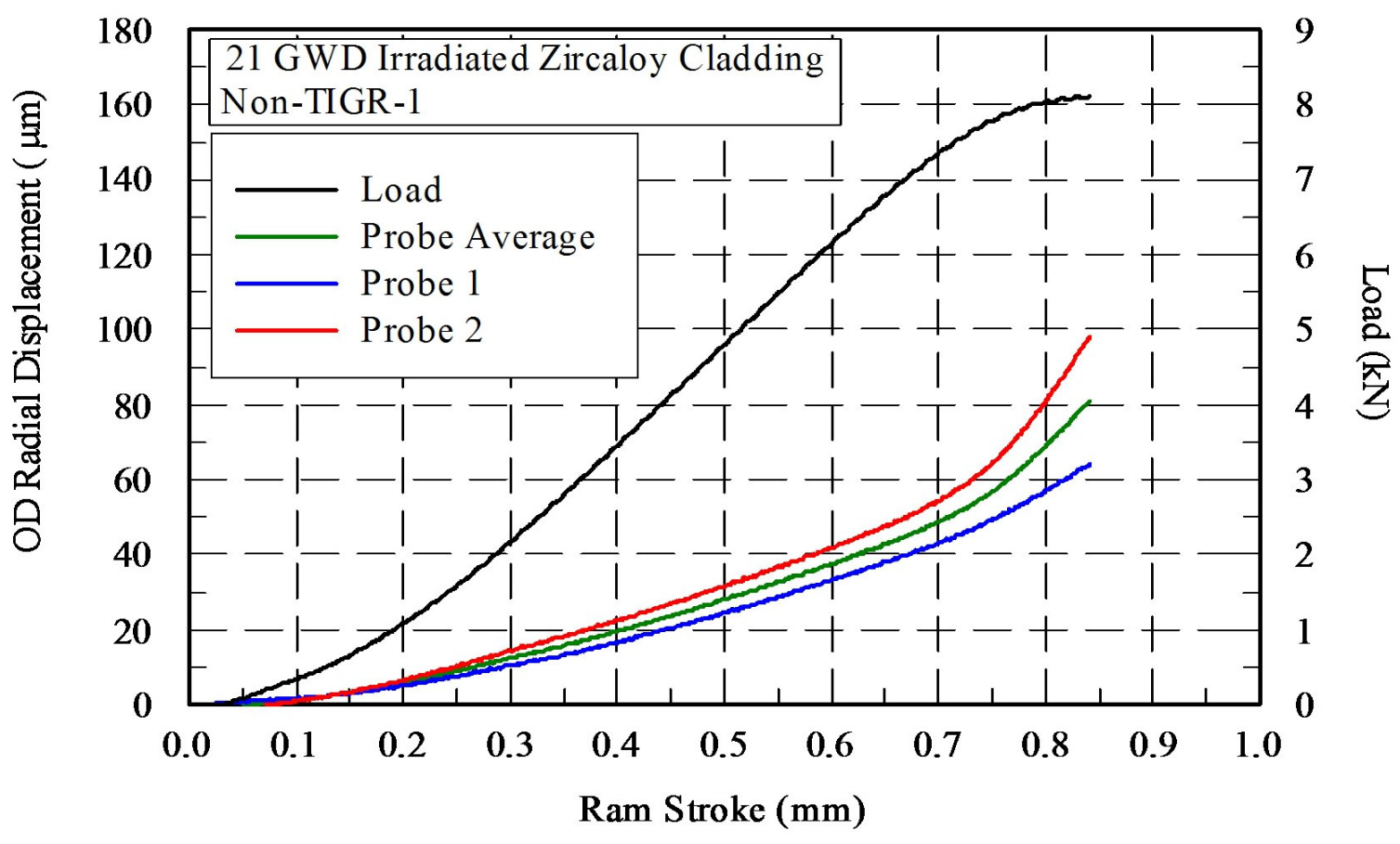

Fig. 12. Load and displacement plots for non-TIGR, 21-GWd/MT fuel burnup cladding specimen 1. 


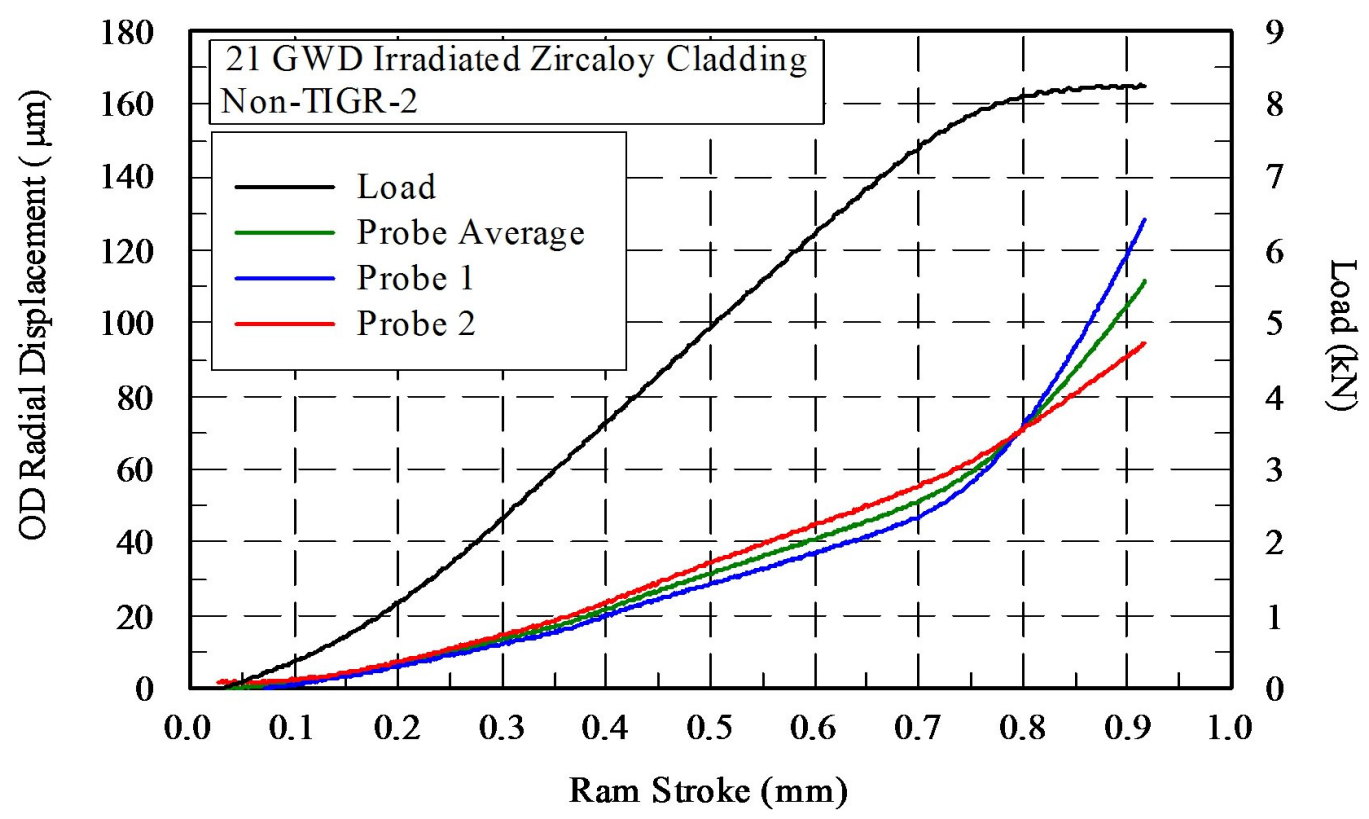

Fig. 13. Load and displacement plots for non-TIGR, 21-GWd/MT fuel burnup cladding specimen 2.

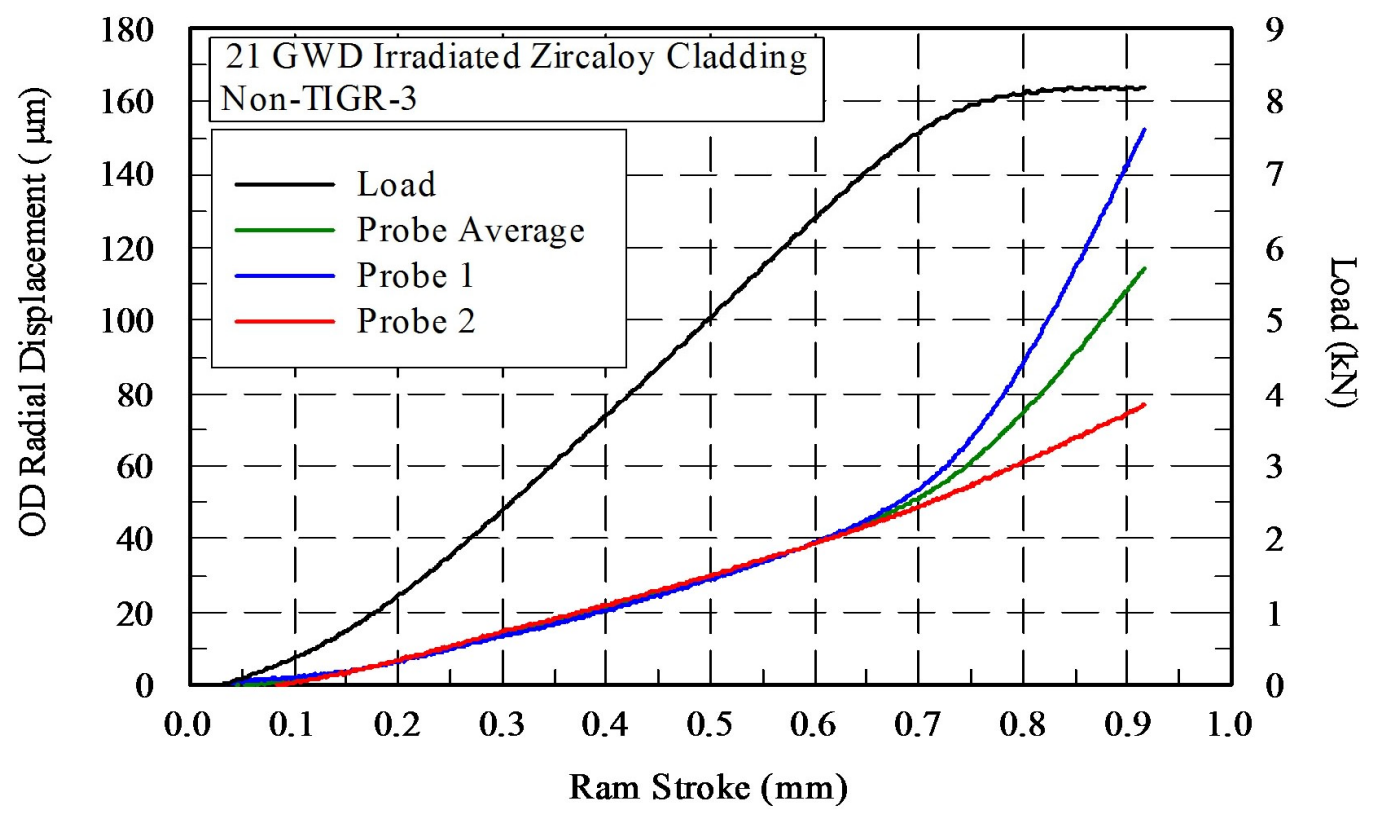

Fig. 14. Load and displacement plots for non-TIGR, 21-GWd/MT fuel burnup cladding specimen 3. 


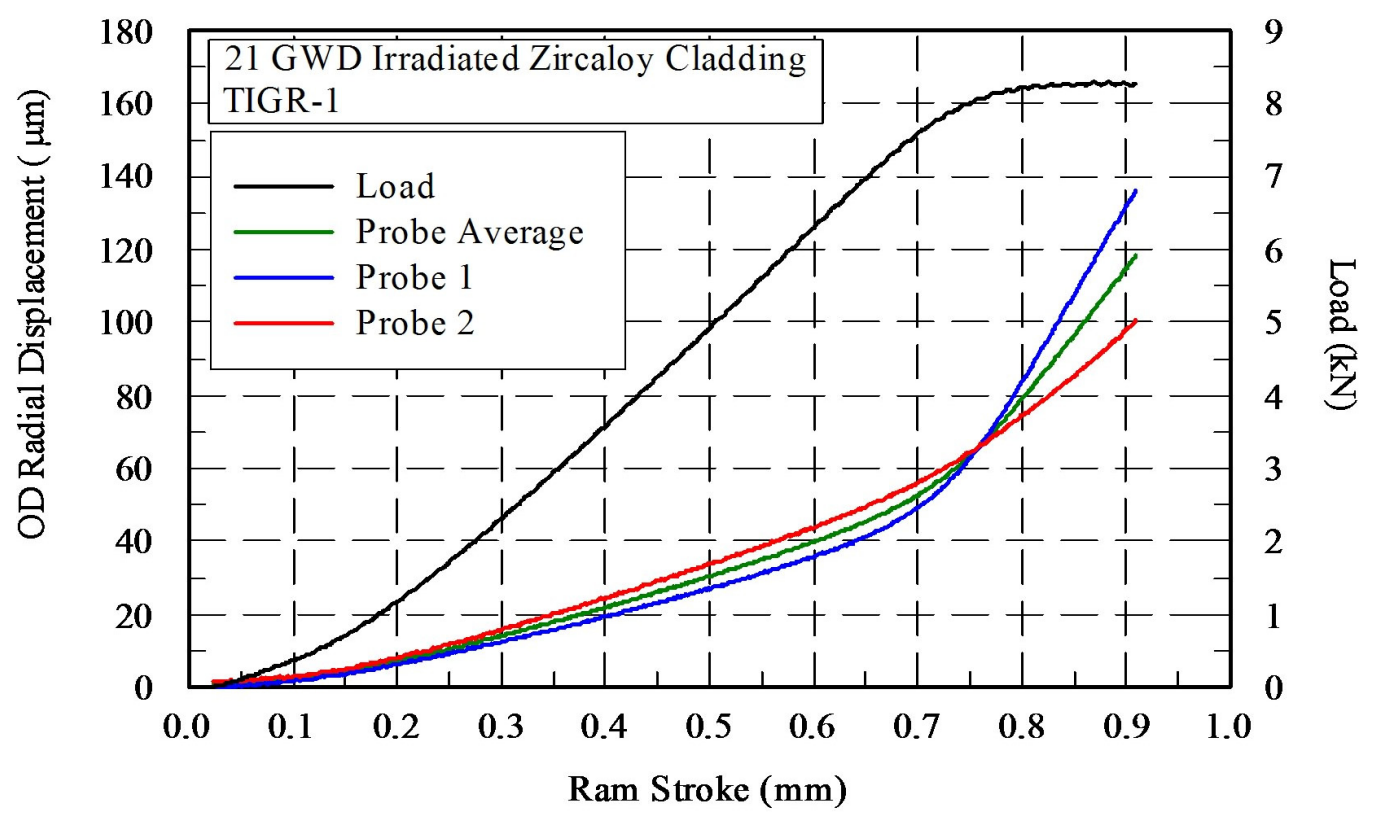

Fig. 15. Load and displacement plots for TIGR, 21-GWd/MT fuel burnup cladding specimen 1.

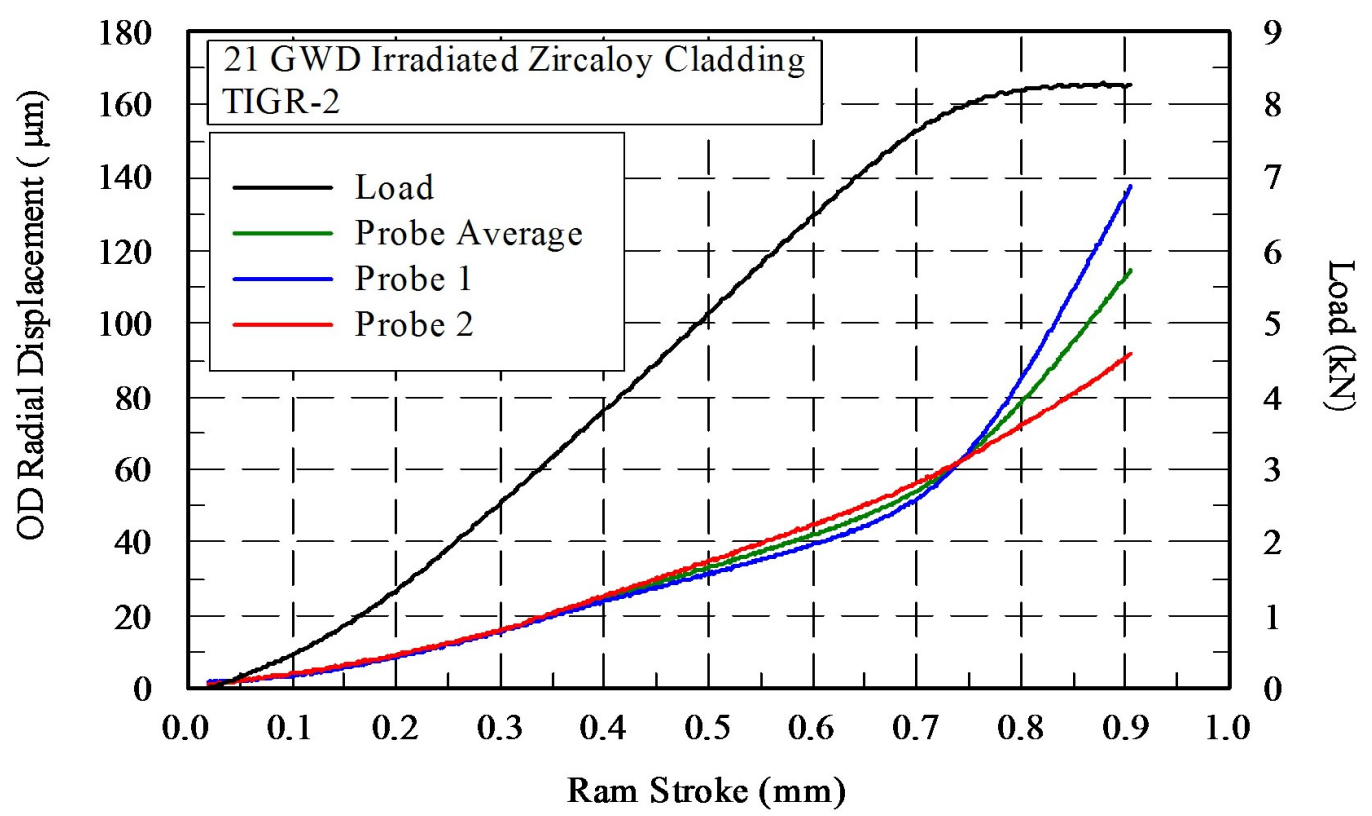

Fig. 16. Load and displacement plots for TIGR, 21-GWd/MT fuel burnup cladding specimen 2. 


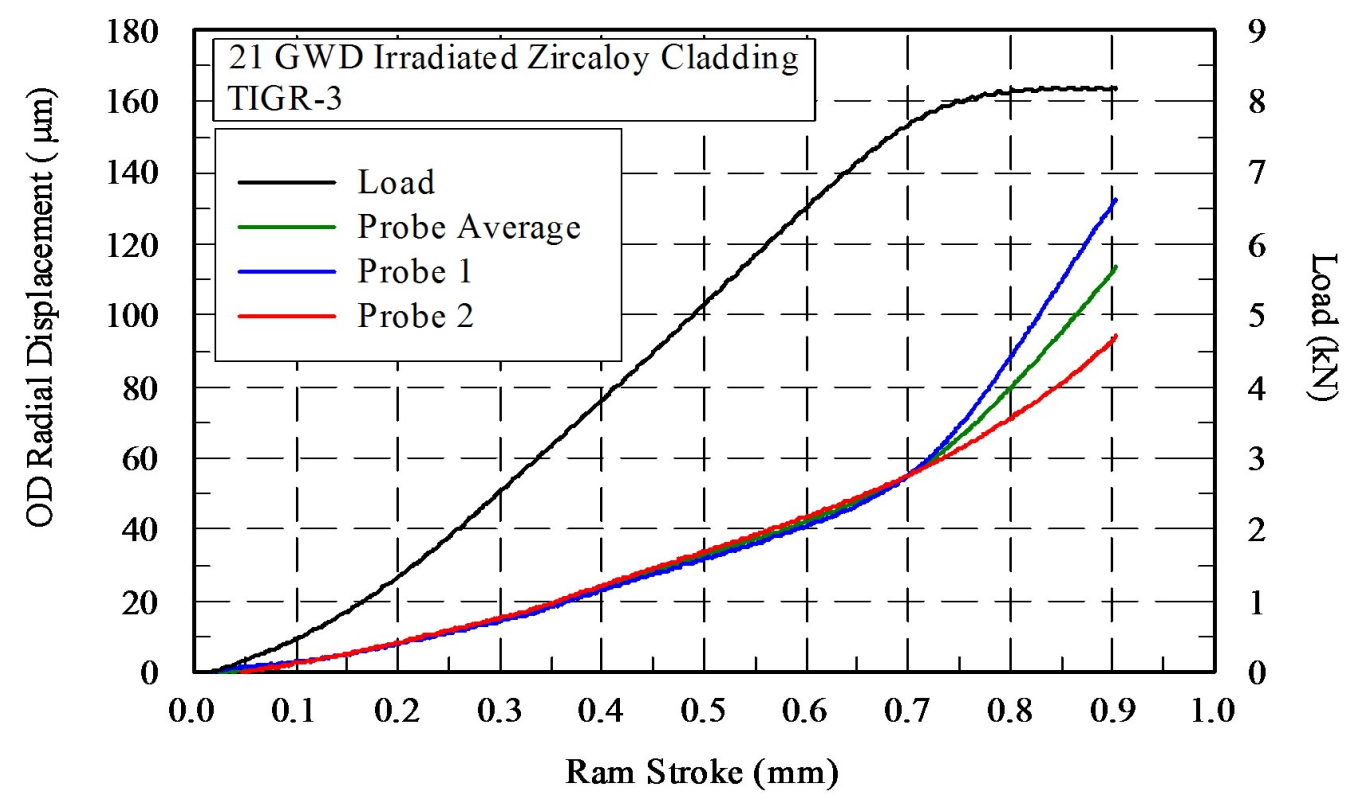

Fig. 17. Load and displacement plots for TIGR, 21-GWd/MT fuel burnup cladding specimen 3.

\subsection{IRRADIATED ZIRCALOY-4 CLADDING FOR 30-GWd/MT FUEL BURNUP}

Figures presenting ductility test results for $30-\mathrm{GWd} / \mathrm{MT}$ fuel burnup cladding are provided in the following section. The figures are in the same format as those found in previous sections showing tensile hoop data.

The non-TIGR, 30-GWd/MT results shown in Figs. 18-20 display a maximum load of approximately $8.5 \mathrm{kN}$ and an approximate OD radial displacement of $110 \mu \mathrm{m}$ at $0.9-\mathrm{mm}$ ram stroke. Like previous results, the uniformity of probe measurements is reduced as plastic deformations commence. However, a slight drop in load is measured prior to termination of the tests. This phenomenon is not observed in results for lower irradiation levels in which the loading appears to reach a steady state.

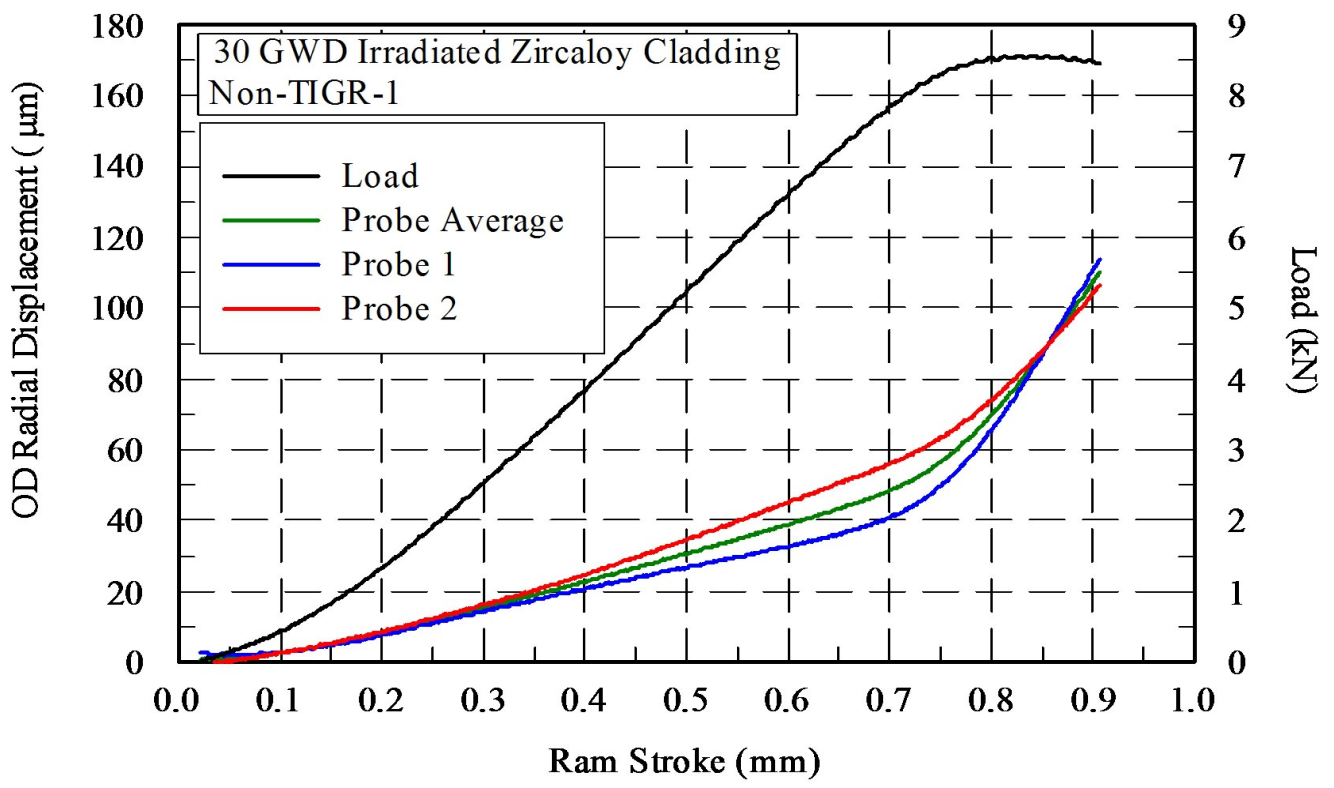

Fig. 18. Load and displacement plots for non-TIGR, $30 \mathrm{GWd} / \mathrm{MT}$ fuel burnup cladding specimen 1. 


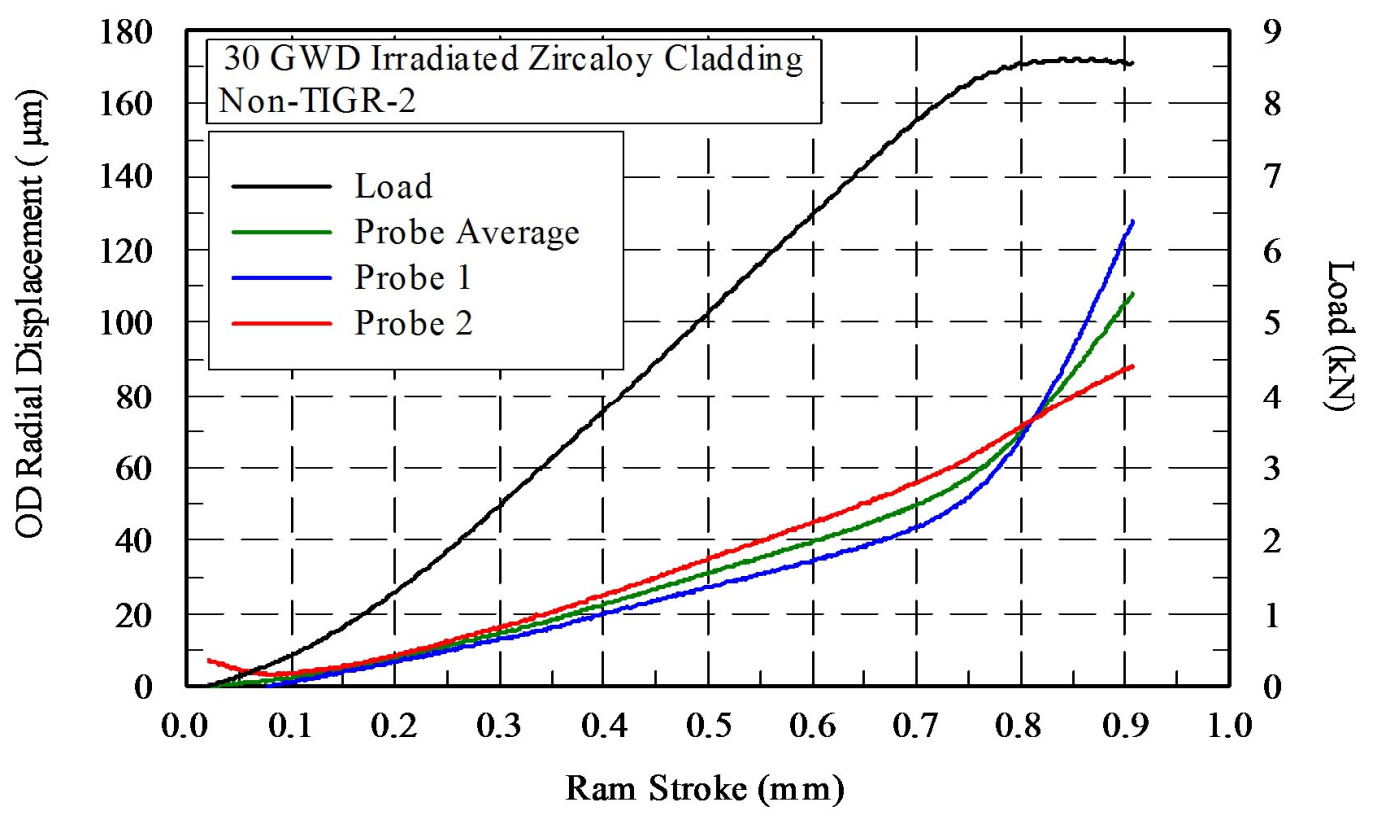

Fig. 19. Load and displacement plots for non-TIGR, 30-GWd/MT fuel burnup cladding specimen 2.

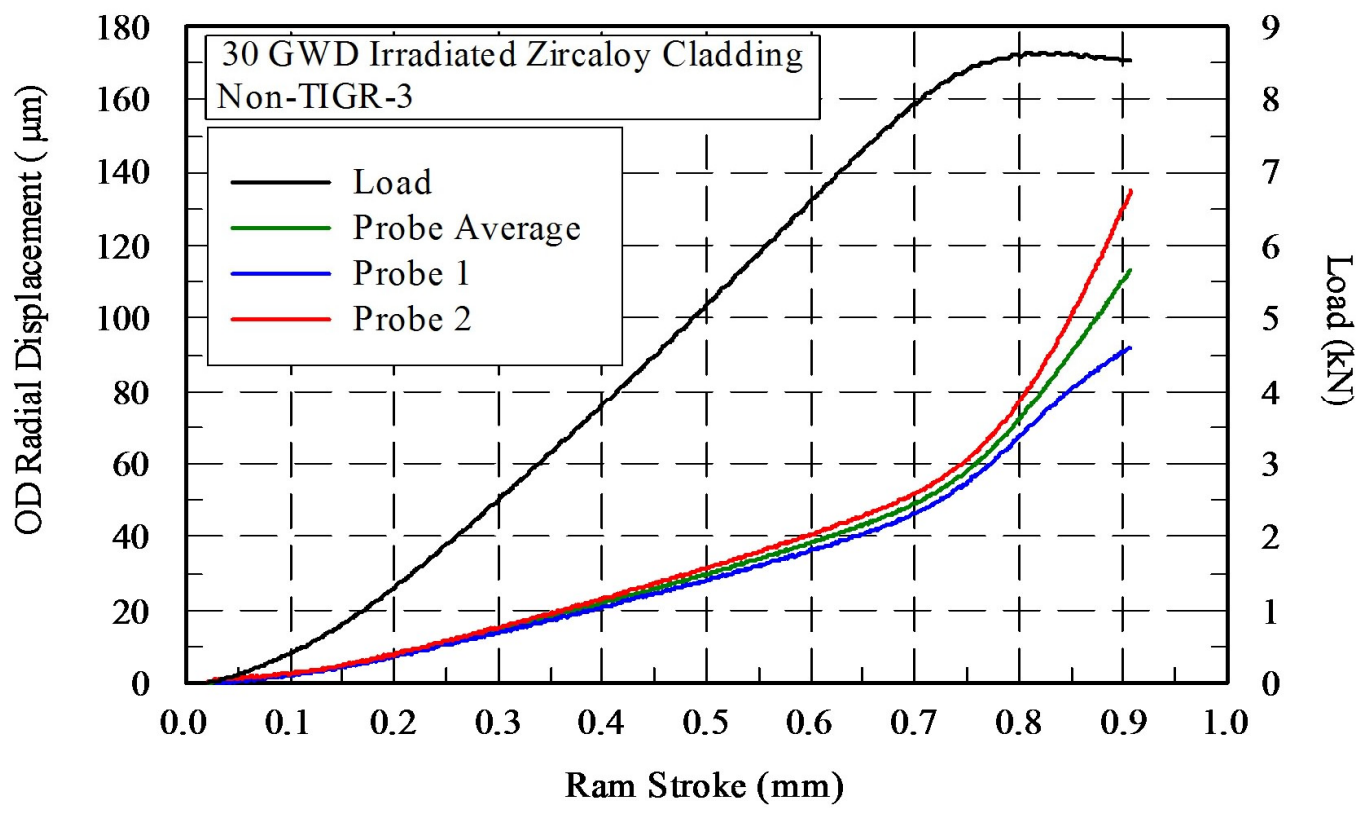

Fig. 20. Load and displacement plots for non-TIGR, 30-GWd/MT fuel burnup cladding specimen 3 . 
Data plots for TIGR specimens (Figs. 21-23) appear to have similar behavior to that measured for non-TIGR data shown in Figs. 18-20. The load drop during plastic deformation suggests instability and is consistent with results for non-TIGR specimens. The significant divergence of individual probe measurements during the elastic portion of the loading in Fig. 22 suggests that the initial positioning of the specimen and plug was not ideal and some repositioning occurred during the test.

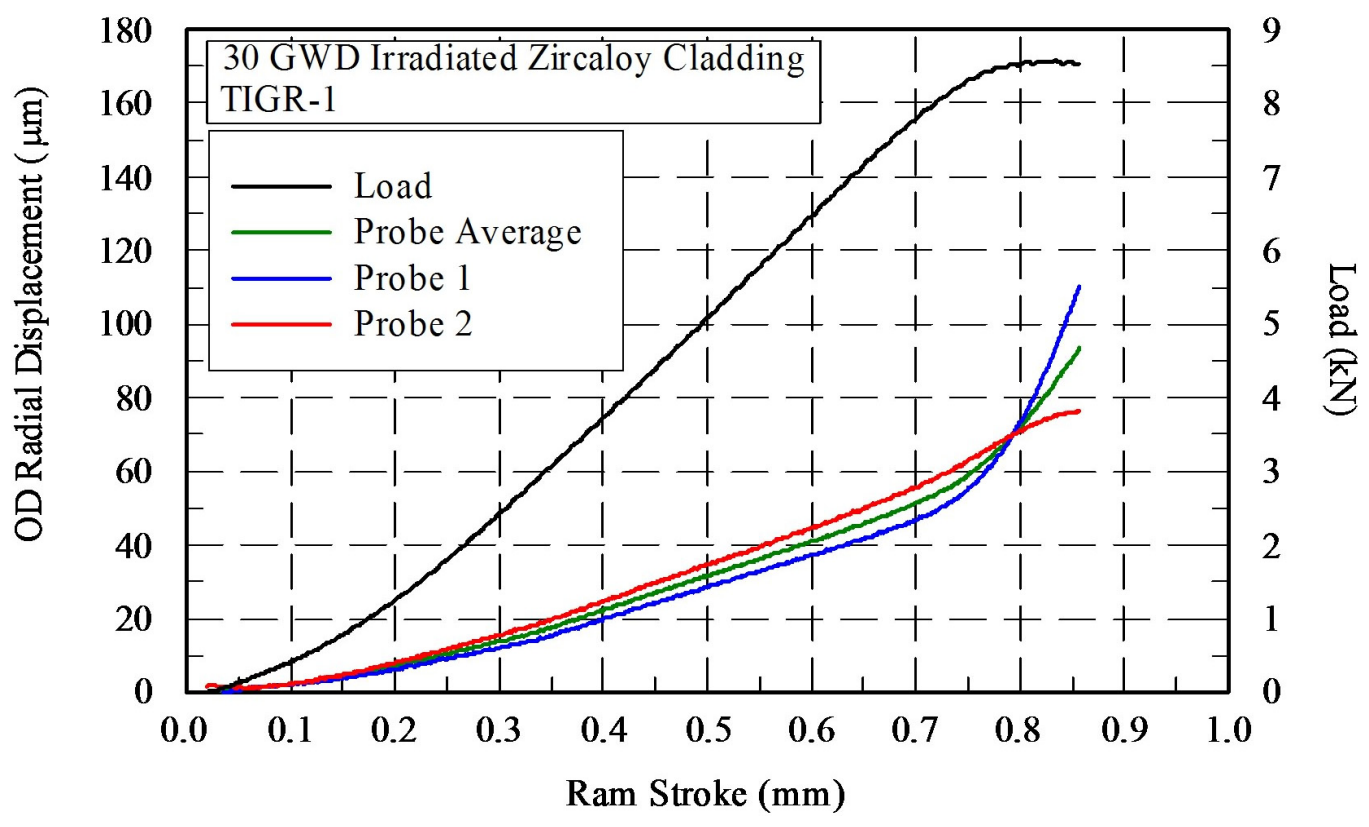

Fig. 21. Load and displacement plots for TIGR, 30-GWd/MT fuel burnup cladding specimen 1.

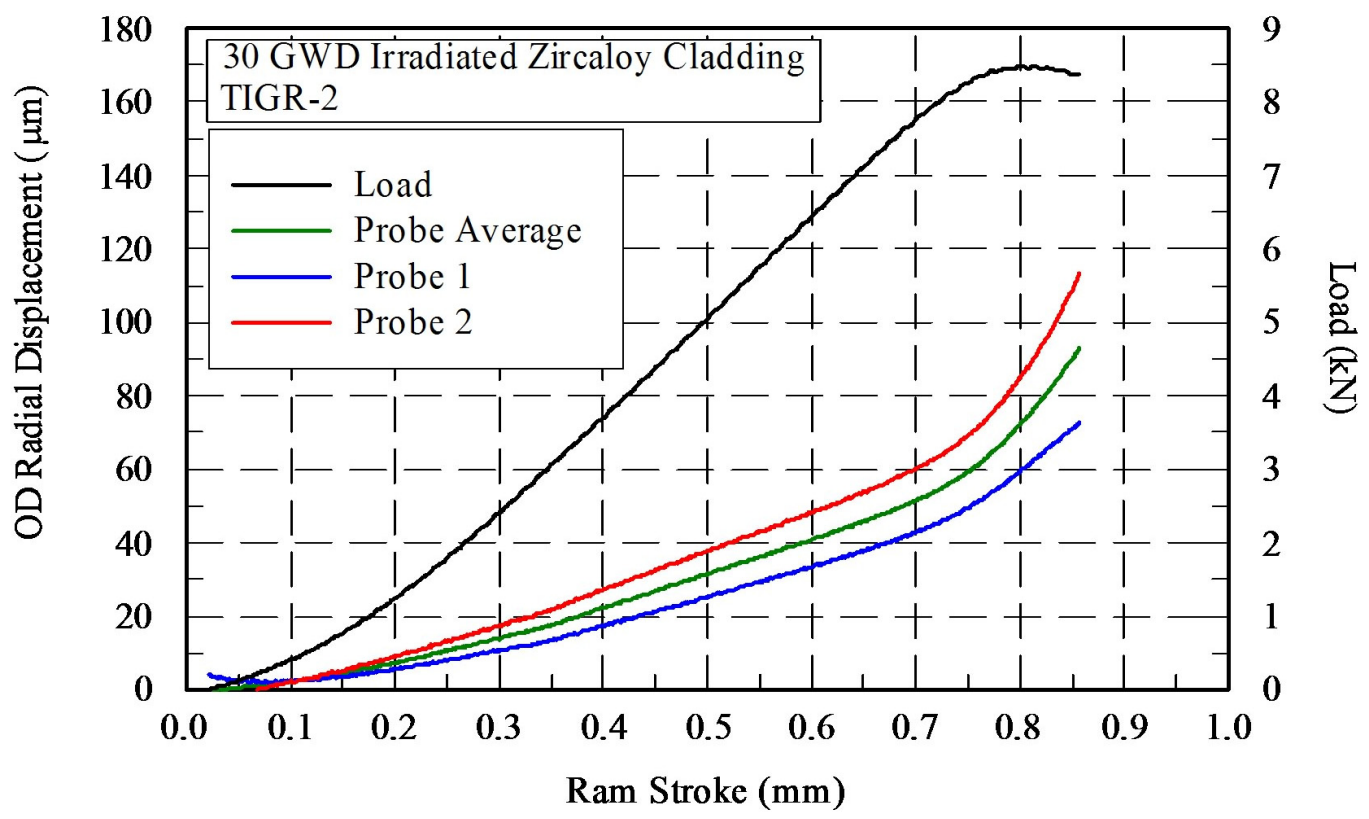

Fig. 22. Load and displacement plots for TIGR, 30-GWd/MT fuel burnup cladding specimen 2. 


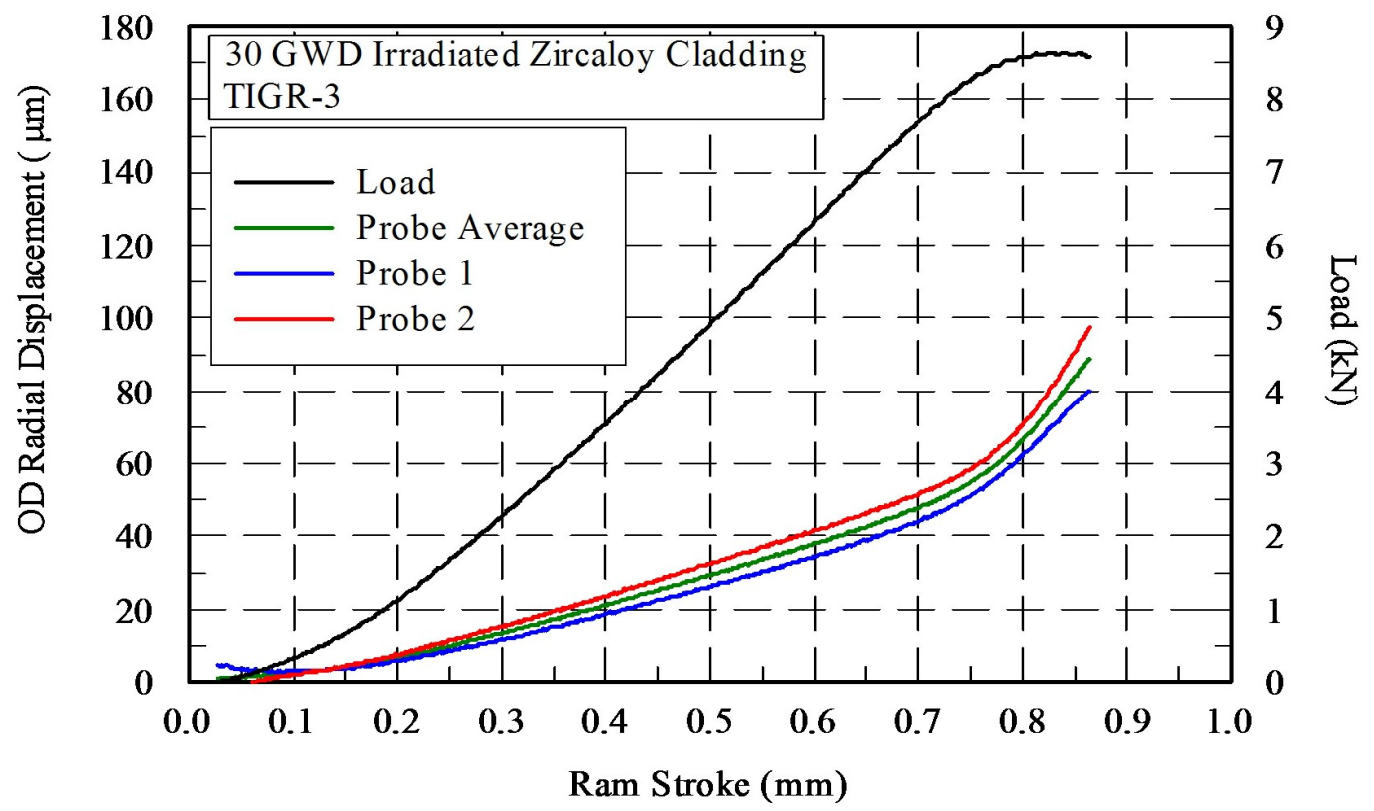

Fig. 23. Load and displacement plots for TIGR, 30-GWd/MT fuel burnup cladding specimen 3.

\subsection{IRRADIATED ZIRCALOY-4 CLADDING FOR 40-GWd/MT FUEL BURNUP}

Figures presenting ductility test results for 40-GWd/MT fuel burnup cladding follow (Figs. 24-29). The format is the same as that used in Figs. 3-23.

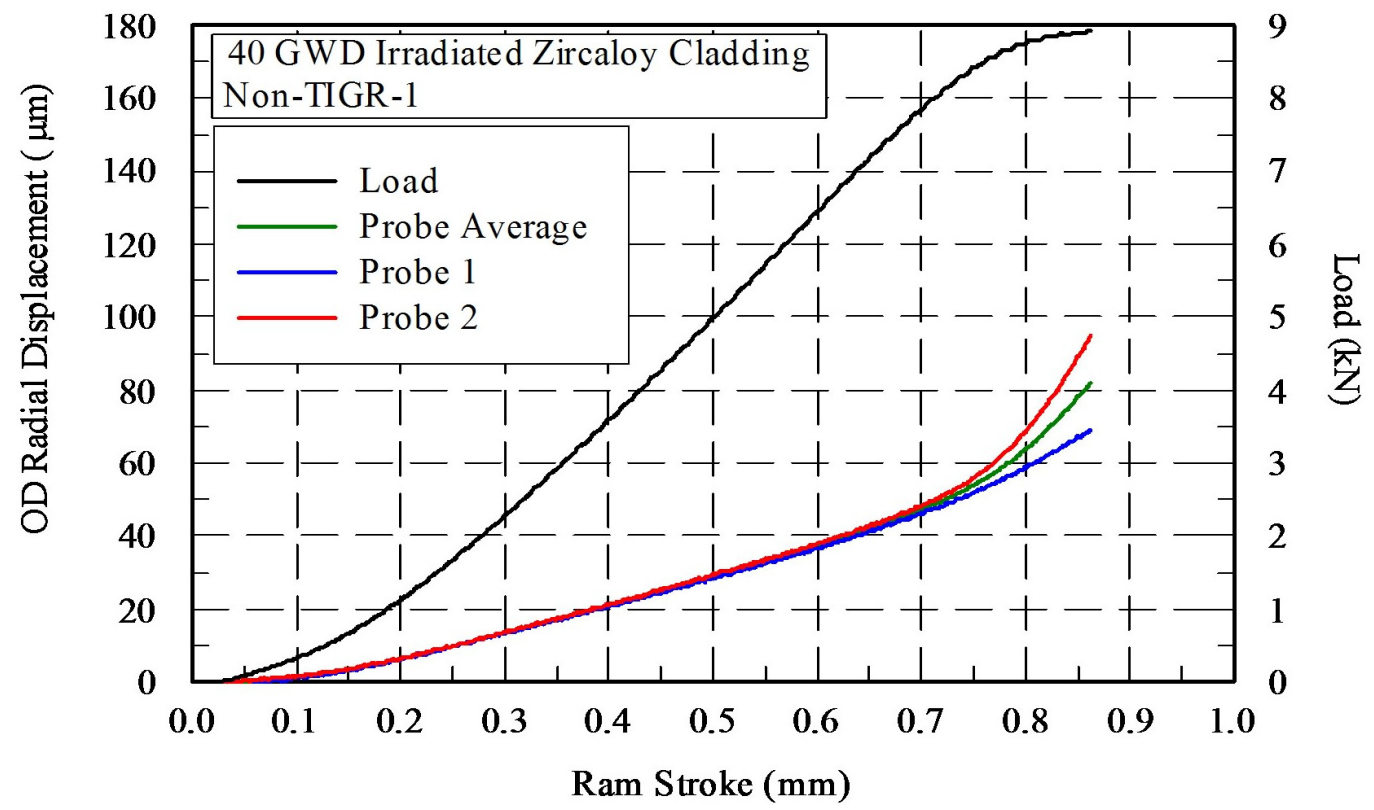

Fig. 24. Load and displacement plots for non-TIGR, 40-GWd/MT fuel burnup cladding specimen 1. 


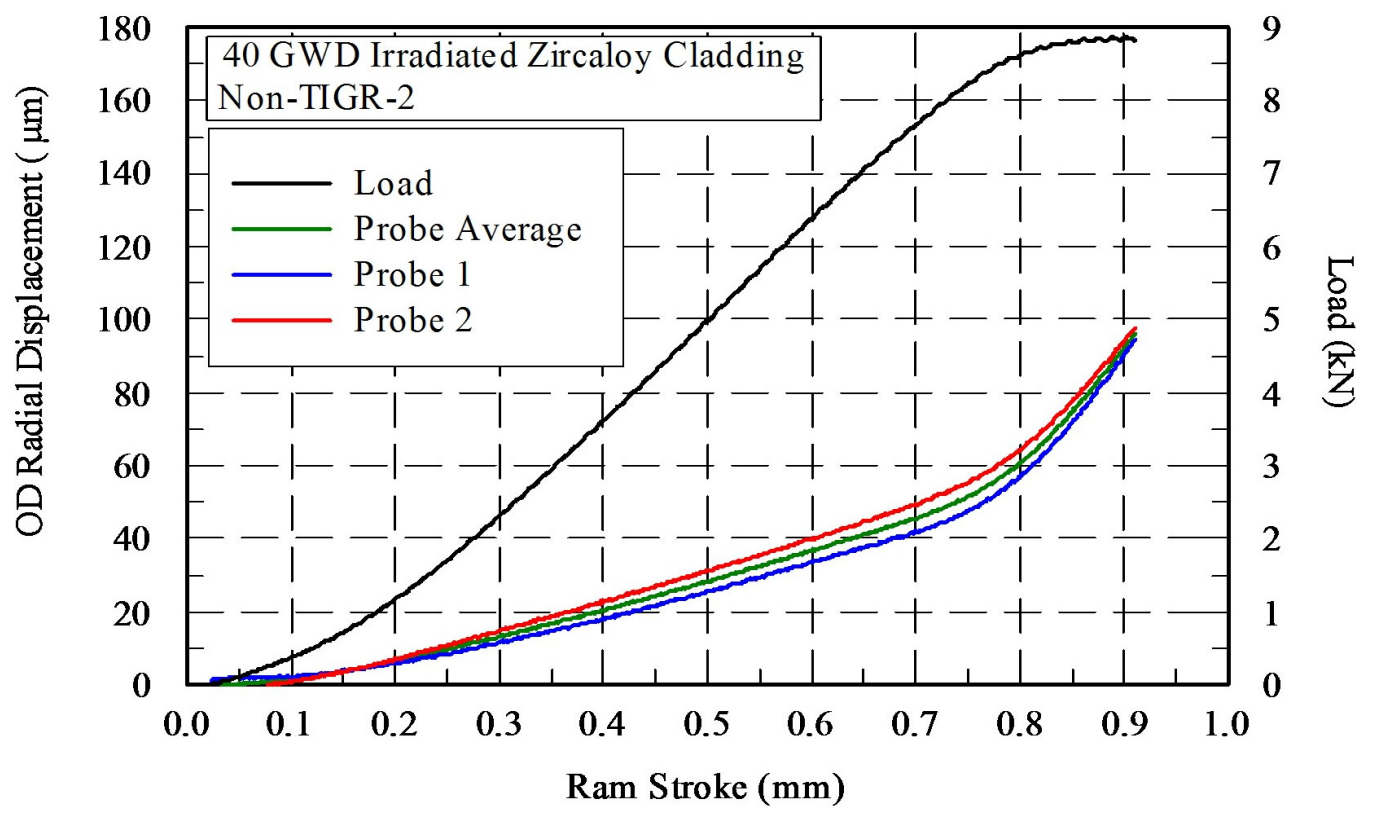

Fig. 25. Load and displacement plots for non-TIGR, 40-GWd/MT fuel burnup cladding specimen 2.

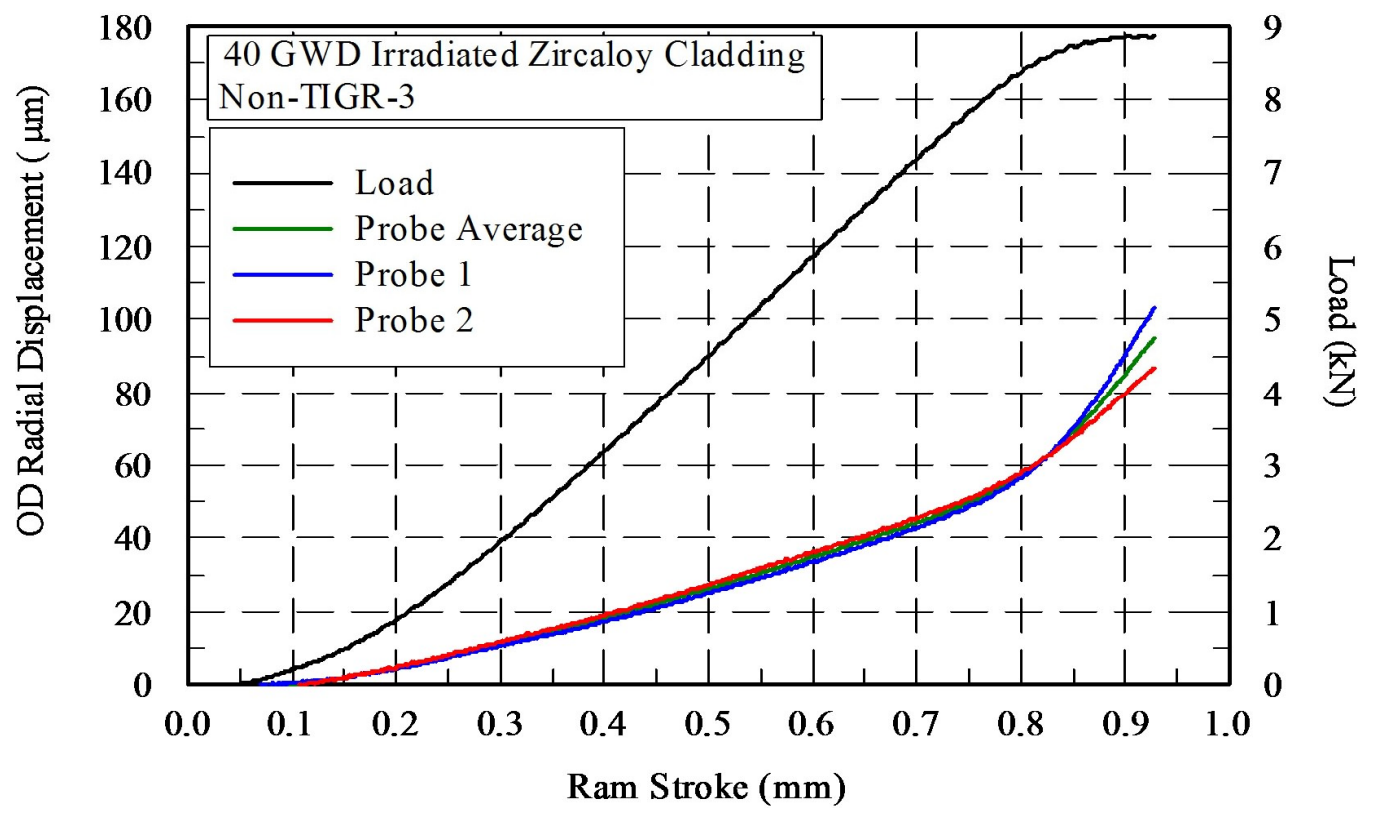

Fig. 26. Load and displacement plots for non-TIGR, 40-GWd/MT fuel burnup cladding specimen 3. 


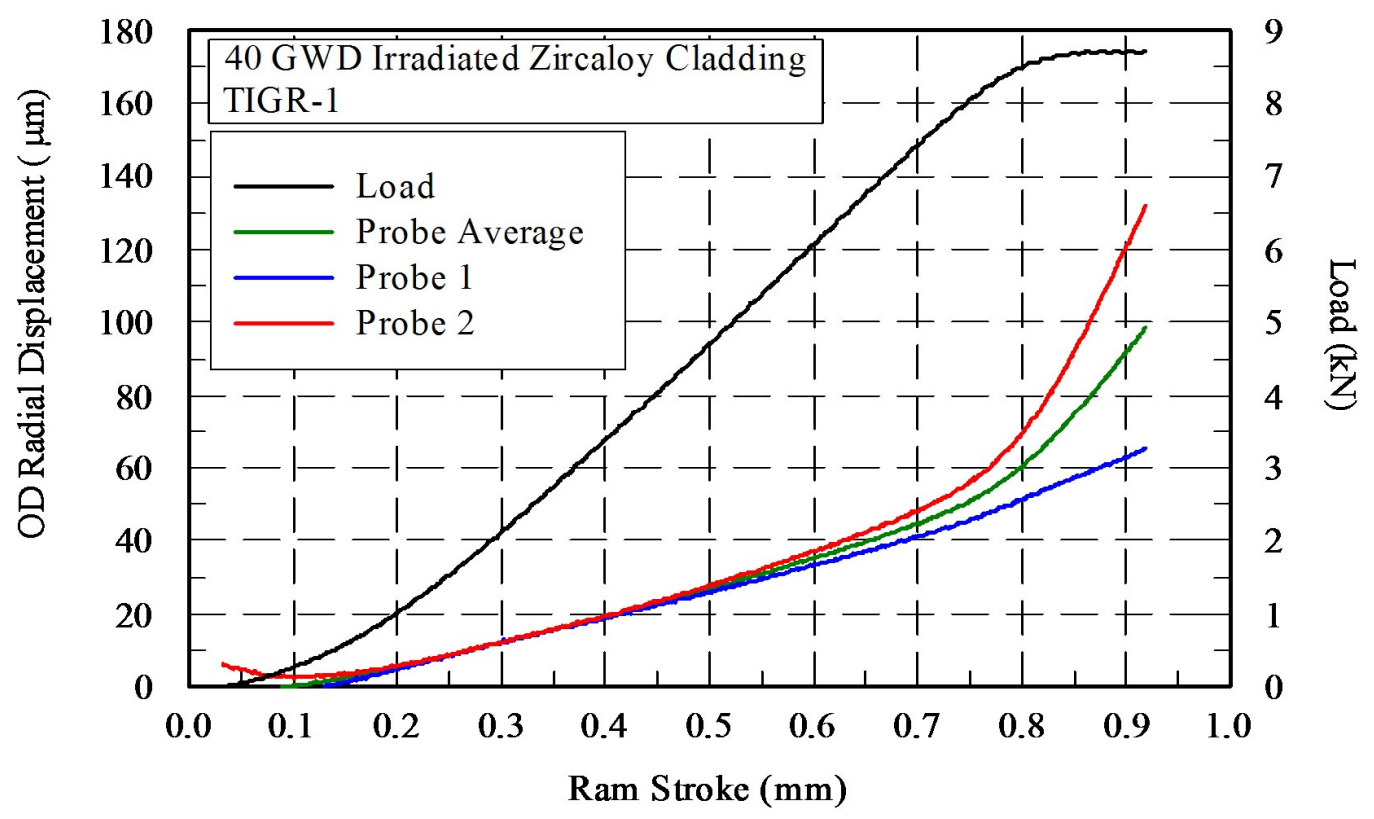

Fig. 27. Load and displacement plots for TIGR, 40-GWd/MT fuel burnup cladding specimen 1.

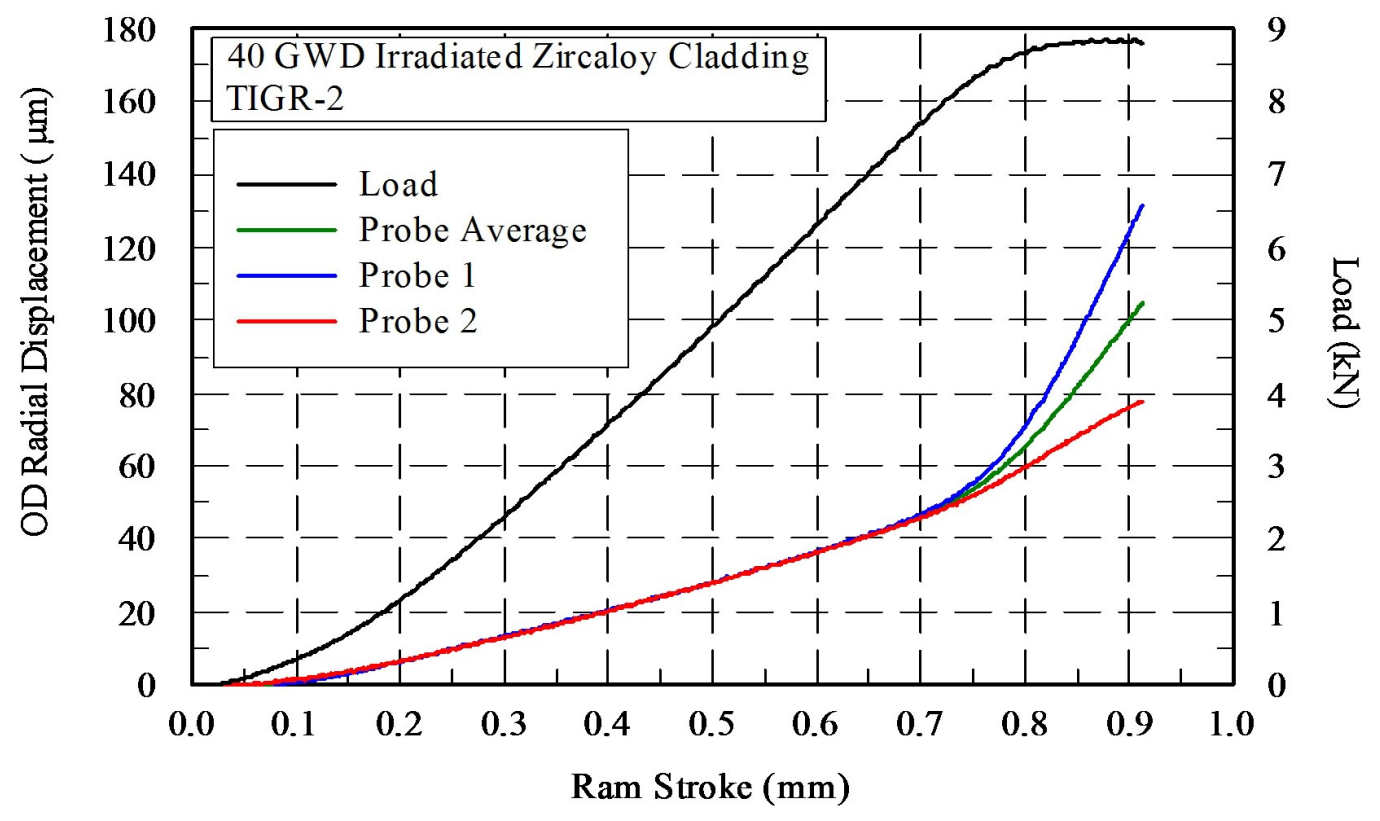

Fig. 28. Load and displacement plots for TIGR, 40-GWd/MT fuel burnup cladding specimen 2. 


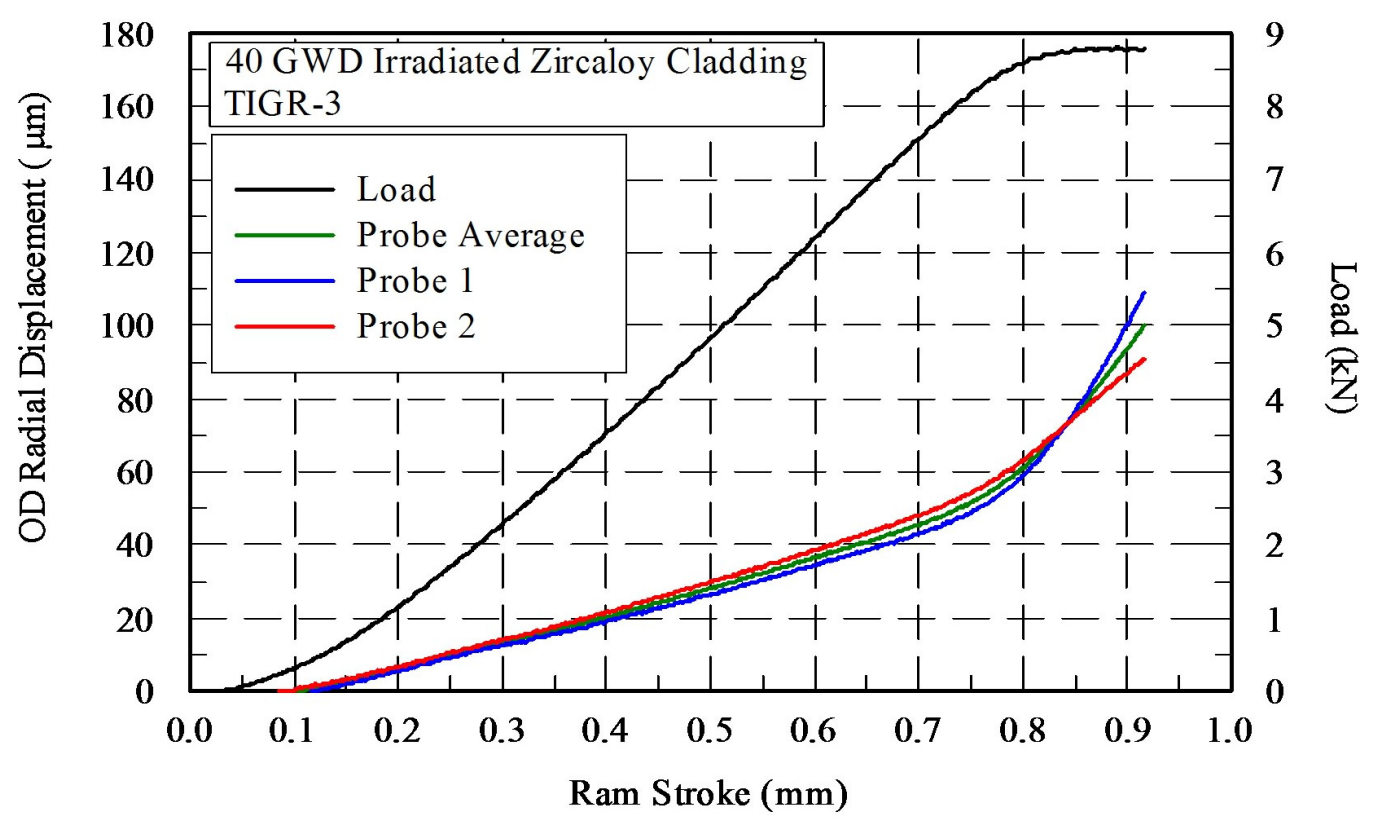

Fig. 29. Load and displacement plots for TIGR, 40-GWd/MT fuel burnup cladding specimen 3.

The load data again showed an increase with increasing irradiation level. A maximum load of nearly $9 \mathrm{kN}$ was measured for the non-TIGR, 40-GWd/MT clad specimens. As the strength of the cladding increases, the elastic portion of the load-displacement curves also increases. Because a fixed total ram stroke was used throughout the project, this increase in the elastic strain is accommodated by a decrease in the measured plastic deformation. In Figs. 24-25, it is not apparent if load drop will occur or the degree of deviation in probe measurements will decrease with additional ram stroke.

Consistent with previous results, the load data for the TIGR specimens are similar to the nonTIGR specimens. The OD displacement data do not reveal any trends that suggest a variation in strain behavior between TIGR and non-TIGR specimens.

\subsection{IRRADIATED ZIRCALOY-4 CLADDING FOR 50-GWd/MT FUEL BURNUP}

Ductility test results for 50-GWd/MT fuel burnup cladding are shown in the following figures (Figs. 30-35). The results were obtained from two fuel pins; however, only non-TIGR fuel pellets were contained within the cladding.

The 50-GWd/MT data displayed significant load drop after plastic yielding. Other irradiation levels had subtle amounts of load drop compared to these data. Also, the severity of deviation in probe measurements appears to have increased. Particularly, Figs. 30 and 34 display data where a probe measured an initial decrease in radial displacement during plastic deformation.

The displacement plots associated with fuel pin 9 in Figs. 33-35 indicated large amounts of displacement deviation between probes. The displacement also shows a discontinuity during plastic deformation. An initial displacement rate is observed with the onset of plastic yielding, but at a point associated with an accelerated load drop, the displacement rate changes. Although this behavior is readily observed in individual probe measurements, the average of these measurements tends to disguise the phenomenon. These measurements suggest that plastic instability has initiated and that nonuniform deformation is occurring. This phenomenon will be discussed further in the following sections. 


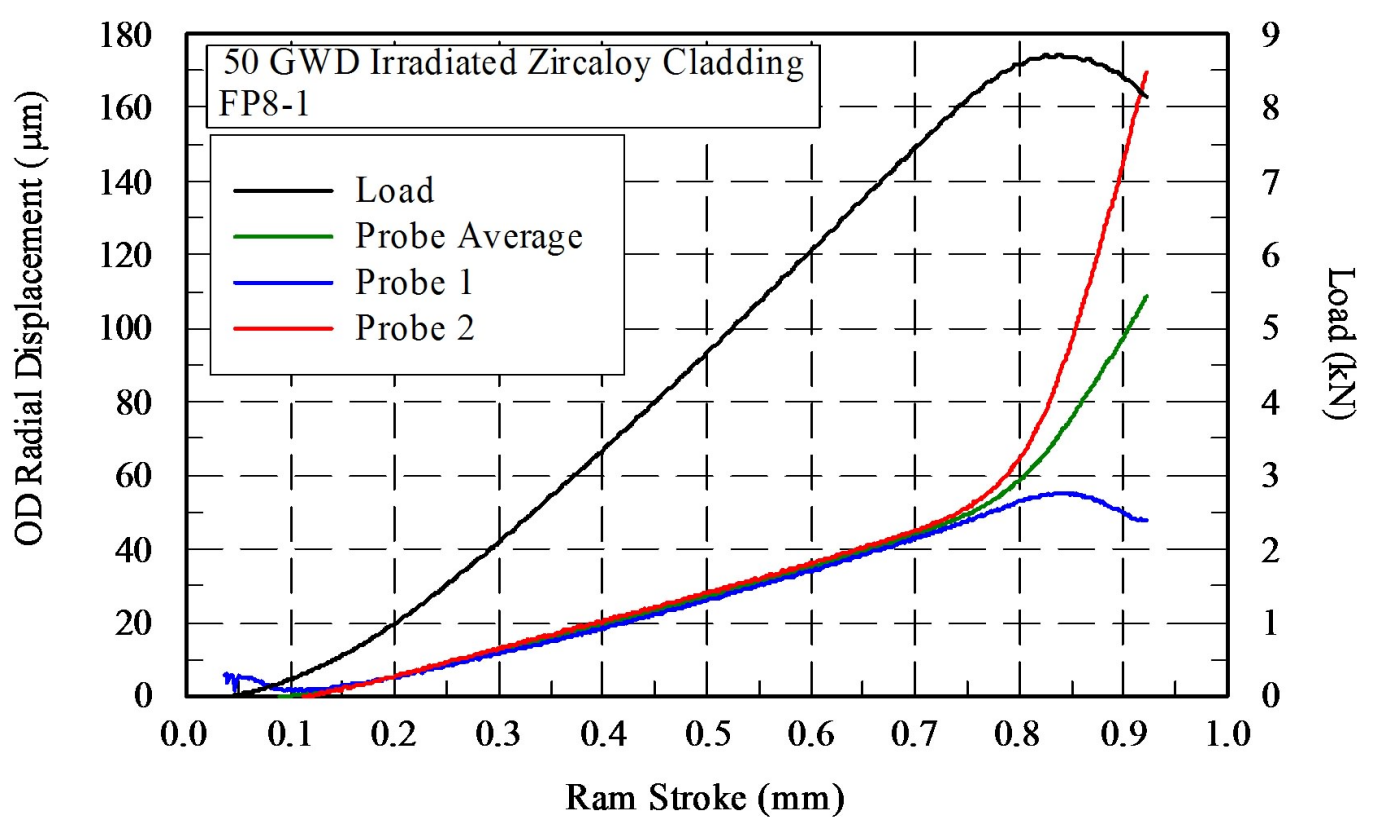

Fig. 30. Load and displacement plots for non-TIGR, 50-GWd/MT fuel burnup cladding specimen FP8-1.

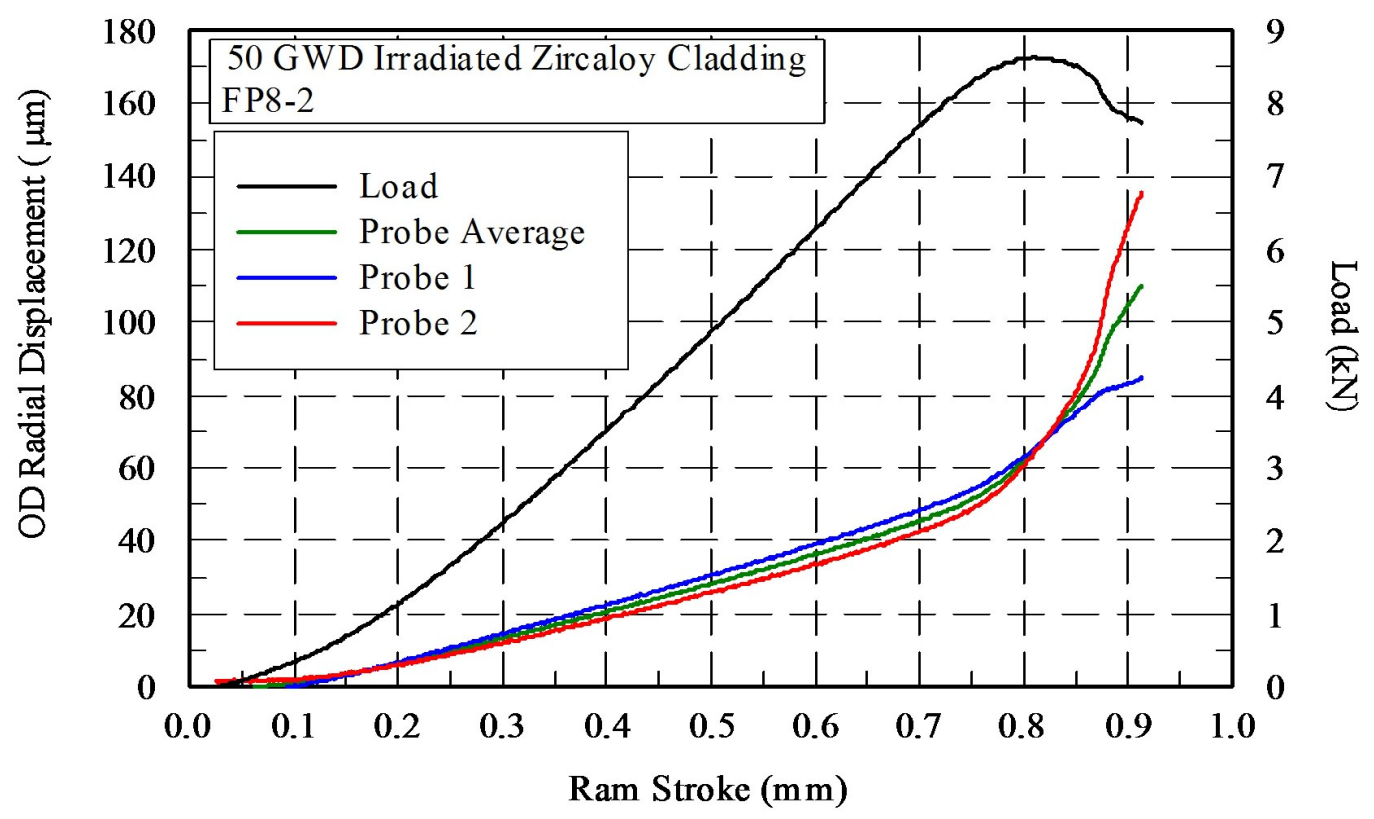

Fig. 31. Load and displacement plots for non-TIGR, 50-GWd/MT fuel burnup cladding specimen FP8-2. 


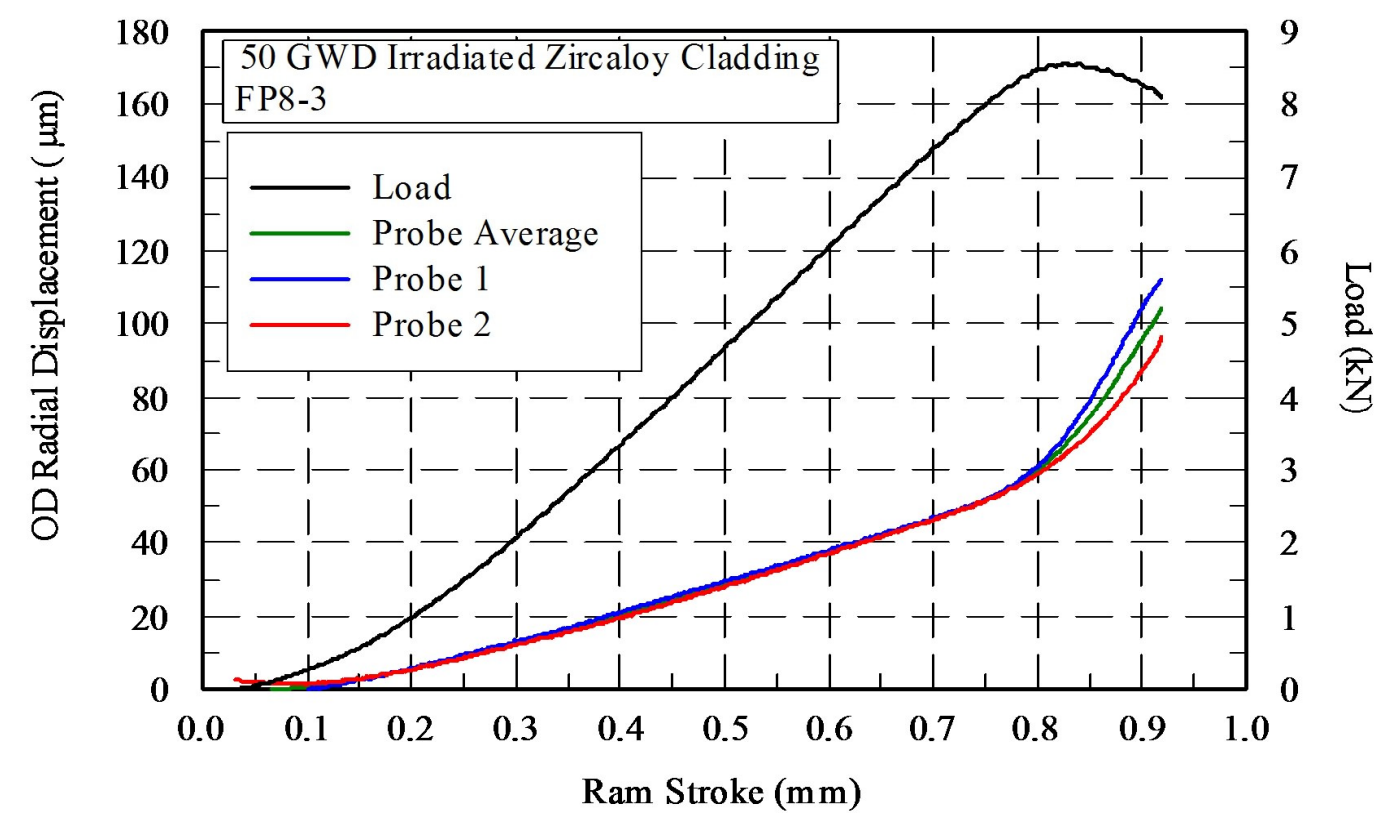

Fig. 32. Load and displacement plots for non-TIGR, 50-GWd/ MT fuel burnup cladding specimen FP8-3.

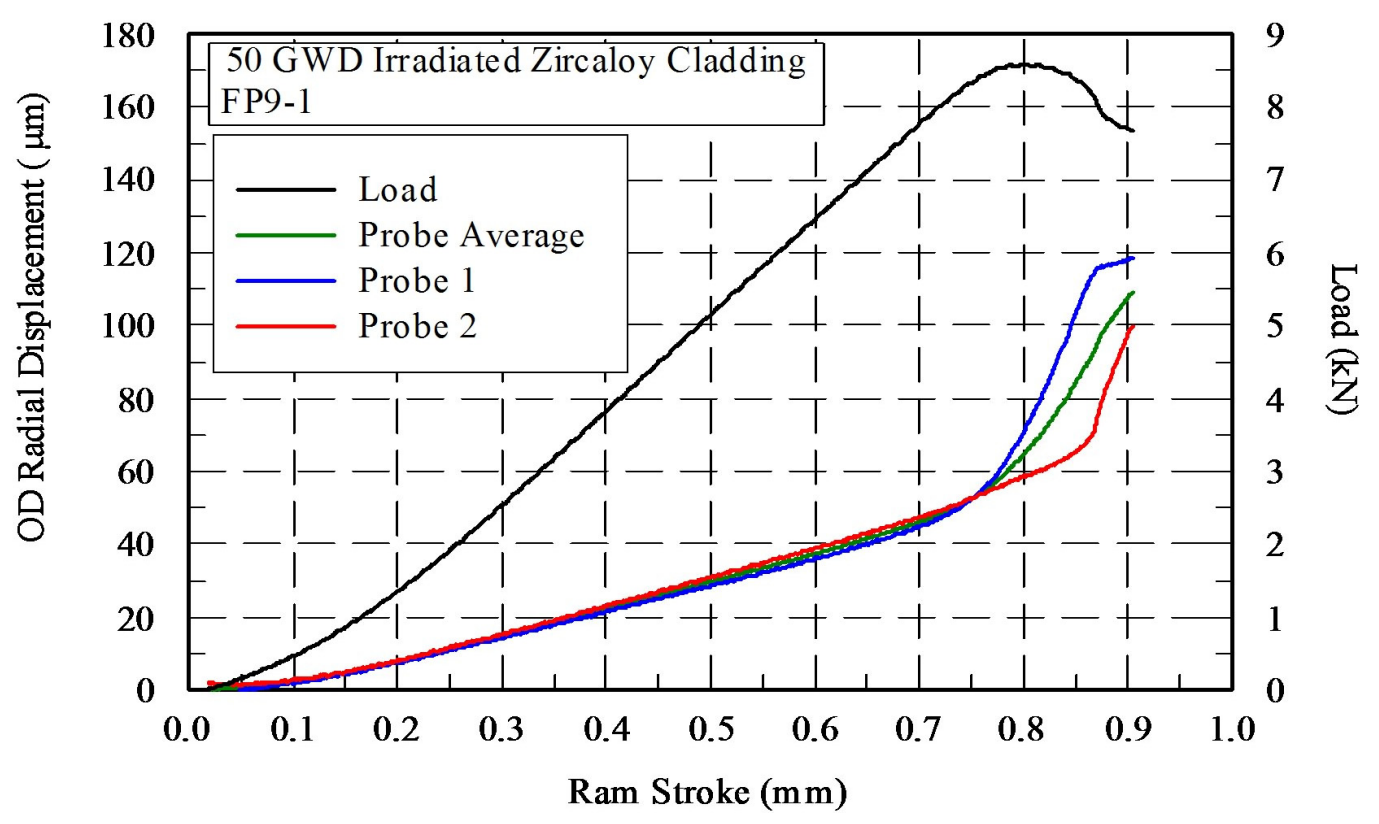

Fig. 33. Load and displacement plots for non-TIGR, 50-GWd/MT fuel burnup cladding specimen FP9-1. 


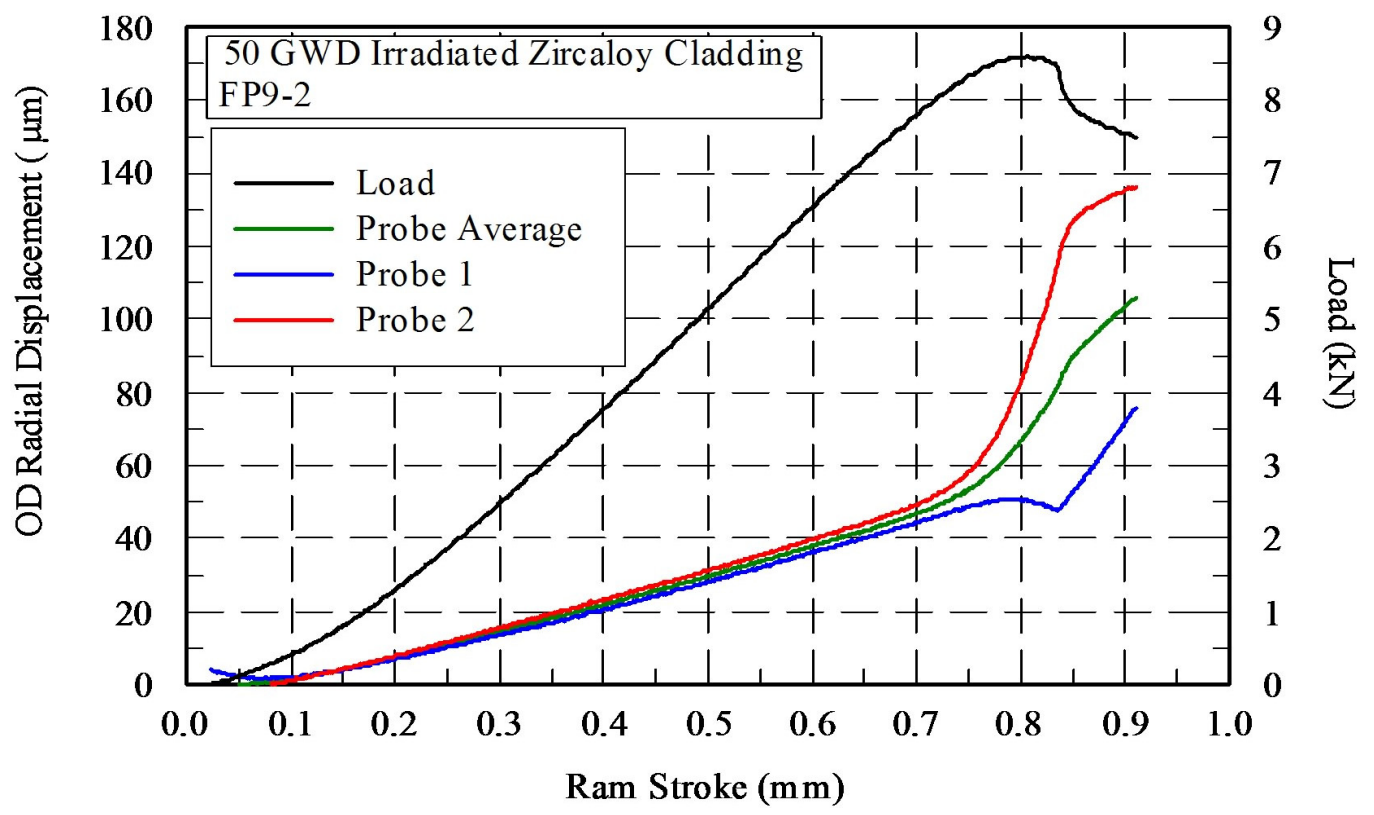

Fig. 34. Load and displacement plots for non-TIGR, 50-GWd/MT fuel burnup cladding specimen FP9-2.

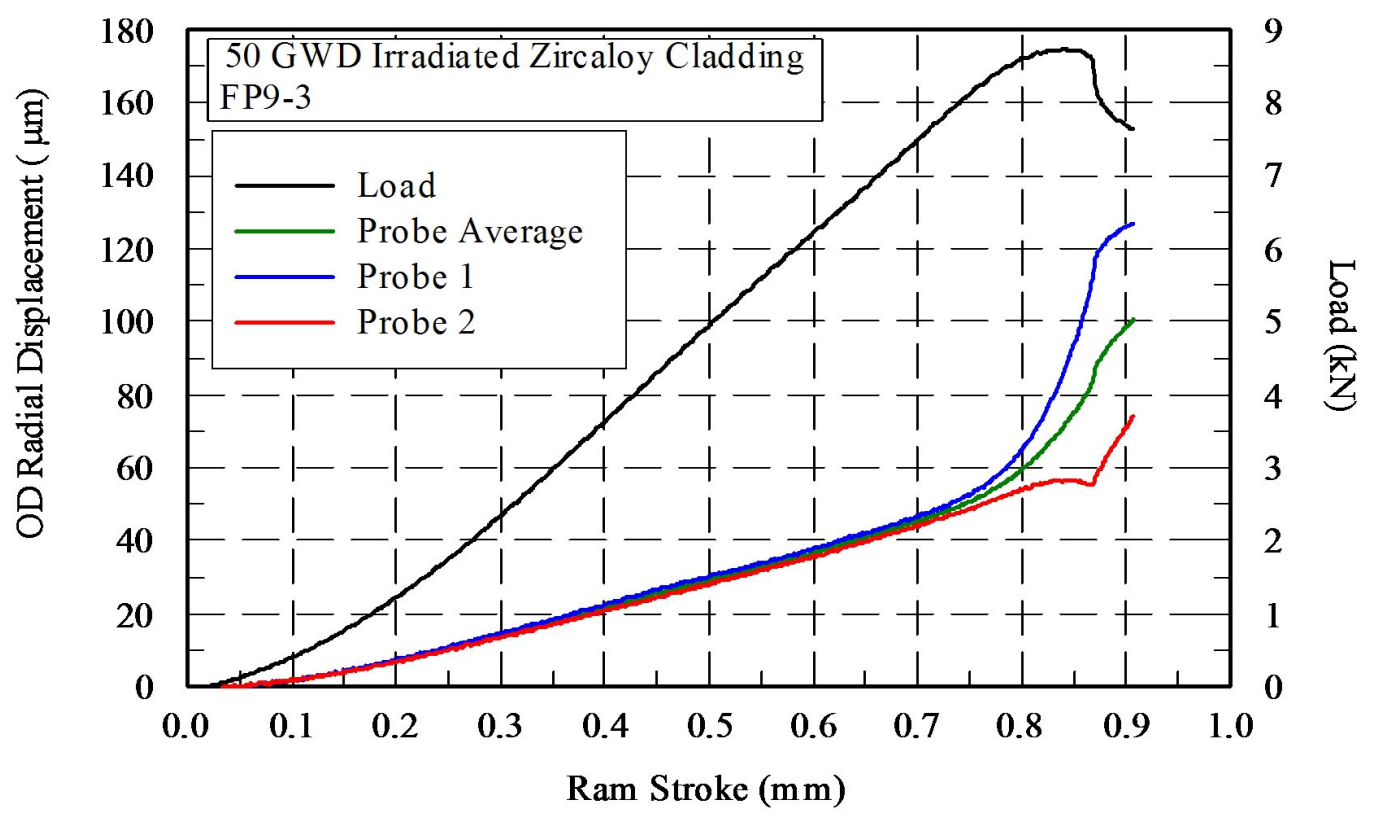

Fig. 35. Load and displacement plots for non-TIGR, 50-GWd/MT fuel burnup cladding specimen FP9-3. 


\section{ANALYSIS AND DISCUSSION}

\subsection{ESTIMATES OF STRESS AND STRAIN}

Data generated from ductility testing can be used to characterize the deformation behavior of irradiated fuel cladding. Because the radial displacement of the specimen OD is measured, the circumferential or hoop strain at the OD can be estimated from Eq. (5.1).

$$
\varepsilon_{\theta \theta}=\frac{u}{b}
$$

Here, $\varepsilon_{\theta \theta}$ is hoop strain, $u$ is radial displacement, and $b$ is the initial radius of the specimen OD. An average hoop strain from the two probe measurements will be used unless noted otherwise. It is understood that under ideal circumstances, the two probe measurements would yield identical measurements. However, imperfections in plug and/or specimen geometry could be a source for nonuniform deformation and deviations in probe measurement. Additionally, any radial displacement of the cylindrical axis due to imperfections would impose a rigid body motion on the sample that could effect probe measurements. These issues will be addressed as they appear in the following sections.

There are several methods for estimating stress from the measured forces. Assuming an ideal uniform pressurization of the specimen ID, closed-form analytical solutions for radial and hoop components of stress exist. The simplest solution applies a thin-walled cylinder assumption which states that the cylinder wall is thin such that any radial stress gradients are small enough to be considered negligible. The equation describing hoop stress for a thin-walled cylinder is given in Eq. (5.2).

$$
\sigma_{\theta \theta}=\frac{p \bar{r}}{t}
$$

Here, $p$ is the pressure, $\bar{r}$ is the radius at the midpoint of the wall thickness, and $t$ is the cylinder wall thickness. A more advanced solution recognizes that a radial stress gradient exists across the wall and is referred to as the thick-walled cylinder solution. ${ }^{14}$ The hoop and radial stresses are dependent upon the radial position as well as geometry and internal pressure. Descriptions of these relationships are provided in Eqs. (5.3) and (5.4).

$$
\begin{gathered}
\sigma(r)_{\theta \theta}=p \frac{a^{2}\left(r^{2}+b^{2}\right)}{r^{2}\left(b^{2}-a^{2}\right)} . \\
\sigma(r)_{r r}=p \frac{a^{2}\left(r^{2}-b^{2}\right)}{r^{2}\left(b^{2}-a^{2}\right)} .
\end{gathered}
$$

The radius of the ID and OD are $a$ and $b$, respectively, and the pressure, $p$, is the difference in measured load and plug-only load divided by the ram cross section. A third, semiempirical method for estimating stress was developed as part of this project. ${ }^{11}$ The method employs some input with respect to specimen geometry but basically scales the load data to reflect a stress value. A scaling parameter, $\Gamma$, is developed by performing a comparison of a tensile hoop test to a standard uniaxial tensile test using a reference material. The parameter value is set to scale the load data from the 
tensile hoop test to match the uniaxial tensile test data at $0.2 \%$ plastic (offset) strain. The relationship is shown in Eq. (5.5).

$$
\sigma_{\theta \theta}=\Gamma \frac{l o a d}{t l}
$$

Here, load is the measured force, and $l$ is the specimen length. For the following comparisons, a value of 0.53 will be used for $\Gamma$. Applying data for an unirradiated Zircaloy-4 specimen, the resulting stress-strain curves are shown in Fig. 36.

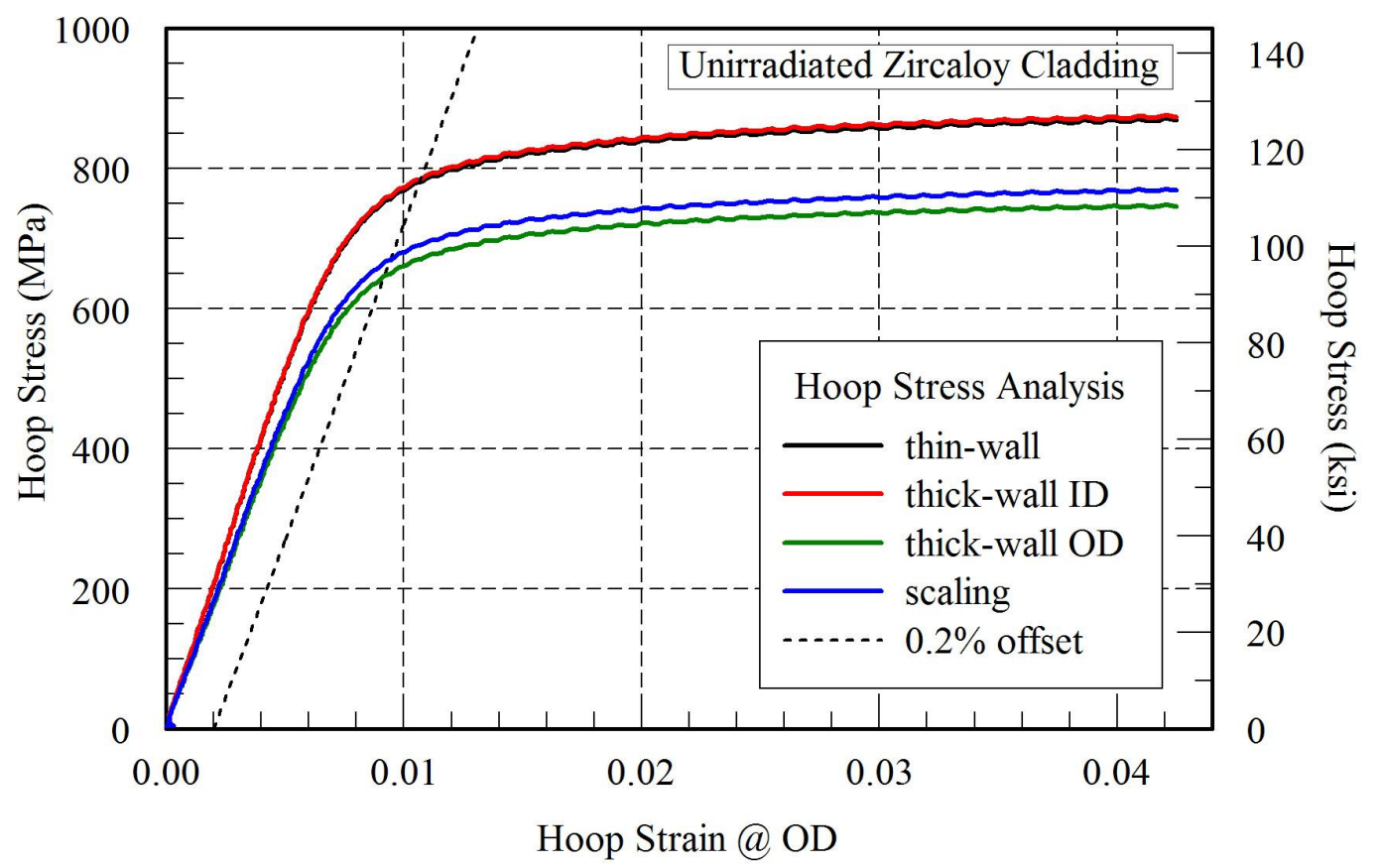

Fig. 36. Hoop stress-strain curves calculated using thin-walled pressurized cylinder, thick-walled pressurized cylinder, and uniaxial tensile test scaling method.

It is important to note that the thin-walled and thick-walled pressurized cylinder analyses are only valid for the fully elastic case. The thick-wall solution shows a $15 \%$ decrease in hoop stress from the ID to the OD and suggests that radial stress gradients should not be neglected. The thin-wall solution is similar to the thick-wall solution at the ID, and it is likely that the stress does not reach the levels calculated for these solutions because of plastic deformation at the ID. The scaling result is within the bounds set by the thick-wall solution and is close to the stress at the OD. This could be explained by the fact that the strain is measured at the OD, and this is the last portion of the cylinder to plastically yield during internal pressurization. Given that the scaling results are reasonable compared to analytical solutions, this method will be applied for any subsequent estimates of stress.

The dashed line in Fig. 36 is a plot of $0.2 \%$ strain offset, and the intersection of this plot with stress has been used for estimating yield strength in previous reports. ${ }^{3,11}$ For the unirradiated Zircaloy-4 data plotted in Fig. 36, the yield strength is $670 \mathrm{MPa}$. This result is larger than the 570-MPa yield strength reported for the as-received material in the annealed condition and is greater than most values reported in the literature for unirradiated Zircaloy-4. ${ }^{5-8,15-17}$ However, it is worth noting that in a study using burst tests, Yagnik et al. ${ }^{18}$ reported hoop strength similar to those measured here for room temperature tests of unirradiated Zircaloy-4. A more detailed analysis of cladding deformation will be addressed in future efforts. 


\subsection{EFFECT OF TIGR TREATMENT}

The effect of the TIGR treatment on irradiated cladding ductility can be assessed using 9-, 21-, 30-, and 40-GWd/MT data. Plots showing these comparisons are presented in Figs. 37-40. The figures plot load vs percent hoop strain using the average of radial displacement measurements.

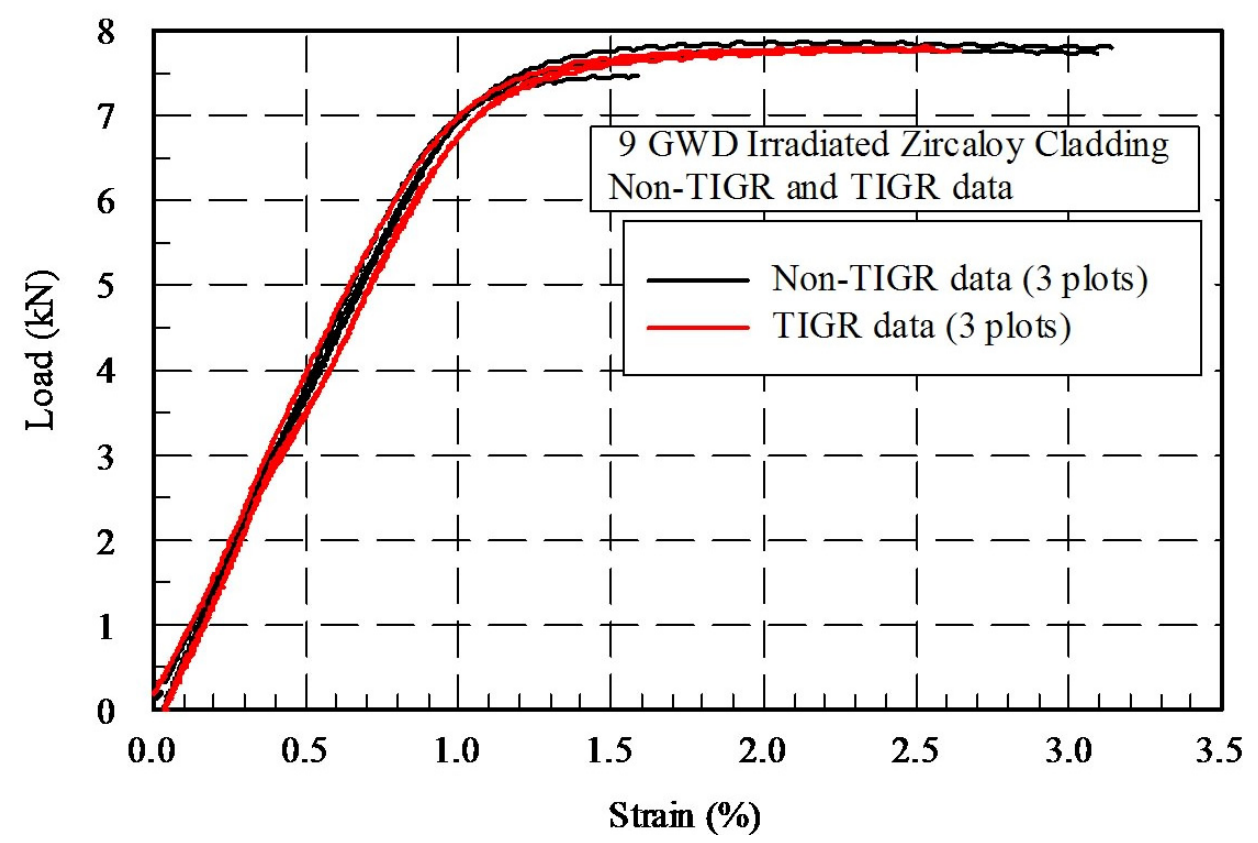

Fig. 37. Load vs OD hoop strain for TIGR-treated (red) and nontreated (black) 9-GWd/MT irradiated Zircaloy cladding.

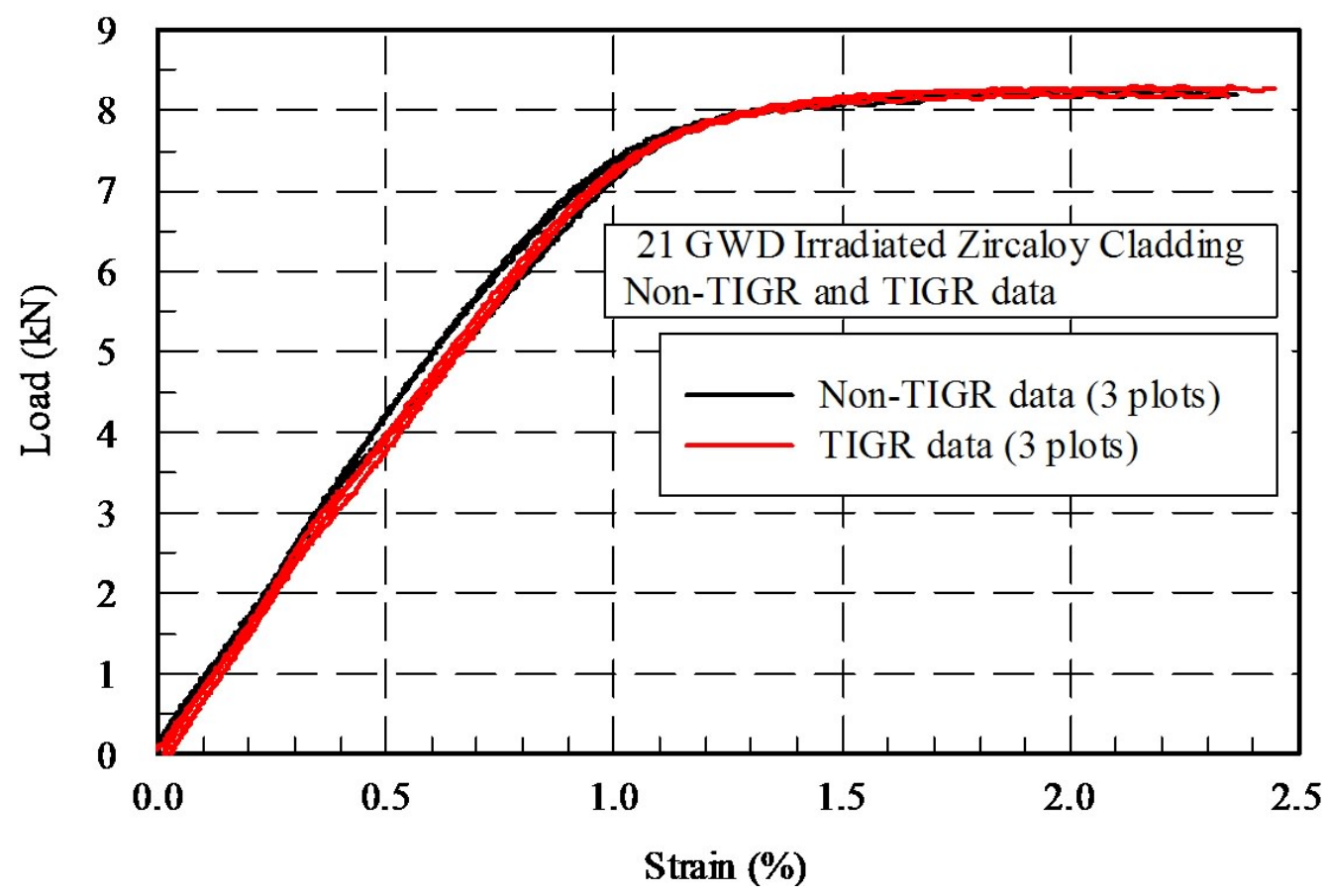

Fig. 38. Load vs OD hoop strain for TIGR-treated (red) and nontreated (black) 21-GWd/MT irradiated Zircaloy cladding. 


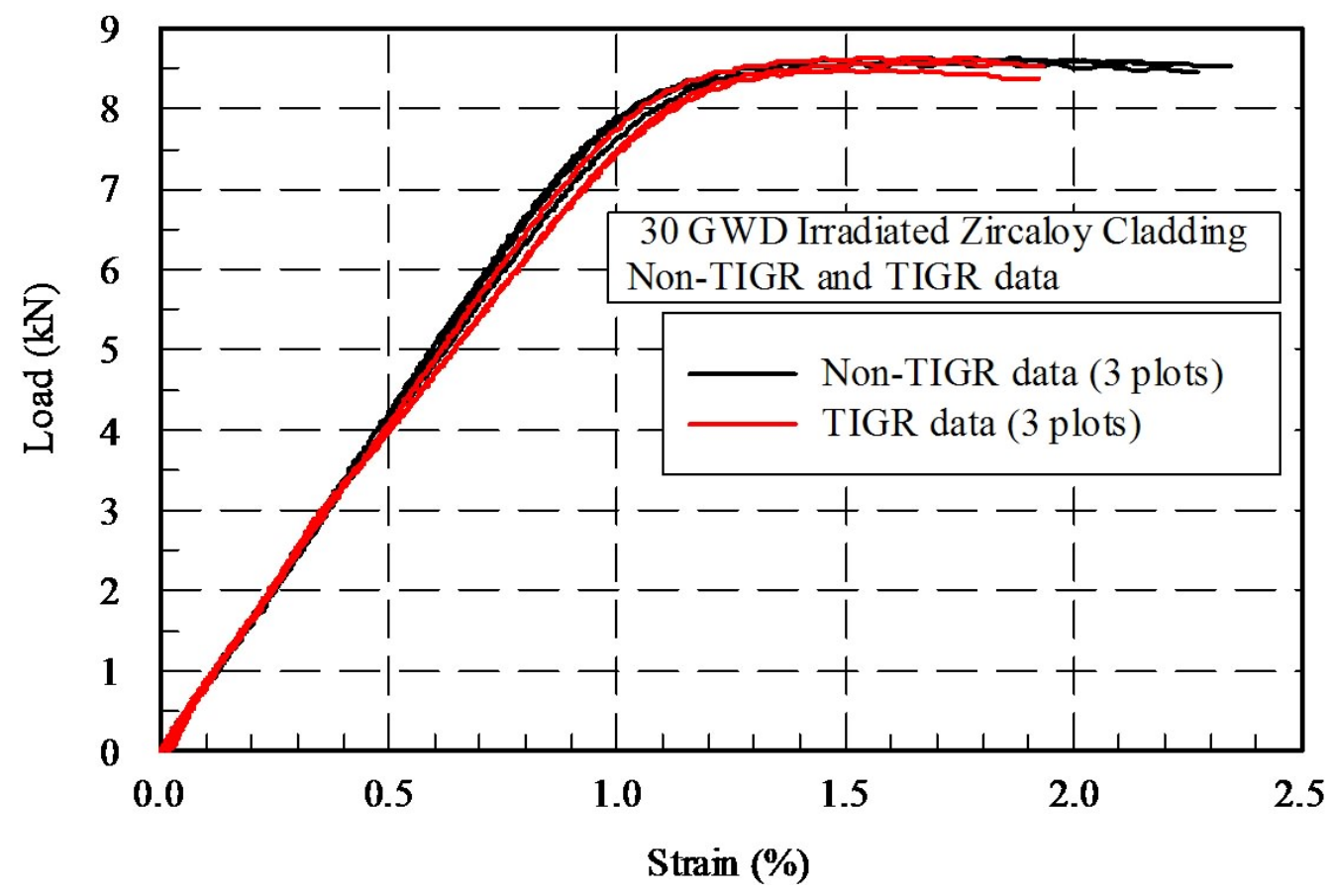

Fig. 39. Load vs OD hoop strain for TIGR-treated (red) and nontreated (black) 30-GWd/MT irradiated Zircaloy cladding.

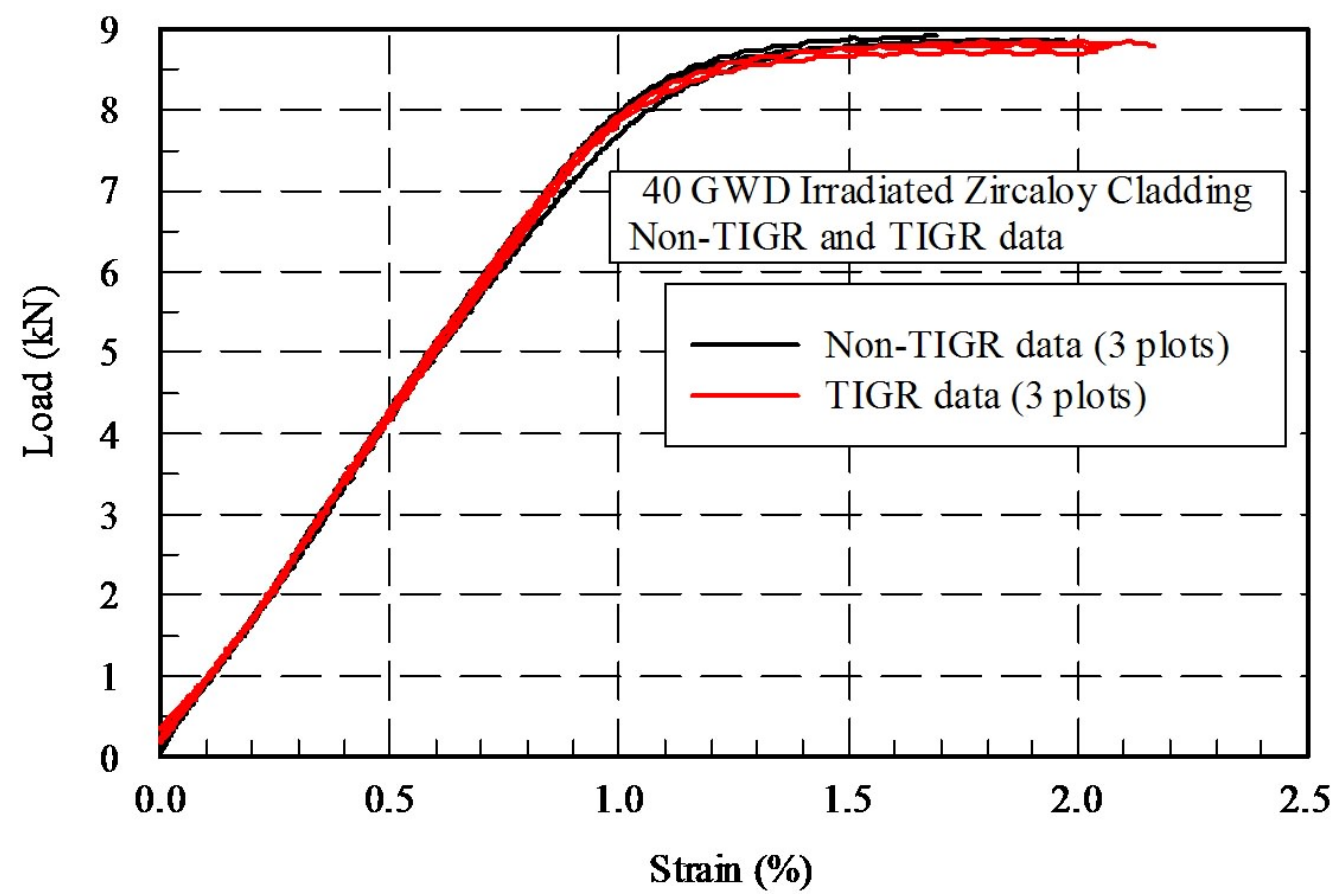

Fig. 40. Load vs OD hoop strain for TIGR-treated (red) and nontreated (black) 40-GWd/MT irradiated Zircaloy cladding. 
Each figure displays six data plots that indicate consistent behavior between TIGR-treated and non-TIGR cladding. In general, the figures show good repeatability for constant conditions, and any differences between TIGR and non-TIGR data fall within experimental variability.

\subsection{EFFECT OF IRRADIATION}

Ductility test results for cladding irradiated to different fuel burnup levels are presented in this section. Figure 41 shows a representative data set for each irradiation level, including a test for unirradiated Zircaloy-4 cladding. Because the results for each irradiation level displayed good repeatability, it was deemed reasonable to use a single representative data set for comparison purposes. Figure 41 plots load vs percent hoop strain. The data plots clearly show hardening due to increasing irradiation treatments. The unirradiated Zircaloy- 4 is the softest material by a significant margin. A large increase in strength is observed for the 9-GWd/MT cladding with the trend continuing in lesser increments and increasing irradiation. Irradiation hardening appears to saturate at approximately 40-GWd/MT burnup or $2.8 \mathrm{dpa}$. At the largest irradiation dose, the material does not experience additional irradiation hardening but shows a significant load drop during plastic deformation. This behavior was consistent for all 50-GWd/MT tests and suggests that plastic instability has occurred.

The plot in Fig. 41 also indicates that the elastic properties of Zircaloy-4 cladding are not a function of irradiation. The initial linear portions of the load-strain plots are noticeably consistent and suggests that the elastic modulus has not been affected by irradiation.

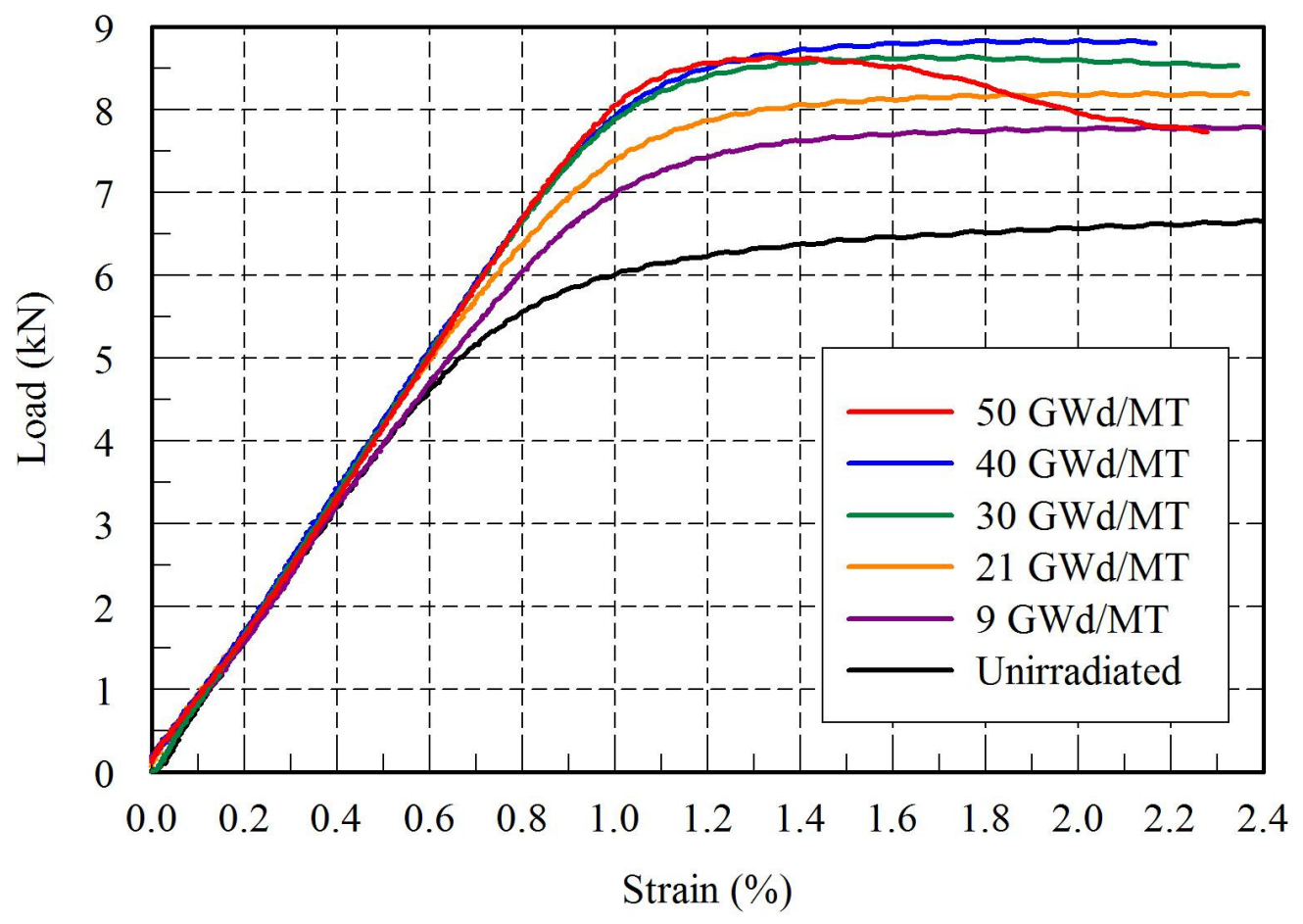

Fig. 41. Load vs percent hoop strain for Zircaloy-4 cladding irradiated to levels represented by fuel burnup.

Estimates for $0.2 \%$ offset hoop yield strength were made using the scaling parameter method described in Sect. 5.1. and are plotted in Fig. 42. The figure plots yield strength as a function of irradiation characterized as neutron fluence. The unirradiated data point is the average of three tests, and remaining data points each represent an average of six tests, including TIGR and non-TIGR 


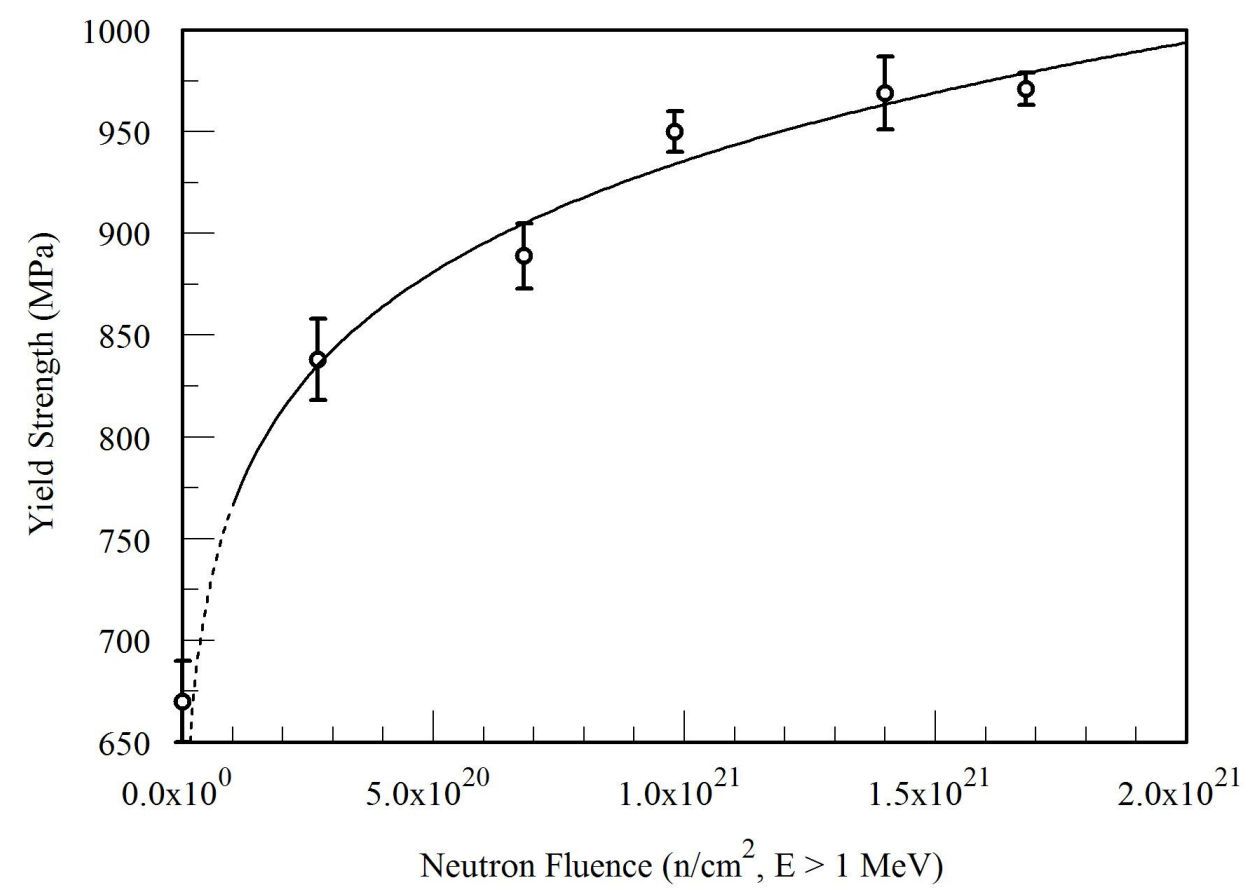

Fig. 42. 0.2\% offset yield strength as a function of neutron fluence for Zircaloy-4 fuel cladding. Error bars are a $95 \%$ confidence limit, and the line is a power law fit of the data.

specimens. Error bars in the plot are a 95\% confidence limit based on the scatter in the tests for each condition. The solid line in the figure is a power law fit of the data. This relationship is shown in Eq. (5.6).

$$
\sigma_{Y S}=K \Phi^{n}
$$

Here, $\sigma_{Y S}$ is the $0.2 \%$ offset yield strength in $\mathrm{MPa}, \Phi$ is neutron fluence in neutrons $/ \mathrm{cm}^{2}, K$ is the proportionality constant, and $n$ is the power law exponent. The results of the fit along with goodnessof-fit statistics are shown in Table 3. Although the fit provides a reasonably good estimate of the data, any application of the relationship should be confined to the approximate ranges of neutron fluence represented in the data.

Table 3. Parameters and goodness-of-fit values for power law description [Eq. (5.6)] of yield strength as a function of neutron fluence

\begin{tabular}{|c|c|c|}
\hline $\boldsymbol{K}$, proportionality constant & $\boldsymbol{n}$, exponent & $\mathbf{R}^{\mathbf{2}}$, goodness-of-fit \\
\hline 14.097 & 0.08676 & 0.955 \\
\hline
\end{tabular}

\subsection{PLASTIC INSTABILITY}

Initially, ductility tests were run to a preset ram displacement such that fracture of the specimen did not occur. Subsequently, a limited number of tests were performed in which the specimen was deformed till fracture. The objective of these experiments was to evaluate the deformation and fracture behavior of the cladding. These experiments were motivated, partially, by the unique deformation observed in the 50-GWd/MT measurements shown in Figs. 30-35. Radial displacement 
measurements for $50 \mathrm{GWd} / \mathrm{MT}$ showed a significant deviation between individual probe measurements during plastic deformation.

Figure 43 plots the load and probe displacement data for a fractured 50-GWd/MT burnup specimen. The specimen displayed the deviation in probe measurements and load drop consistent with other tests of this material.

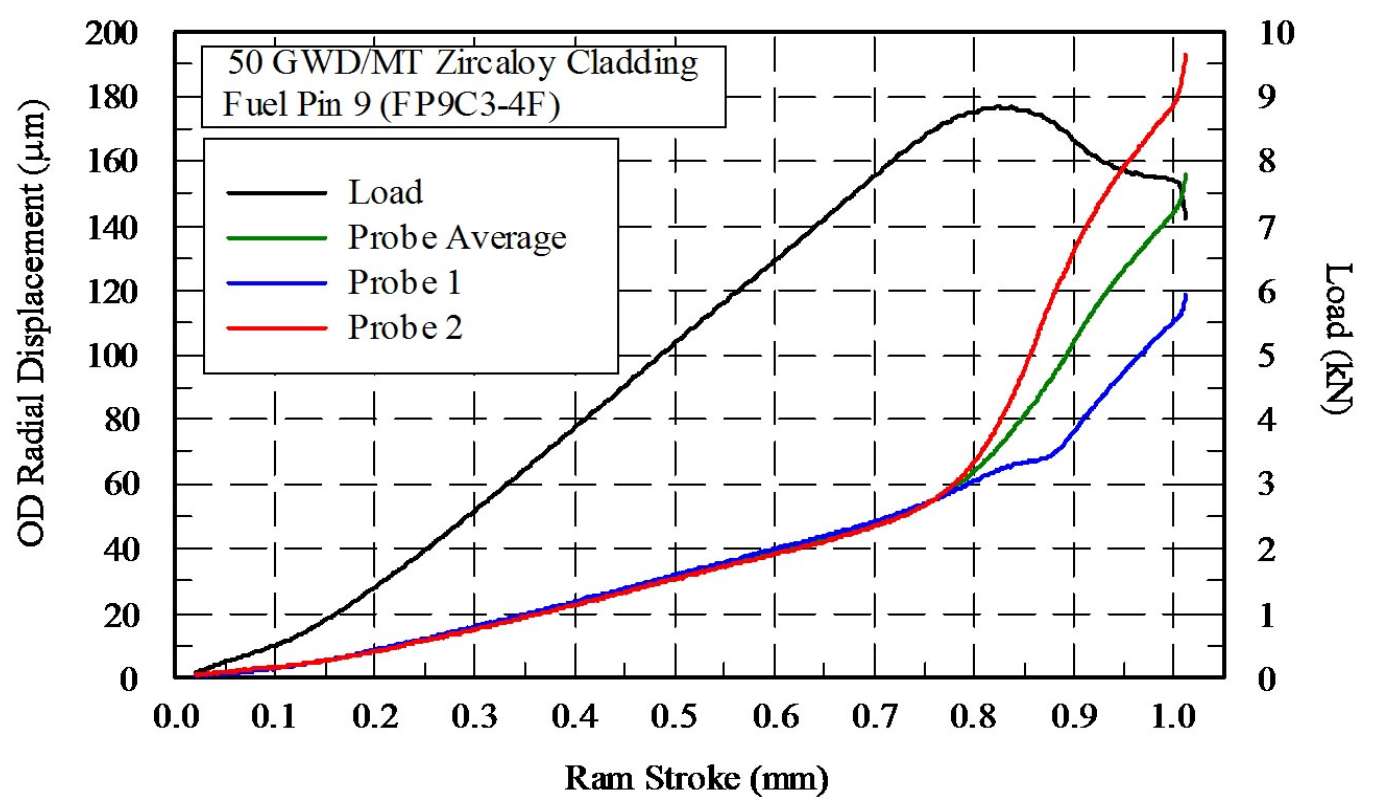

Fig. 43. Load and displacement plots for non-TIGR, 50-GWd/MT fuel burnup cladding specimen FP9-3. The specimen was strained to fracture.

The load drop and nonuniform displacements suggests that plastic instability has occurred. The manifestation of these measurements on the load-strain behavior is evident in Fig. 44. The figure plots load as a function of strain measured by each probe and the average strain. It is clear that different amounts of strain are measured by each probe. One probe recorded a fracture strain of $4 \%$, while the other measured approximately $2.5 \%$. These deviations begin at about $1.4 \%$ strain when the load drop for probe 1 occurs. However, because of the large displacements measured by probe 2, the same load drop does not occur until after $2 \%$ strain and the rate of decrease with respect to strain is much less.

A scanning electron microscope (SEM) photograph of the fractured 50-GWd/MT burnup specimen is shown in Fig. 45. Two features are readily observed in the figure. One is the fracture surface which extends the length of the specimen. The other feature, labeled "shear band", is indicated by the white arrows and locates a region of localized deformation in the form of a shear band. This observation reinforces the measured data suggesting that plastic instability has occurred. The occurrence of instability with the onset of plastic deformation has also been reported by Byun et al. ${ }^{7}$ In that work, tensile tests of irradiated Zircaloy-4 revealed an immediate stress drop associated with the onset of plastic deformation. This behavior was observed in material irradiated to $0.1 \mathrm{dpa}$ and greater with the stress drop increasing with increased irradiation. The 3.4-dpa irradiation represented in the 50-GWd/MT burnup cladding is significantly greater than the 0.1 dpa required for load drop in a uniaxial tensile test. 


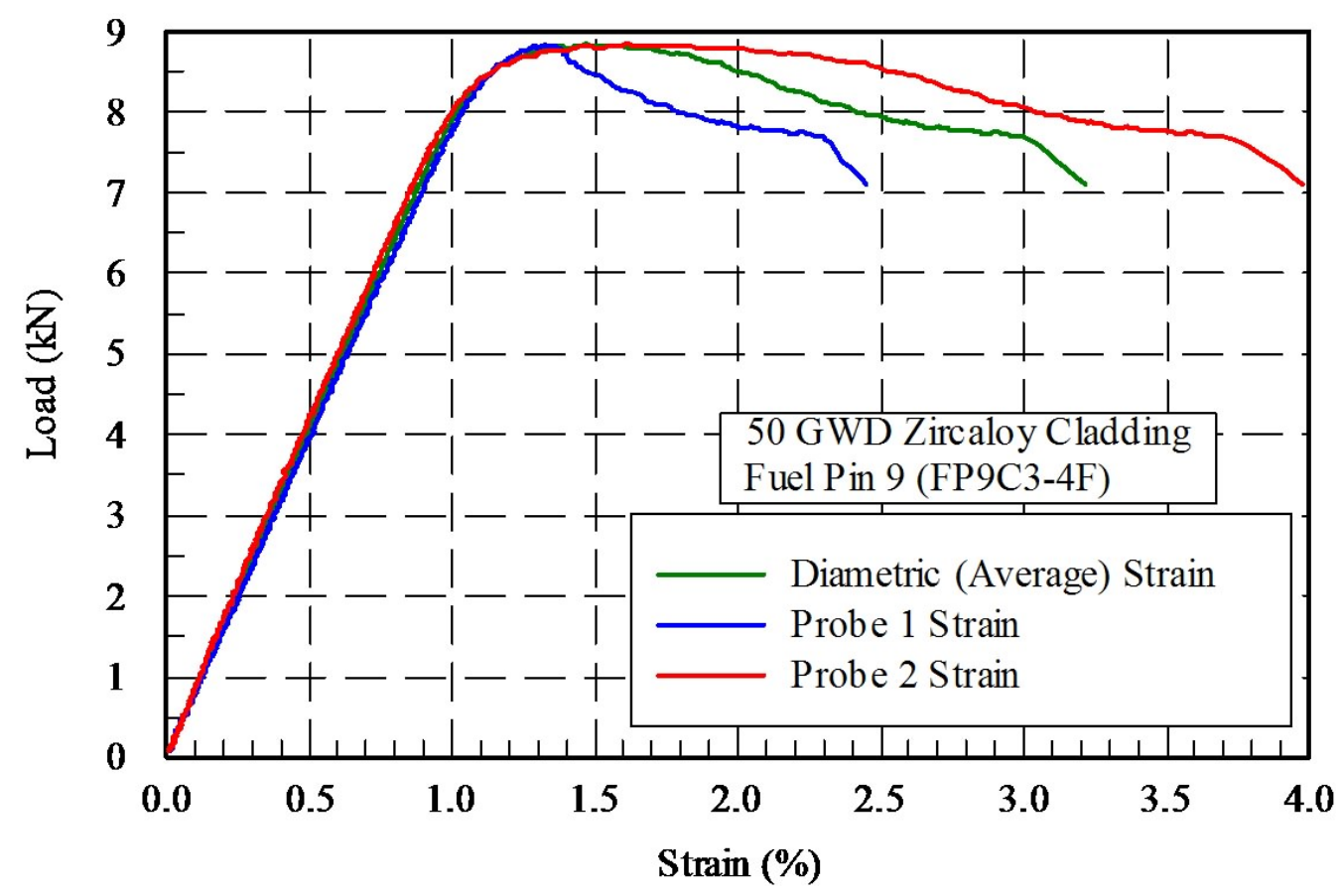

Fig. 44. Load vs OD hoop strain for 50-GWd/MT burnup specimen deformed to fracture. Strain data from probe 1 (blue), probe 2 (red), and the average (green) are plotted.

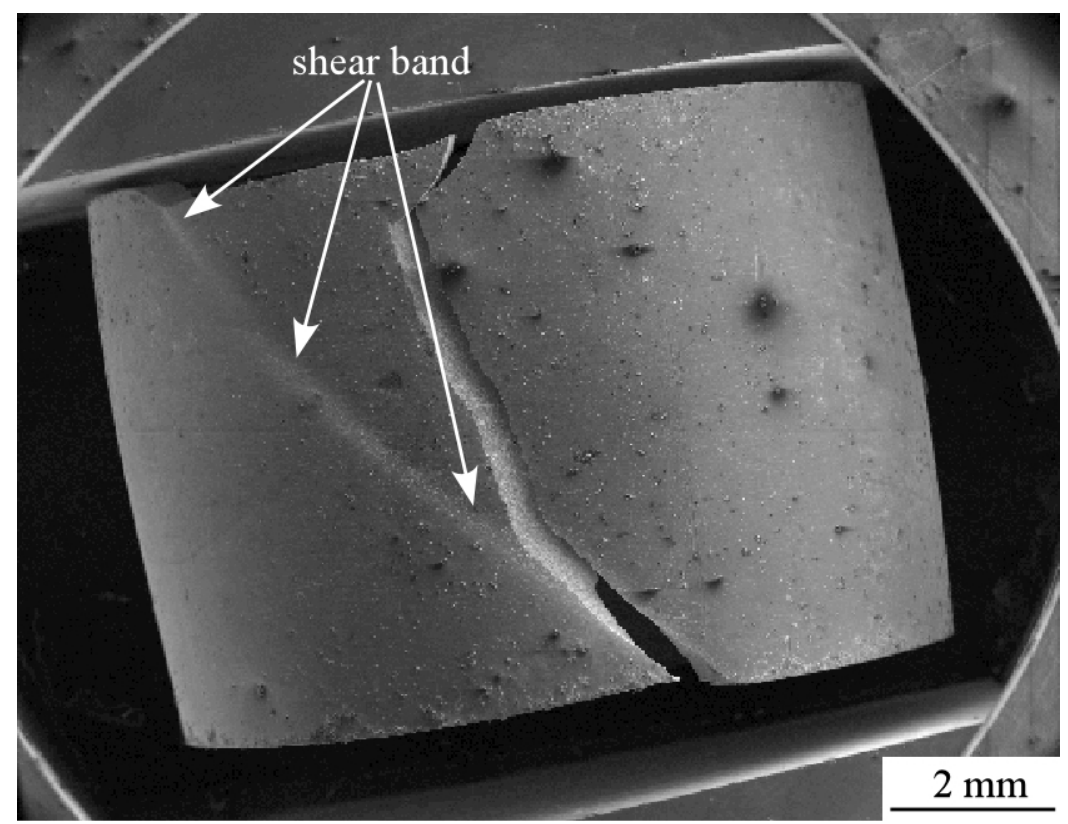

Fig. 45. SEM photograph showing fractured Zircaloy-4 cladding irradiated to 50-GWd/MT burnup. The arrows identify flow localization in the form of a "shear band."

Shear banding was observed in fractured 30-GWd/MT specimens. Figure 46 is an SEM photograph of a fractured Zircaloy-4 cladding specimen irradiated to $30 \mathrm{GWd} / \mathrm{MT}$. Note that multiple shear bands at different levels of development are observed in the photo. The shear band associated 


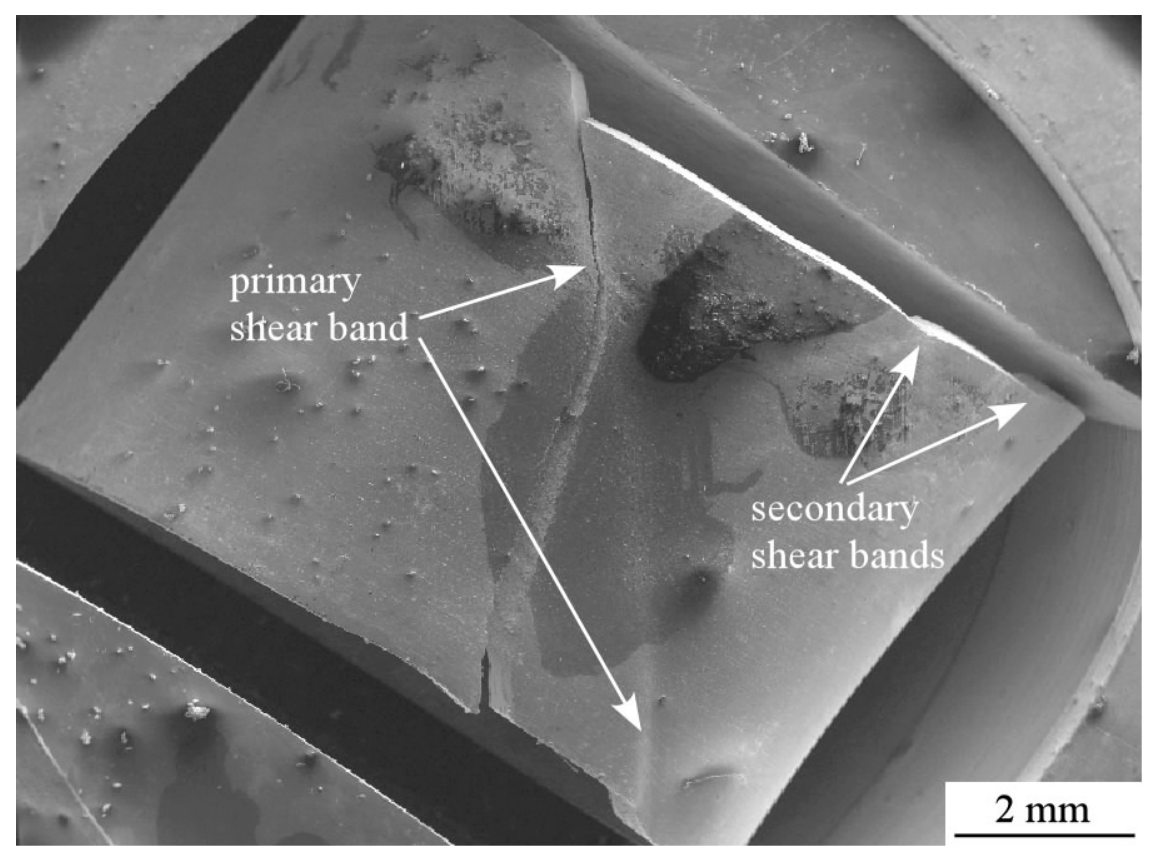

Fig. 46. SEM photograph showing fractured Zircaloy-4 cladding irradiated to 30-GWd/MT burnup. The arrows identify flow localization in the form of a "shear band."

with the fracture of the specimen traverses the length, displays well-defined slip-surfaces at each end and is identified as the primary shear band. However, evidence of additional shear bands is observed at the end of the specimen and labeled secondary shear bands. These do not traverse the specimen and are mostly revealed by the offset at the end of the specimen.

Evidence of shear banding has been observed in specimens irradiated to burnup as low as 21 $\mathrm{GWd} / \mathrm{MT}$ and is displayed in Fig. 47. The figure is an optical photograph of a 21-GWd/MT burnup specimen. The arrow in the figure identifies a shear band in the deformed specimen.

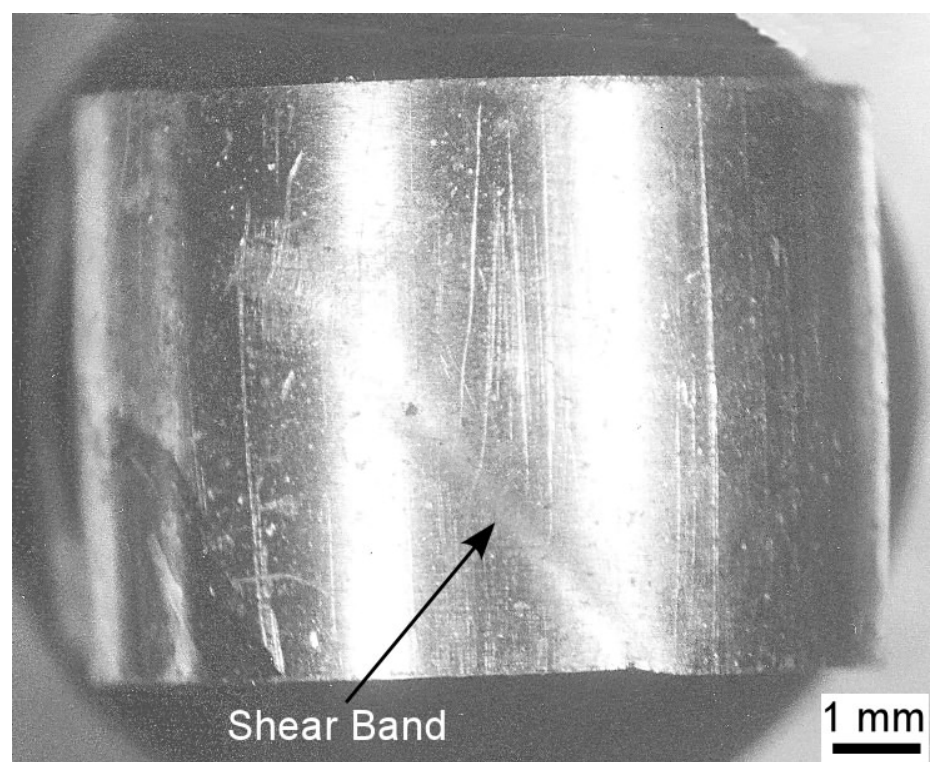

Fig. 47. Optical photograph showing a shear band in deformed Zircaloy-4 cladding irradiated to 21-GWd/MT burnup. 
Plastic instability in the form of shear bands has been observed in cladding specimens irradiated to 21-GWd/MT fuel burnup and higher. Evidence of multiple shear bands in a single specimen has been observed in a specimen irradiated to $30-\mathrm{GWd}$ /MT fuel burnup. Typically, a load drop is associated with the onset of plastic instability. ${ }^{19}$ However, for these tests, a significant load drop is only observed in cladding irradiated to 50-GWd/MT fuel burnup.

\subsection{FRACTURE}

The primary motive for fracturing specimens was to examine the fracture surface and characterize the fracture behavior. The following SEM images provide a visual record of the fracture surfaces found in Zircaloy-4 cladding irradiated to 21- and 50-GWd/MT fuel burnup.

Figure 48 is a collection of SEM micrographs showing the fracture surface of a cladding specimen irradiated to $21-\mathrm{GWd} / \mathrm{MT}$ fuel burnup. The figure is composed of photos at three different magnifications to depict the location of the fracture surface shown in the high-magnification photo.

The fracture surface is oriented at approximately a $45^{\circ}$ angle to the loading direction and is positioned within a shear band. The angled fracture surface is consistent with previously reported results for room temperature testing of irradiated Zircaloy. ${ }^{6}$ The high-magnification image (upper left of Fig. 46) reveals a dimpled fracture surface typical of ductile fracture. ${ }^{6,20}$

Figures 49 and 50 display series of SEM micrographs showing two fracture surfaces from a Zircaloy-4 specimen irradiated to 50-GWd/MT fuel burnup. Unlike the fracture from the 21-GWd/MT burnup specimen shown in Fig. 48, this fracture is partially located within the shear band and partially located outside the shear band with the surface aligned predominantly normal to the circumferential loading direction. The high-magnification micrograph in Fig. 49 shows the fracture surface located within the shear band. This micrograph shows the dimpled fracture surface morphology associated with ductile fracture and similar to that observed in the $21-\mathrm{GWd} / \mathrm{MT}$ fuel burnup specimen.

A fracture surface from the same specimen shown in Fig. 49 is presented in Fig. 50 except the fracture surface is located in a region external to the deformation shear band. The figure shows micrographs taken at varying magnifications to illustrate the location of the fracture surface with respect to the shear band. An examination of the fracture surface shown in the high-magnification micrograph is characterized by a dimpled morphology. This is consistent with results shown for fractures in cladding irradiated to $21-\mathrm{GWd} / \mathrm{MT}$ burnup and independent of location with respect to shear banding. Because the 50-GWd/MT tensile hoop test data indicated that the specimen experienced plastic instability immediately upon yielding, it is noted that the dimpled fracture surface external to the shear band did not experience plastic deformation. This suggests that the dimpled fracture surface may be a product of the irradiation damage and not necessarily the result of ductile plastic deformation. 


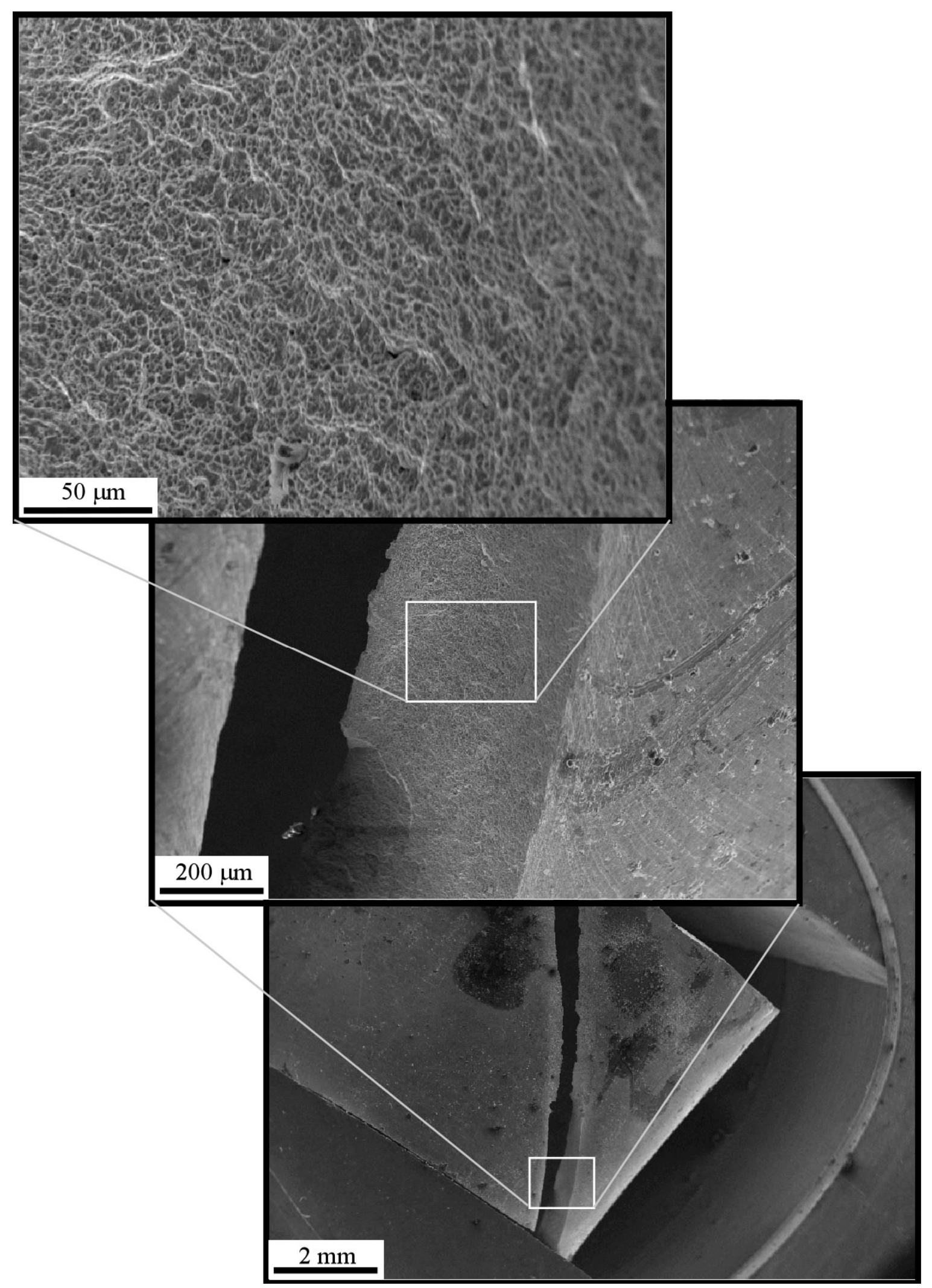

Fig. 48. SEM micrographs showing the fracture surface of Zircaloy-4 cladding irradiated to 21-GWd/MT fuel burnup. 


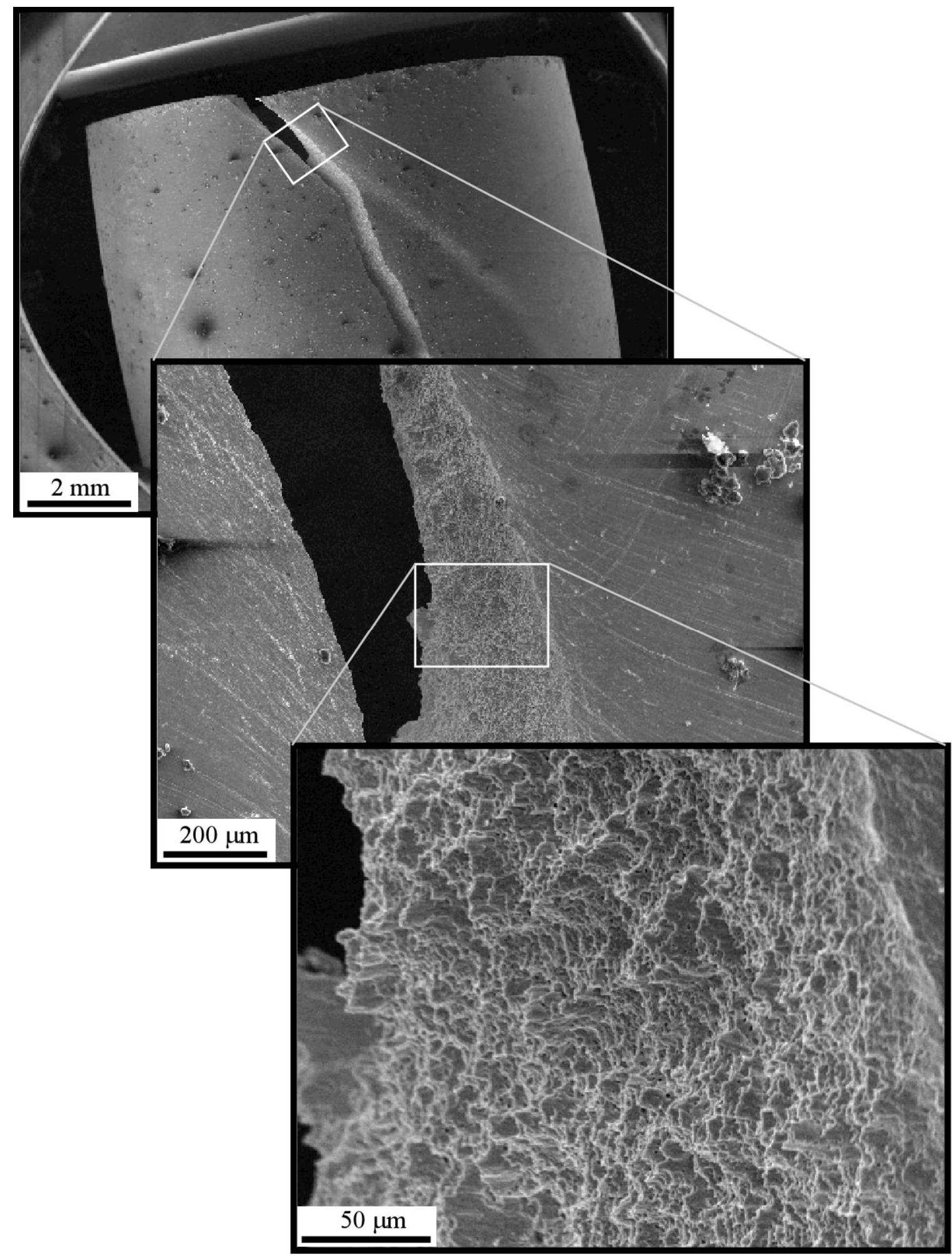

Fig. 49. SEM micrographs showing the fracture surface of Zircaloy-4 cladding irradiated to 50-GWd/MT fuel burnup. High-magnification micrograph show fracture surface within deformation shear band. 


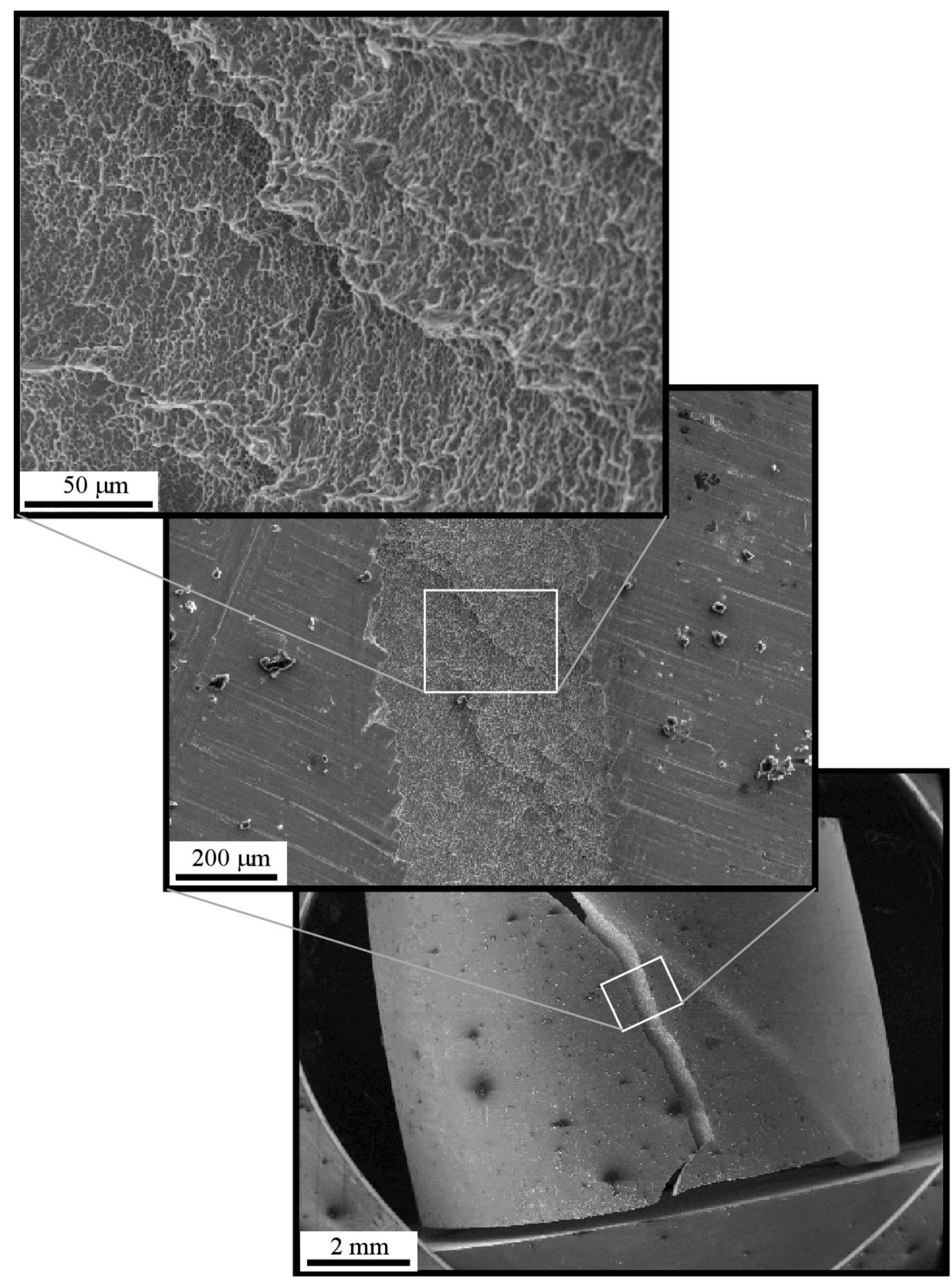

Fig. 50. SEM micrographs showing the fracture surface of Zircaloy-4 cladding irradiated to 50-GWd/MT fuel burnup. High-magnification micrograph shows fracture surface outside of deformation shear band. 



\section{SUMMARY AND CONCLUSIONS}

Tensile hoop strength and ductility testing of irradiated and unirradiated Zircaloy-4 fuel cladding was performed. Specimens consisted of sections of Zircaloy-4 fuel cladding irradiated to various burnup levels as well as unirradiated Zircaloy- 4 specimens. Fuel rod assemblies were constructed with MOX fuel pellets fabricated from weapons-grade plutonium via two processing routes. One route applied a conventional pellet fabrication path; the other included an additional thermal-induced gallium removal step. Although subsequent chemical analysis revealed that the gallium content was very low for both processing methods, an objective of this project was to determine if the gallium had any deleterious effects on cladding performance. Fuel rod assemblies were irradiated to five levels of neutron fluence. The cladding in these assemblies provided specimen material for measurements of cladding performance as a function of the evolving material state associated with neutron irradiation.

In order to assess cladding properties, a novel expanding plug tensile hoop test was developed and applied to determine tensile hoop performance. The test uses a cylindrical polyurethane plug sized to closely fit within the cladding inner diameter. Axial compression of the plug creates a radial displacement that acts upon the cladding ID and produces a predominantly tensile hoop stress. The force required to compress the plug and the radial displacement of the cladding OD are measured and recorded. These tests proved to be a valid method for evaluating the tensile hoop strength of cladding material. Tensile hoop strength results were supplemented with SEM for characterizing fracture surfaces and deformation behavior. From the results generated in this project, the following conclusions were drawn.

1. The tensile hoop properties of irradiated cladding are independent of pellet gallium removal processing. Tests performed on cladding associated with MOX pellets produced with an additional thermal-induced gallium removal step displayed negligible difference to cladding that housed MOX pellets fabricated without the extra gallium removal step.

2. A significant degree of irradiation hardening was observed in tensile hoop test results. Stress estimates indicate that tensile hoop yield strength increased from $670 \mathrm{MPa}$ for the unirradiated material to $\sim 830 \mathrm{MPa}$ for the lowest neutron fluence of $2.7 \times 10^{20}$ neutrons $/ \mathrm{cm}^{2}$ up to $950 \mathrm{MPa}$ for the highest irradiation levels.

3. Plastic instability or flow localization in the form of shear bands was observed in specimens irradiated to $6.8 \times 10^{20}$ neutrons $/ \mathrm{cm}^{2}$ and greater. Deviations in displacement measurements of the specimen OD suggested nonuniform deformation in some irradiated specimens, and optical and SEM micrographs clearly reveal the formation of shear bands. At the highest irradiation dose, load displacement data suggest negligible uniform plastic deformation. However, the material appears to exhibit a significant amount of nonuniform plastic deformation.

4. SEM micrographs of fracture surfaces in irradiated specimens reveal a dimpled fracture surface suggesting ductile behavior. However, in specimens irradiated to $16.8 \times 10^{20}$ neutrons $/ \mathrm{cm}^{2}$, a dimpled fracture surface was observed in the fracture external to the deformation shear band. Because these specimens experienced flow localization with the onset of plastic deformation, a dimpled fracture surface outside the shear band suggests that this characteristic may be a product of neutron irradiation and not associated with ductile behavior.

5. A new test for determining tensile hoop properties of irradiated nuclear fuel cladding has been demonstrated and shown to provide excellent characterization of clad tensile hoop behavior. The method is cost-effective, applicable to irradiated specimens, and has demonstrated good reproducibility. The results generated in this project validate the expanding plug test as a method for evaluating irradiated fuel cladding tensile hoop properties and performance. 



\section{REFERENCES}

1. S. S. Hecker, D. R. Harbur, and T. G. Zocco, "Phase stability and phase transformations in PuGa alloys," Progress Matls. Sci. 49, 429-485 (2004).

2. W. J. McAfee et al., Postirradiation Ductility Demonstration Tests of Weapons-Derived MOX Fuel Cladding, ORNL/MD/LTR-254, December 2003.

3. W. J. McAfee, W. R. Hendrich, and N. H. Packan, Postirradiation Ductility Measurements of Weapons-Derived MOX Test Fuel Cladding Over the Range $0.27-1.40 \times 10^{21} \mathrm{n} / \mathrm{cm}^{2}(E>1 \mathrm{MeV})$, ORNL/MD/LTR-268, December 2004.

4. C. Lemaignan and A. T. Motta, "Zirconium Alloys in Nuclear Applications," in Nuclear Materials, Part II (Materials Science and Technology: a Comprehensive Treatment, Vol. 10b), B. R. T. Frost (Ed.), Wiley \& Sons, pp. 5-51.

5. H. R. Higgy and F. H. Hammad, "Effect of Neutron Irradiation on the Tensile Properties of Zircaloy-2 and Zircaloy-4,” J. Nucl. Matls. 44, 215-227 (1972).

6. T. Yasuda, M. Nakatsuka, and K. Yamashita, "Deformation and Fracture Properties of Neutron-Irradiated Recystallized Zircaloy-2 Cladding under Uniaxial Tension," in Zirconium in the Nuclear Industry: 7th International Symposium, R. B. Adamson and L. F. P. Van Swam (Eds.), American Society for Testing and Materials, Philadelphia, Pennsylvania, 1987, pp. 734-747.

7. T. S. Byun and K. Farrell, "Plastic Instability in Polycrystalline Metals After Low

Temperature Irradiation," Acta Materialia 52, 1597-1608 (2004).

8. ATI Wah Chang, "Reactor Grade Zirconium Alloys for Nuclear Waste Disposal," Technical Data Sheet, Allegheny Technologies, Albany, Oregon (2003).

9. T. M. Link, D. A. Koss, and A. T. Motta, "Failure of Zircaloy cladding under transverse planestrain deformation," Nucl. Eng. Des. 186, 379-394 (1998).

10. R. S. Daum et al., "Mechanical Property Testing of Irradiated Zircaloy Cladding Under Reactor Transient Conditions," in Small Specimen Test Techniques: Fourth Volume, ASTM STP 1418, M. A. Sokolov, J. D. Landes, and G. E. Lucas, Eds., American Society for Testing and Materials, West Conshohocken, Pennsylvania, 2002.

11. W. J. McAfee, W. R. Hendrich, and C. R. Luttrell, Postirradiation Cladding Ductility Test

Program Semiannual Progress Report April-September 2002, ORNL/MD/LTR-237, October 2002.

12. S. A. Hodge, R. N. Morris, and L. J. Ott, Weapons-Derived Mixed Oxide Fuel Test

Irradiation Summary, ORNL/TM-2005/255, November 2005.

13. L. J. Ott, "Thermal/Hydraulic Behavior Calculations for Weapons-Derived MOX Fuel with Comparison to PIE Observations," presented at the 2004 International Meeting on LWR Fuel Performance, Orlando, Florida, September 19-22, 2004.

14. A. P. Boresi and O. M. Sidebottom, Advanced Mechanics of Materials, 4th edition, Wiley, 1985, pp. 499-500.

15. K. Kapoor et al., "Effect of processing on properties on thin walled calandria tubes for pressurized heavy water reactor," J. Nucl. Matls. 312, 125-133 (2003).

16. J. E. Talia and F. Povolo, "Tensile Properties of Zircaloy-4,” J. Nucl. Matls. 67, 198-206 (1977).

17. P. Morize, J. Baicry, and J. P. Mardon, "Effect of irradiation at 588K on Mechanical Properties and Deformation Behavior of Zirconium Alloy Strip," in Zirconium in the Nuclear Industry: 7th International Symposium, R. B. Adamson and L. F. P. Van Swam (Eds.), American Society for Testing and Materials, Philadelphia, Pennsylvania, 1987, pp. 101-119.

18. S. K. Yagnik, A. Hermann, and R-C. Kuo, "Ductility of Zircaloy-4 Fuel Cladding and Guide Tubes at High Fluences," J. ASTM Intl. 2, 1-26 (2005).

19. G. E. Dieter, Mechanical Metallurgy, 3rd edition, McGraw-Hill, 1986, pp. 289-292.

20. A. M. Garde, G. P. Smith, and R. C. Pirek, "Effects of Hydride Precipitate Localization and Neutron Fluence on the Ductility of Irradiated Zircaloy-4," in Zirconium in the Nuclear Industry:

11th International Symposium, E. R. Bradley and G. P. Sabol (Eds.), ASTM STP 1295, Philadelphia, Pennsylvania, 1996, pp. 407-430. 



\section{ORNL/TM-2006/163}

\section{INTERNAL DISTRIBUTION}

\author{
1. C. A. Baldwin \\ 2. K. J. Beierschmitt \\ 3. J. L. Binder \\ 4. E. E. Bloom \\ 5. W. R. Corwin \\ 6. B. S. Cowell \\ 7. K. M. Downer \\ 8. S. E. Fisher \\ 9. S. R. Greene \\ 10. F. P. Griffin \\ 11. D. W. Heatherly \\ 12. W. R. Hendrich \\ 13. J. N. Herndon
}

\author{
14. L. L. Horton \\ 15-19. R. A. Jaramillo \\ 20. C. R. Luttrell \\ 21. R. N. Morris \\ 22. D. L. Moses \\ 23-25. L. J. Ott \\ 26-28. N. H. Packan \\ 29. J. E. Rushton \\ 30. D. J. Spellman \\ 31. K. R. Thoms \\ 32. G. L. Yoder, Jr. \\ 33. S. J. Zinkle \\ 34. ORNL Laboratory Records (RC)
}

\section{EXTERNAL DISTRIBUTION}

35. D. Alberstein, Los Alamos National Laboratory, MS-E541, P.O. Box 1663, Los Alamos, NM 87545

36. P. Bailey, Duke Energy, P.O. Box 1006, Charlotte, NC 28201-1006

37. S. Basu, U.S. Nuclear Regulatory Commission, RES/DSARE/AREAB, Two White Flint North, MS-10F13A, 11555 Rockville Pike, Rockville, MD 20852

38. C. Beyer, Pacific Northwest National Laboratory, 3230 Q Street, Richland, WA 99354

39. R. N. Boudreau, DOE/NA-26, Forrestal Building, 1000 Independence Avenue SW, Washington, DC 20585

40. R. Clark, Duke/Cogema/Stone \& Webster, P.O. Box 31847, Charlotte, NC 28231-1847

40. F. Eltawila, U.S. Nuclear Regulatory Commission, RES/DSARE, Two White Flint North, MS-10E32, 11555 Rockville Pike, Rockville, MD 20852

41. M. W. Kennard, Stoller Nuclear Fuel, 1 Baltic Place, Suite 201A, Croton-on-Hudson, NY 10520

42. D. Lanning, Pacific Northwest National Laboratory, 3230 Q Street, Richland, WA 99354

43. R. Y. Lee, U.S. Nuclear Regulatory Commission, RES/DSARE/SMSAB, Two White Flint North, MS-10K8, 11555 Rockville Pike, Rockville, MD 20852

44. G. D. Lunsford, DOE/NA-265, Forrestal Building, 1000 Independence Avenue SW, Washington, DC 20585

45-49. G. Meyer, Framatome Cogema Fuels, 3315 Old Forest Road, Lynchburg, VA 24506

50. R. O. Meyer, U.S. Nuclear Regulatory Commission, RES/DSARE/SMSAB, Two White Flint North, MS-10K8, 11555 Rockville Pike, Rockville, MD 20852

51. S. Nesbit, Duke Energy, P.O. Box 1006, Charlotte, NC 28201-1006

52. M. D. Newdorf, DOE/NA-261, Forrestal Building, 1000 Independence Avenue SW, Washington, DC 20585

53. J. Olencz, DOE/NA-26, Forrestal Building, 1000 Independence Avenue SW, Washington, DC 20585

54-57. R. C. Pedersen, Idaho National Laboratory, Mail Stop 7101, P.O. Box 1625, Idaho Falls, ID 83415-7101 
58. P. T. Rhoads, U.S. Department of Energy, 1000 Independence Avenue SW, Forrestal Building, Washington, DC 20585

59. H. H. Scott, U.S. Nuclear Regulatory Commission, RES/DSARE/SMSAB, Two White Flint North, MS-10K8, 11555 Rockville Pike, Rockville, MD 20852 